
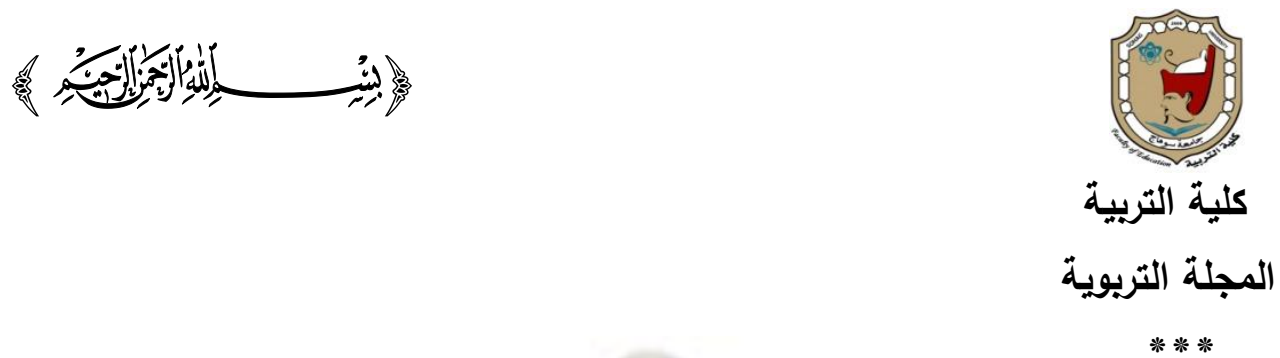

\title{
سيناريوهات هقتزحة
}

لمستقبل تسويق الفدمات التعليمية بالجاهعات الصرية فى ضوء نهاذج بعض الجاهعات الاجنبية

$$
\begin{aligned}
& \text { المالت } \\
& \text { د/ وفاء زكى بدروس } \\
& \text { مدرس بقسم التربية المقارنة } \\
& \text { كلية التربية - جامعة الاسكندرية }
\end{aligned}
$$

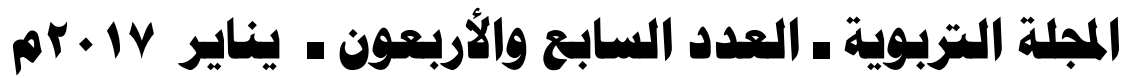

Print:(ISSN 1687-2649) Online:(ISSN 2536-9091) 


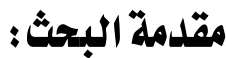

يقوم التسويق بدور كبير في نجاح المنظمات مهما اختلفت أحجامها، ولذلك يطلق

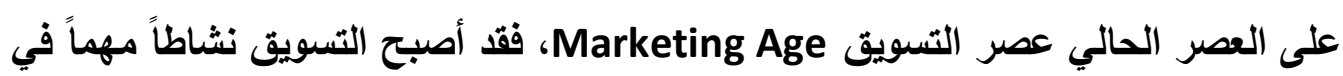
المنظمات غير الهادفة للريح Nonprofit Organizations - مثل مؤسسات التعليم العالي بهدف تحسين الخدمات وتحقيق رضا العميل، فضلاً عن زيادة موارد تلك المؤسسات، وهو ما مواتسات يؤدي بالتبعية إلى رفع كفاءة الأداء في تلأك المؤسسات. أن تسويث الجامعات لخدماتها التعليمية يؤدي إلى ارتفاع كفايتها الإنتاجية ويالتالي

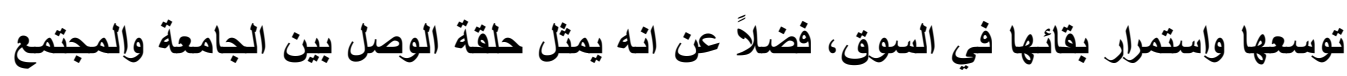

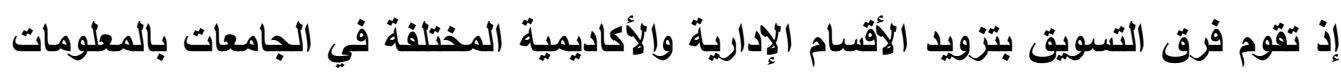
عن حاجات المجتمع من الخدمات. تؤكد إحدى الدراسات(!) أن عملية التسويق بالجامعات تنقسم إلى ثلاث مراحل كما

المرحلة الأولى: تحديد المنافسة من خلال تحديد المؤسسات المنافسة. المرحلة الثانية: تحديد المركز التسويقي من خلال تحديد صورة الجامعة ومركزها في السوق، وتصور الطلاب المتوقعين عنها، وكيف يتم مقارنتها بأقرب المنافسين لها. المرحلة الثالثة: تجزئة السوق من خلال تقبيم الطلاب المتوقعين إلى مجموعات وفقاً لميولهم نحو الجامعة أو الجامعات المنافسة. يتطلب نجاح الجامعات في تحقيق أهدافها إتباع سياسة تسويقية ناجحة ذات بعدين، أحدها تريوي والآخر اقتصادي، وتتلتزم بتوفير الجوانب والأسس والتمعايير التريوية التي تضمن إنتاج أفضل مخرج، وجذب أفضل العناصر للمؤسسة الجامعية. يعتبر تسويق الخدمات الجامعية اتجاهاً عالمياً تأخذ به عديد من الجامئه الجامعاته في في دول

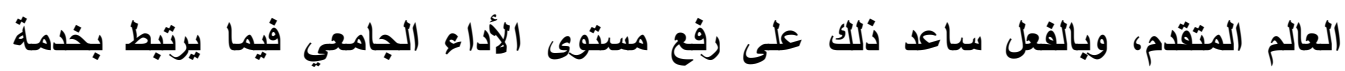

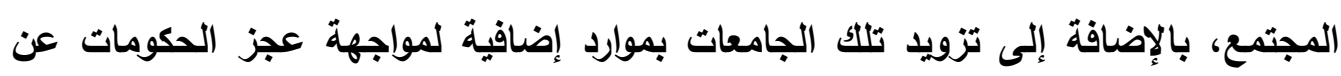
تمويل الجامعات. هناك جهود للتسويق بالجامعات المصرية من خلال وجود رصيد كبيز من المراكز البحثية المتخصصة، والوحدات ذات الطابع الخاص، مع تغيير مصاحب في هيكل التظيم 


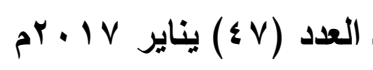

الجامعي - مثل استحداث وظيفة نائب رئيس الجامعة لشئون البيئة - لمواكبة خدمة المجتمع، وتتمية البيئة، ويداية محاولات لتسويق الخدمات الجامعية(؟).

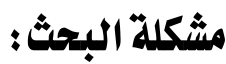

على الرغم من المحاولات التي تبذلها الجامعات في تسويث خدماتها، إلا أن هناك

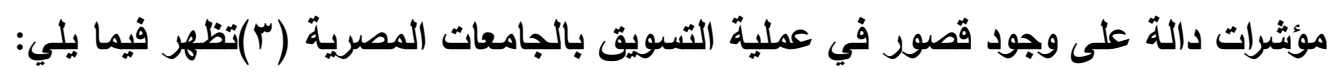

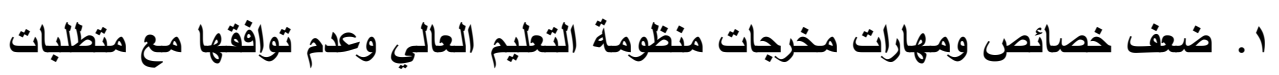
سوق العمل المتطورة والمتغيرة ، وهو ما يدل على ضعف التخطيط التسويق منطيق بالجامعات المصرية. r. العائد التسويقي للخدمات الجامعية التي تقدم للمجتمع يعد عائداً ضعيفاً، كذلك يلاحظ أن الوحدات ذات الطابع الخاص بالجامعات تأثيرها لا يزال محدوداً، وأنها لهابها

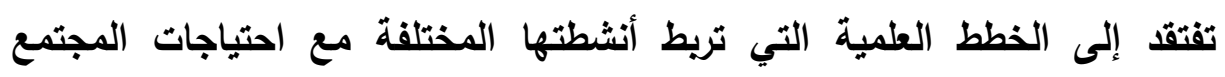
ومشكلاته.

r. ضعف الكفاءات الإدارية المدربة القادرة على تنفيذ ما يوكل إليها من أعمال خاصة

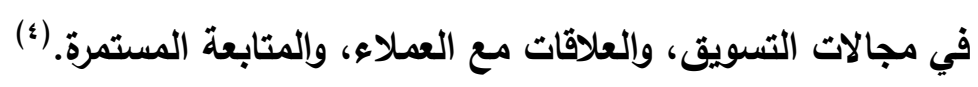

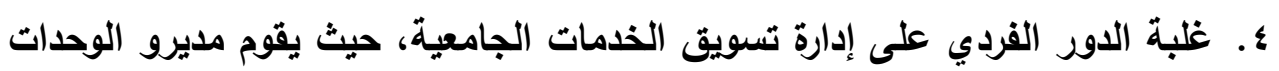

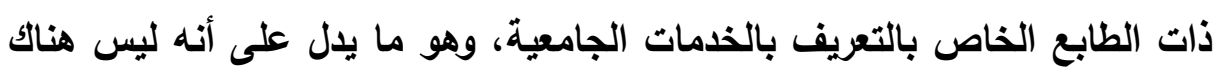

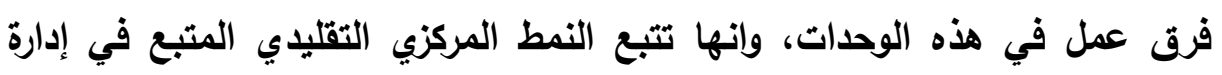
الجامعة على المستوى الأعلى. لذا يسعى البحث عن الاجابة على السؤال الرئيس الأتى: ما مستقبل تسويق الخدمات التعليمية بالجامعات المصرية ؟ التهاته ومن هذا السؤال تتفرع التساؤلات التالية:-

(1 ) ما الأساس الفكري والمعياري لتسويق الخدمات التعليمية بالجامعات؟

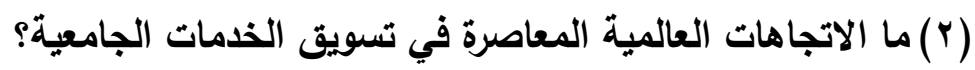
(r) ما نواحي القوة بالجامعات المصرية التي تلاعم تسويق الخدمات التعليمية، ونواحي الضعف التي تعوق عملية التسويق؟ 


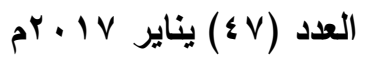

( ) ما القوى المحركة والدافعة لتسويث الخدمات التعليمية بالجامعات المصرية؟

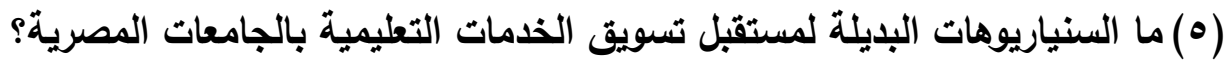
أهمية البهث: تتمثل أهمية البحث مما يأتي: 1- المساهمة في بناء الأساس الفكر النظري وعرض نتائج الاراسات التطبيقية في مجال تسويق الخدمات التعليمية بالجامعات والمؤسسات التريوية المصرية وتحقيق الميزة التنافسية لها. r - يعد هذا البحث من المحاولات المحدودة والههامة في تضييق الفجوة البحثية في هذا المجال على حد علم الباحثة.

r- يمكن لهذا البحث أن يكون لنتائجه مردود إيجابي خاصة للقائمين على التخطيط

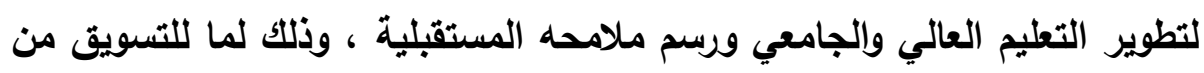
إسهام فعال في معالجة بعض مشكلاته خاصة فى مجال بدائل التمويل.

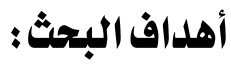

يسعى البحث إلى تحقيق الأهداف التالية:

- - إمكانية بناء وتكوين إطار نظري يساعد على تفهم الأطر الفكرية والمعيارية لعملية

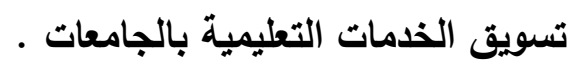

r- الوقوف على مدى ملائمة بيئة الجامعات المصرية لممارسة التسويق كوظيفة إدارية يمكن أن تمارسها في المستقبل وتضاف إلى قائمة الوظائف المطلوية منها. r- التوصل إلى سيناريوهات بديلة لمستقبل تسويق الخدمات التعليمية بالجامعات المصرية.

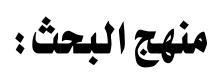

يستعين البحث الحالي بالمنهج الوصفي الأي يمكن من فهم الظاهرة التريوية

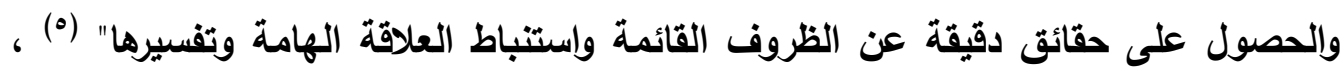
ووفقاً لألك سيتم وصف وتثخيص بيئة الجامعات المصرية لتحديد ما بها من نواحي قوة تسمح لها بالتوجه بالسوق ونواحي الضعف تقف حائلاً دون توجهها بالسوق. 


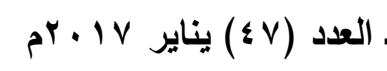

كما يستعين البحث أيضاً بأسلوب السيناريو كأسلوب من الأساليب المستخدمة في

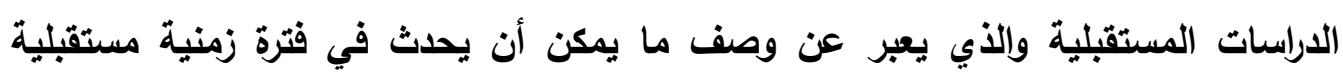

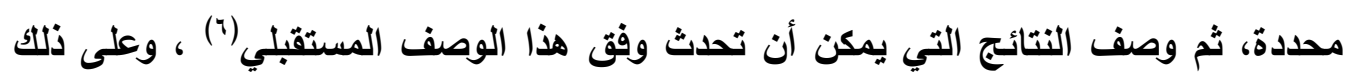

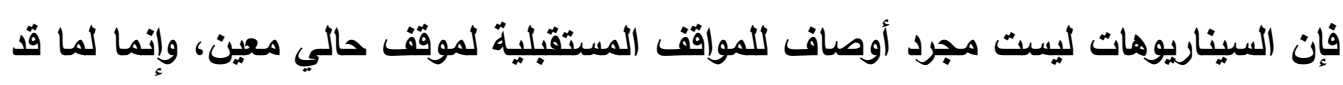

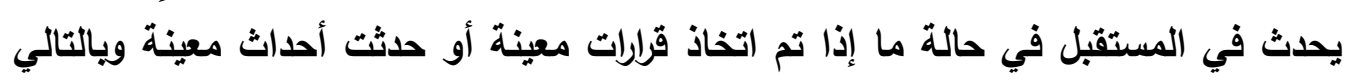

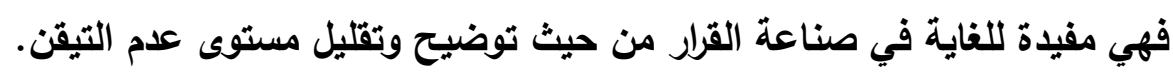

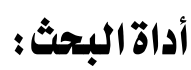
سيتم تصميم استمارة استطلاع رأي لمجموعة من الخبراء فى المجال بهاف التعرف

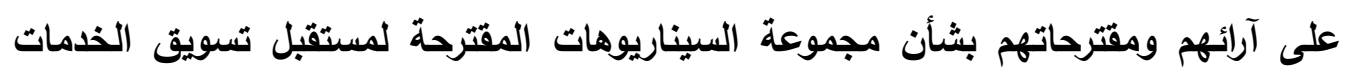
التعليمية بالجامعات المصرية.

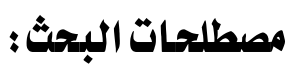
يعرف التسويق بأنه "عملية تدليد الطلب على المنتج أو الذذمة وترويج المبيعات

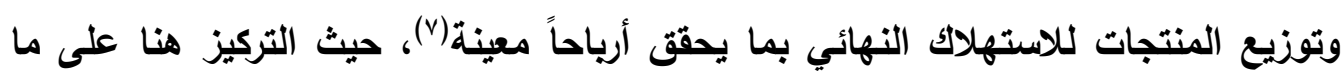

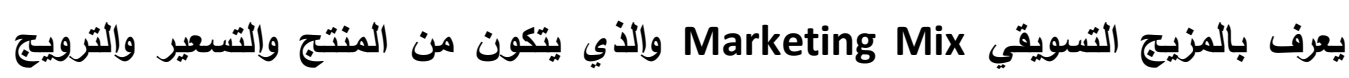
والتوزيع.

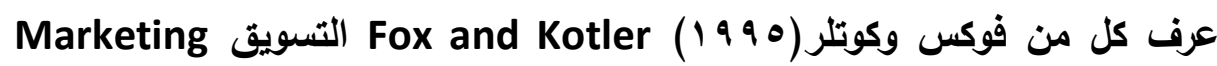

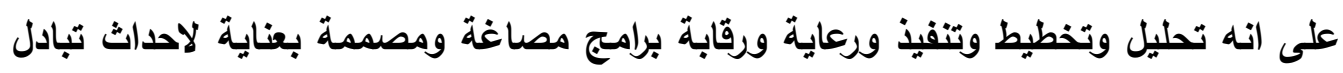

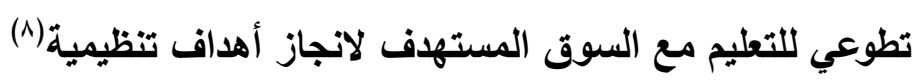
وحدد كل من ديفيد واليسون(1990) David and Ellison تسويق الخدمات التعليمية على انها الوسائل التي من خلالها تتصل المؤسسة التعليمية بفعالية وترتقي بهدفئا

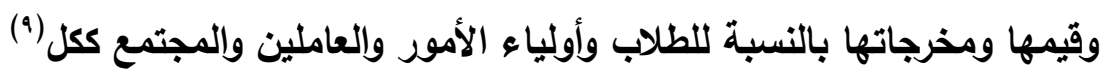

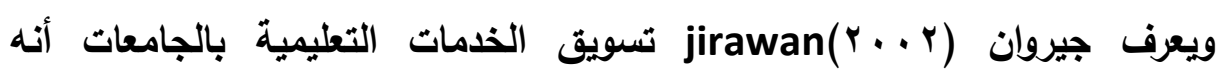
"تصميم العروض الدراسية المقدمة من الكليات في ضوء احتياجات ورغبات الطلاب

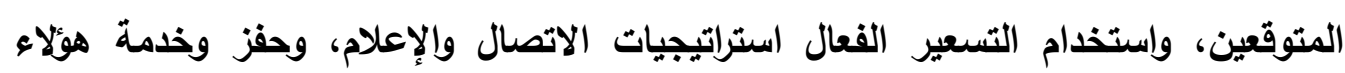

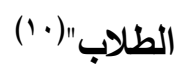




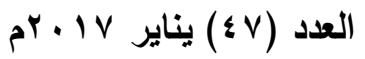

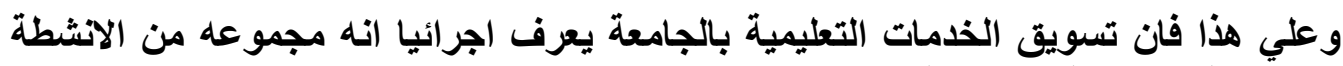

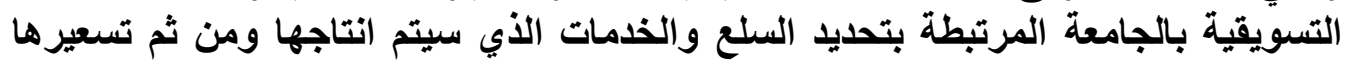

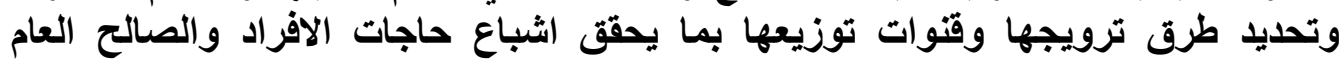

لامجتمع.

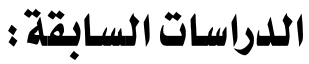

( ) دراسة جيروان (r ( . ب)"تطبيق التسويق في التعليم العالي في تايلاند: دراسة

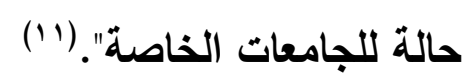

هدفت الاراسة إلى استكشاف تطبيق مزيج تسويقي مدروس لمحاولة ضمان التحاق الطلاب بجامعات تايلاند الخاصة، من خلال الإجابة على الأسئلة التالية:

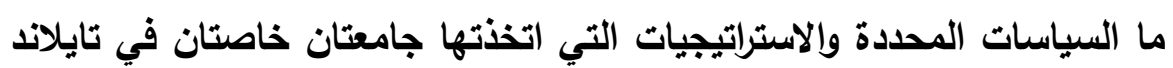

لضمان التحاق الطلاب بها؟

(ب) ما مدى انعكاس نظريات التسويق على تلك الاستراتيجيات؟

ما الأي يساعد على ضمان تسجيل الطلاب - إلى جاتب المزيج التسويقي التي

$$
\text { تساعد في؟ }
$$

وقد اعتمدت الاراسة على مدخل دراسة الحالة لتحقيق غرض الدراسة بالتطبيق على جامعتين خاصتين في تايلاند، حيث تم تقسيم مجتمع الجامعة إلى ثلاث مجموعات تمثل ملثل

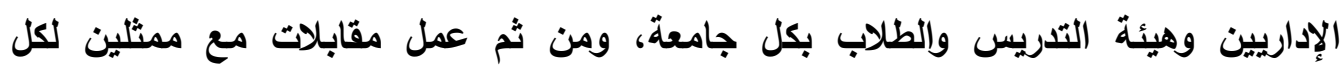
مجموعة.

وقد توصلت الدراسة إلى جملة نتائج من أهمها:

المؤسسات الجماعية بدأت إدخال التسويق في ممارستها بسبب اعتبارئ إنبارهم أنه وسيلة للتطوير وتحقيق موقف تنافسي أفضل للجامعة الخاصة في قيد الطلاب. المزيج التسويقي مطبق في كلا الجامعتين، ولكن الهية كل عنصر من عناصره تختلف من جامعة لأخرى.

المكان وجودة العملية التعليمية واستراتيجيات التسعير والإعلان من اهم العوامل المؤثرة على اختيار الطالب للاراسة في جامعة خاصة مانه ما.

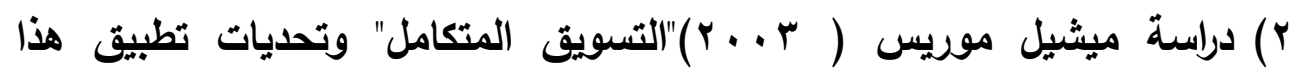

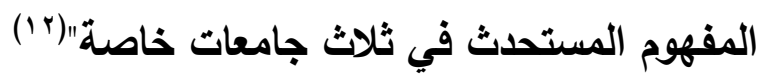




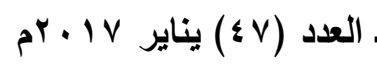

هدف الاراسة إلى:

الوقوف على عمليات وتحديات تعريف، وتطوير، وتطبيق، وتقييم، التسويق

المتكامل في حالة الجامعات الخاصة.

الوقوف على المستوى التظظيمي، والاستراتيجي المتكامل، والرسالة المتكاملة مع

وظائف التسويق في الجامعات الخاصة الثلاثة.

المقارنة وييان الفروق في الخبرات بين الإداريين والموظفين في الجامعات

الخاصة الثلاثة من خلال كيفية تطبيق التسويق المتكامل.

وقد اعتمدت الدراسة على أسلوب دراسة الحالة، حيث تناول البحث ثلاث جامعات

خاصة، مرحلة الاراسة الجامعية بها أريع سنوات، وطبقت بنجاح التسويق المتكامل كما

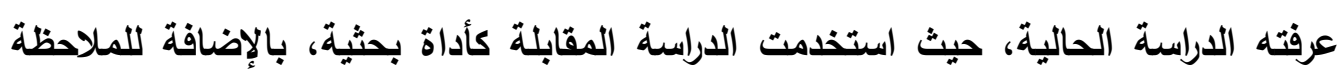
بالمشاركة من قبل الباحث.

وقد توصلت الدراسة إلى نتائج ، من أهمها:

أن التسويق المتكامل يختلف نتيجة لاختلاف الأفراد والخطط والسياسات من النمات

$$
\text { مؤسسة لأخرى. }
$$

أن تطبيق التسويق المتكامل لم يأخذ شكل واحد في الجامعات الثلاثة، حيث

$$
\text { اختلف من جامعة لأخرى. }
$$

ان قادة التسويق في الجامعات الثلاثة لايهم خبرات ناجحة في مجال التسويق

المتكامل في جامعاتهم.

r) دراسة رويرت (ب . . ץ)"تشويق الجامعة، تحليل أسواق المنظمة، وعملية قيد

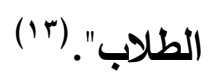

هدفت الدراسة إلى تحليل الأسواق الرئيسة للجامعات، خاصة الأسواق المرتبطة

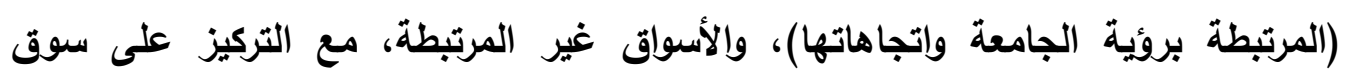
الطلاب، خاصة عملية قيد الطلاب.

وقد توصلت الدراسة إلى أن الأسواق المرتبطة تشمل: سوق الطلاب، سوق العلماء وأعضاء هيئة التدريس بالجامعات، سوق مصادر تمويل التعليم العالي (مثل التبرعات والمنح 


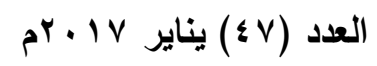

والتمويل الحكومي) والمساهمين، وسوق الخريجيم (والتي تعتبر مصدر مهم للتغذية الراجعة للجامعة)، حيث يعتبر سوق الطلابمن أهم الأسواق المرتبطة.

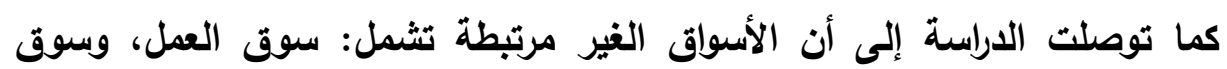
المنتجات غير الاستثمارية، وسوق الخدمات، وسوق المال.

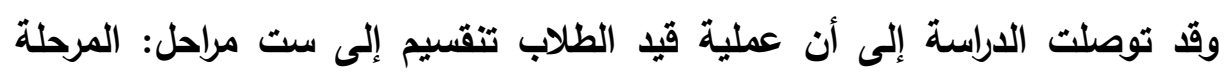

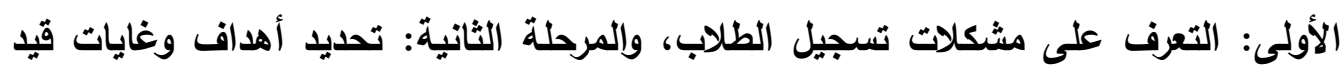
الطلاب، والمرحلة الثالثة: القيام ببحوث التسويق، والمرحلة الرابعة: تحديد استراتيجية

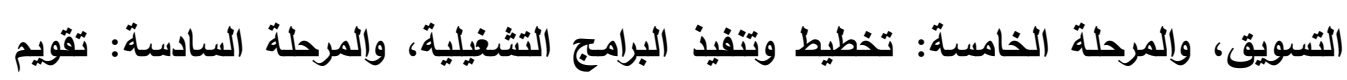
النتائج والإجراءات.

ع) دراسة محمد صبرى (ع . . ץ)"المشكلات التظيمية لتسويق الخدمات الجامعية

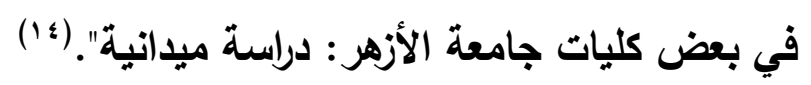
هدفت الدراسة إلى الوقوف على المشكلات التنظيمية لتسويق الخدمات الجامعية في بعض كليات جامعة الأزهر، والوصول إلى تصور مقترح لتحقيق التسويق الجيد للخدمات الجامعية بجامعة الأزهر .

اعتمدت الدراسة على المنهج الوصفي، وتمثلت أدوات الدراسة في استبيان مقدم إلى الى الدان عينة عشوائية من اعضاء هيئة التدريس بكليات الجامعة، بالإضافة إلى المقابلة الشخصية

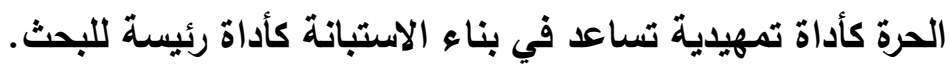
توصلت الاراسة إلى وجود عدة مشكلات تنظيمية تعوق تسويق الخدمات الجامعية من أهمها: مشكلات تتعلق بتشريعات وهيكل وعمليات التظظيم الجامعي القائم. (ب) مشكلات تتعلق بالموارد والامكانات المتاحة. (ج) مشكلات تتعلق بأعضاء هيئة التدريس.

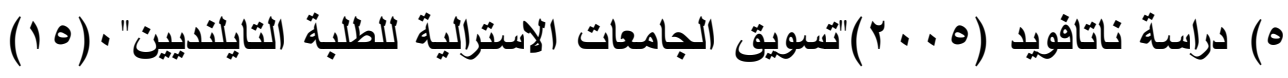
هدفت الدراسة إلى الوقوف على العوامل التي تؤدي إلى تسويق الجامعات الدولية

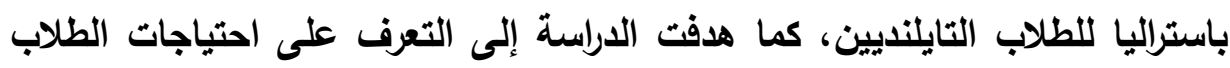
التايلتديين من التعليم الدولي وذلك لتحسين معايير وأداء الجامعات الدولية باستراليا. 


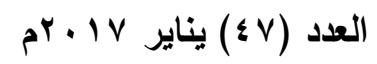

اعتمدت الاراسة المنهج الوصفي حيث قامت بعمل مسح من خلال الاستبيان كأداة،

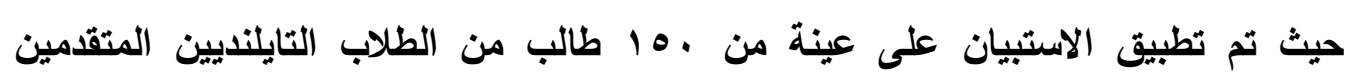
بطلبات للالتحاق بالجامعات الدولية باستراليا.

توصلت الدراسة إلى أن من أهم عوامل تفضيل طالب لجامعة دولية على اخرى، هوان الهوان

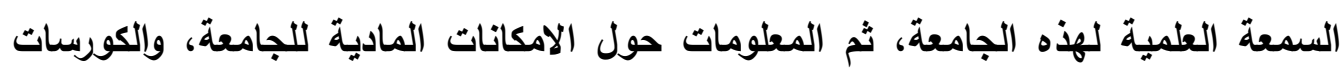
الأكاديمية المقدمة، والخدمات.

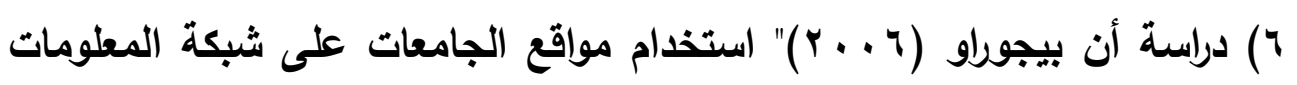
الدولية (الانترنت) لقيد الطلاب: دراسة للصفحات الرئيسة لمواقع الجامعات الكندية واختبار العلاقة بين وسائل التسويق وإمكانية الاستفادة من الموقع الالكتروني بالانترنت". (1) هدفت الدراسة إلى دراسة جانبين : الأول تقويم المواقع الاكتترونية للجامعات الكندية على شبكة الانترنت من حيث مدى استخدام تلك المواقع لنظريات وتقنيات (تسويق العلاقة) الاتصال بالطلاب المتوقعين، والثاني تقويم مدى استفادة الجامعات من تلك المواقع. اعتمدت الدراسة على أسلوب تحليل المحتوى للموقع الاكتروني لاثثتين وأريعين جامعة كندية، حيث تم تجميع البيانات حول أريعة أبعاد وهي: رسوم الاخول، ومعلومات حول

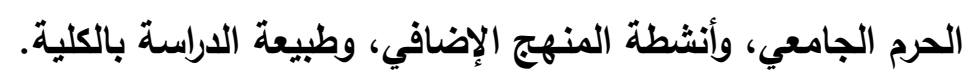
توصلت الدراسة إلى عدة نتائج من أهمها:

أن معظم تلك الجامعات لايها نقص في الأبعاد الأريه التي تم قياسها. (ب) أن هناك علاقة إيجابية بين حجم الجامةع (من حيث عدد الطلاب)، والميزانية

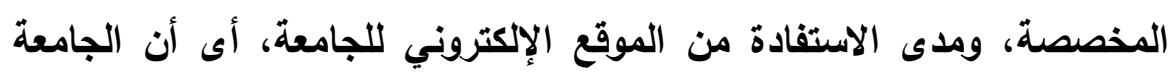

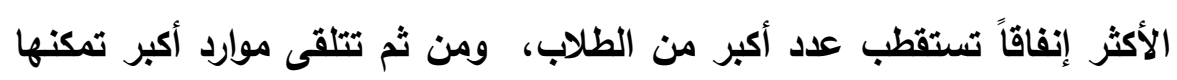
من الأنفاق على مواقعها على الانترنت. 


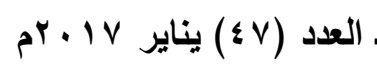

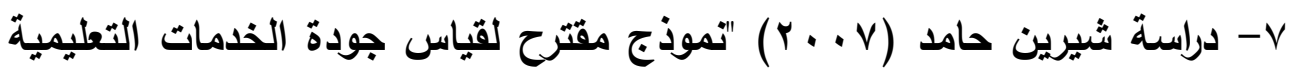

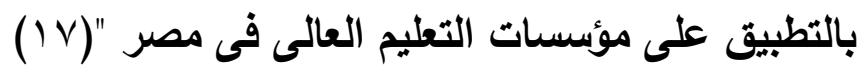
هدفت الدراسة الى تظوير مقياس جودة الذدمة للتعليم العالى ، وتكونت عينة

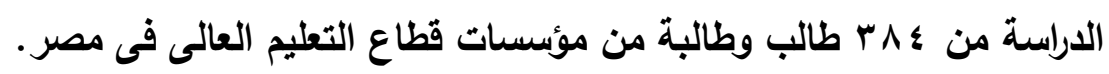
واسفرت نتائج الدراسة عن درجة عالية من الصلاحية والجودة والكفاءة للمقياس المعدل ، وكانت أكثر الابعاد قدرة على تفسير جودة الخدمات التعليمية هى الجوانب الأكاديمية يليها الثهرة والجوانب غير الاكاديمية.

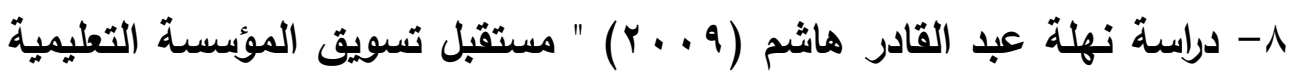

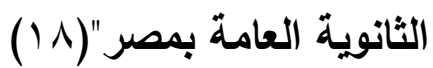
هدفت الدراسة الدراسة الى التعرف على الاساس الفكرى للتسويق ومن ثم القوى المحركة لعملية التسويق فى التطليم الثانوى وخبرات بعض الدول الاجنبية فى الميدان وتوصلت الدراسة عن ثلاثة سيناريوهات بديلة لمستقبل تسويق المدرسة الثانوية.

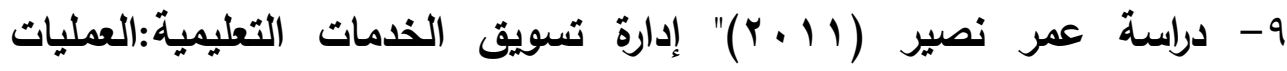
ومتطلبات التطبيق بالجامعات المصرية"( 9 (1)

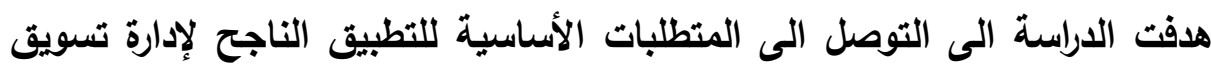
الخدمات التعليمية بالجامعات المصرية. وتوصلت الدراسة الى متطبات عامة،متطلبات تتصل بالتخطيط التسويقى ، متطلبات

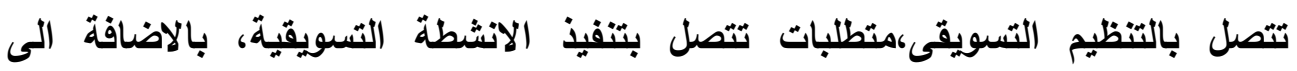
منطلبات تتصل بالرقابة التسويقية.

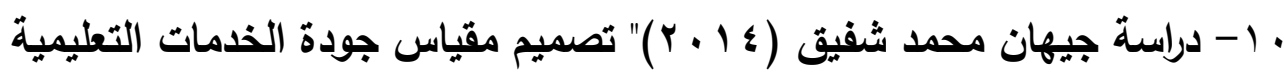

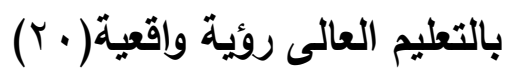
هدفت الاراسة الى تصميم وتقتين مقياس لجودة الذذمات التعليمية بالتعليم العالى الى

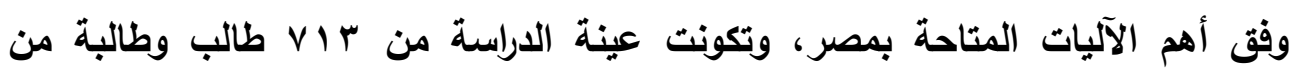

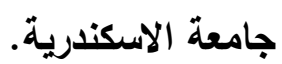




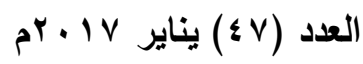

وأسفرت النتائج عن توفير أداة قياسية ذات خصائص سيكومترية جيدة وعدم وجود فروق جوهرية بين الجنسين فيما يتعلق بجودة الخدمات التعليمية والجودة الكلية.

\section{التعليق عام على اللدراسات السابقة :}

من خلال استقراء الدراسات السابقة المرتبطة بالتسويق في الجامعات يمكن الخروج بعدد من المؤثرات والنتائج العامة التي قد تمثل نقطة انطلاق للبحث الراهن، وهي على بلى باءل النحو التالي: - (الني

1. المؤسسات الجامعية بأت إدخال التسويق في ممارساتها بسبب اعتباره وسيلة للتطوير وتحقيق موقف تنافسي أفضل للجامعة الخاصة في قيد الطلاب. r. المكان وجودة العملية التعليمية واستراتيجيات التسعير والإعلان (المزيج التسويقي) من اهم العوامل المؤثرة على اختيار الطالب للاراسة في جامعة ما. r. أن الأسواق الرئيسة للجامعات تتضمن العديد من الأسواق مثل: سوق الطلاب؛ وسوق هيئة التدريس، وسوق المستثمرين، وسوق الخدمات إلا أن سوق الطلاب من

$$
\text { أهم الأسواق المرتبكة. }
$$

ء. أن هناك حاجة ماسة لتطبيق التخطيط الاستراتيجي التسويقي القائم على الدراسات التحليلية للسوق والمنافسين في الجامعات. ه. أن هيئة التدريس، وجودة العملية التعليمية من أهم عوامل القوة في المؤسسة، والتي تؤدي إلى ميزة تنافسية للجامعة في مجال التسويق. 7. أن هناك علاقة بين حجم الإنفاق على الموقع الإكتروني ومدى الاستفادة من هذا الموقع في جذب الطلاب. 


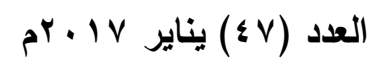

\section{الإطار النظري \\ الجزء الأول : الإطار الفكري والمعياري لتسويق \\ الخدمات التعليمية بالجامعات}

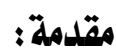

تسعى المنظمات والمؤسسات المختلفة فى المجتمع ، ومنها المؤسسات التعليمية فى ظل

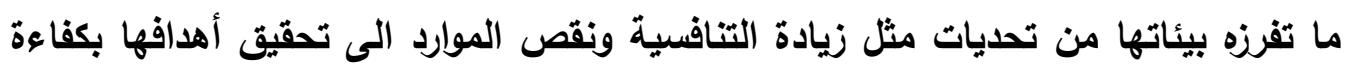

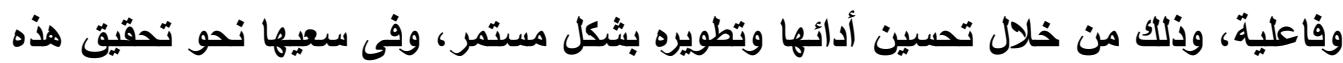
الأهداف اتجهت الى تسويق ذاتها وخدماتها كوسيلة يمكن ان تحقق لها مستويات عالية من الأداء من ناحية ، وتضمن لها البقاء فى بيئة تنافسية دائمة التغير من ناحية أخرى.

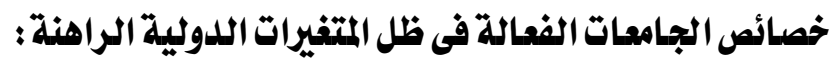

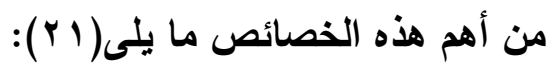

1. العمل من خلال رسالة واضحة شارك فى وضعها جميع العاملين بها. r. الاهتمام بالعنصر البشرى من حيث الاعداد والاختيار والتطوير والتثنجيع الدائم. r. r. الاهتمام بالجودة طبقا لمعايير الجودة العالمية. ؛. الاهتمام بالتطوير والتحسين المستمر . هـ السماح بمشاركة كافـة العاملين فى اتخاذ القرارات. 4. الاهتمام بالمستفيدين من الخدمات التعليمية التى تقدمها الجامعات. بعض التحليات المعاصرة التى تواجه الإدارات بالجامعات:

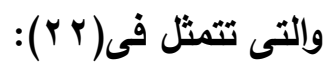

1. التقدم التكنولوجى والادارى وما يتطلبه من موارد بشرية. r. العولمة والاتفاقيات الدولية والتكتلات الاقتصادية.

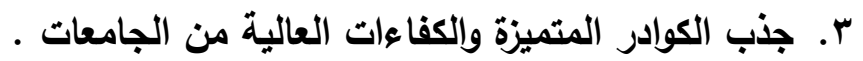
؛. التوجه نحو خصخصة بعض الذدمات التعليمية . ه. الاتجاهات الديثة فى الادارة وتطبيقاتها المختلفة. 
هى منتجات غير ملموسة تهذف أساسا إلى إثباع حاجات المستفيذ من الخدمة

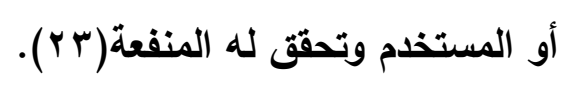

أما بالنسبة للخصائص فتتمثل فى ( ع r)

ا . . عدم فصل الخدمة عن مقدمها.

r . علدم إمكانية نقلها وتخزينهاأو تجزئتها.

r. لا يتوافر فى تقديمها عنصر نقل الملكية.

ع. الاختلاف والتعددية فى انواع الخدمات.

\section{التسويق فى الجامعات :}

يعرف التسويق بأنه "عملية تحديد الاحتياجات، وإثباع تلك الاحتياجات من خلال

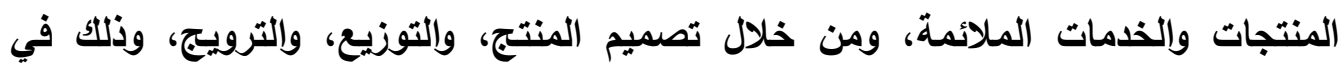
منظمات الأعمال والمنظمات غير الريحية على حد سواء".(ror)

وتعرف "إدارة التسويق" على أنها "عملية تخطيط وتتظيم وتنفيذ ورقابة الأنشطة

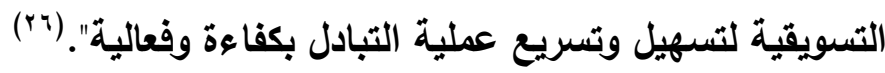
ويتحليل التعريفات السابقة يلاحظ أنها تركز على أن إدارة التسويق تتضمن:

( ) تخطيط وتنظيم وتتفيذ ورقابة الأنشطة التسويقية.

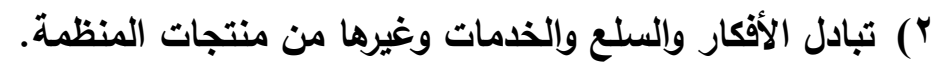
r) تحقيق الإثباع المزدوج لأطراف التبادل (المنظمة والمستهلكـ).

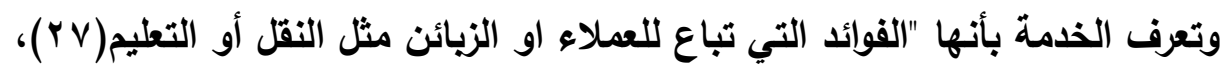
والخدمة "هي نشاط أو فائدة يمكن أن يقدمها أحد الأقسام أو الأشخاص إلى آخر وهي أثنياء

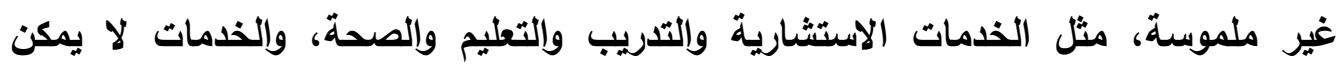
تخزينها في آن واحد"(^^).

ويمكن القول أن الخدمات الجامعية هي كل ما يمكن أن تقدمه الجامعة من خدمات يمكن تسويقها مثل الخدمات الاستثارية والبحوث التعاقدية والبرامج التدريبية والمهنية وغيرها من الخدمات، وصولاً إلى تسويق مرافق الجامعة كالقاعات والمعارض والملاعب. 


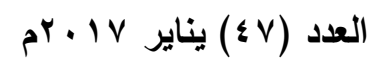

والخدمات التعليمية بالجامعات هي جزء من الخدمات الجامعية، ويقصد بها الأنشطة والمنافع التعليمية التي يمكن أن تقدمها الجامعات للطلاب أو الخريجين أو أعضاء هيئة التدريس ومعاونيهم أو الإداريين والموظقين سواء من داخل الجامعة أو من خارجها وكذا

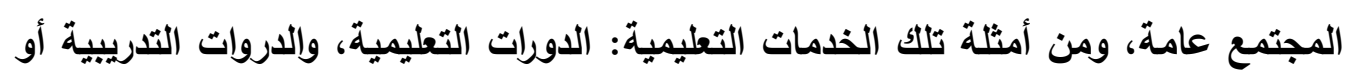
المهنية، وورش العمل، ويرامج التعليم المفتوح، ويرامج التعليم عن بعد ، الدبلومات التقليدية

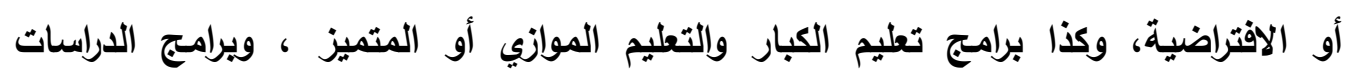
الصيفية وغيرها من الخدمات التعليمية. وتمثل احتياجات العملاء واهتمامات المجتمع - من وجهة نظر البحث الحالي - لب الب مئه

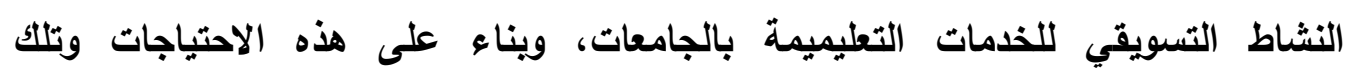
الاهتمامات يتم وضع المزيج التسويقي للخدات التعليمية بالجامعات، والذي يتكون من:

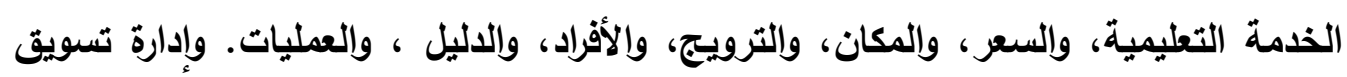
الخدمات التعليمية بالجامعات هي إدارة هذا النشاط التسويقي، وتتأثر إدارة التسويق بالبيئة التسويقية الداخلية بالجامعة، والتي تتكون من: أهداف وأنظمة وإجراءات وتتظيم وموارد مادية ويشرية وتكنولوجية وشهرة ومكانة للجامعة والمناخ السائد، ويبيئة التسويق الخارجية القريبة، والتي تتكون من مجموعة عناصر، من أهمها: الوسطاء والمنافسون والموزعون والموردون، ويبيئة التسويق الخارجية البعيدة، والتي تثتكون من: البيئة الطبيعية والتكنولوجية، والبيئة الاجتماعية والثقافية، والبيئة السياسية والقانونية، والبيئة السكانية والاقتصادية

\section{تسويق الخدمات الجامعية :}

يقصد به التحليل والتخطيط وإلتفيذ والرقابة علي الخدمات الجامعية التي يتم اعدادها لتحقيق تبادل طوعي للاشياء التي لها قيمة في الاسواق المستهدفه لتحقيق اهداف المؤسسة ويعتمد التسويق بلرجة كبيرة علي تحديد المنتجات التي تقوم الجامعه بتقديمها بناء علي

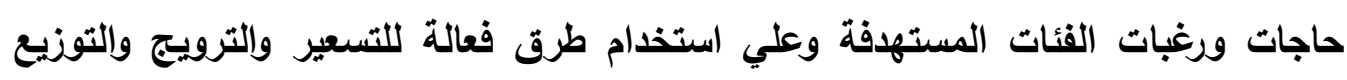

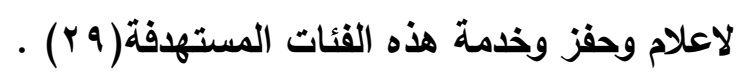
ويتحليل المفهوم السابق يتضح ان تسويث الخدمات الجامعي : 


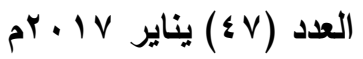

*علية اجتماعية حيث انها تعتمد علي اشباع حاجات ورغبات المستفيدين وعملية ادارية

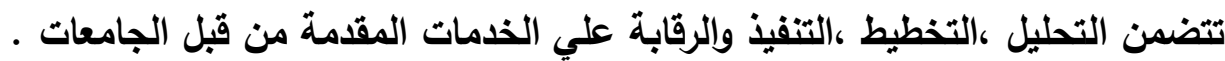

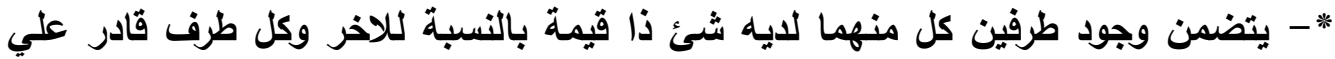
التغير وكل طرف له مطلق الحرية في قبول او رفض العرض( • ب).

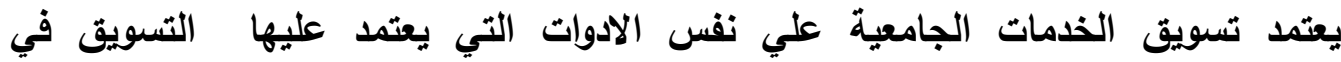

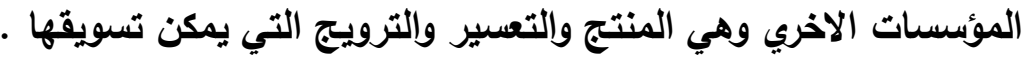
وفيما يخص مفهوم الذدمات الجامعية فق حداته الجامعات علي انه :خدمات موجهة للمجتمع الذي توجد به الجامعه وهناك مجموعة من المميزات للذدمات الجامعية بوصفها احدات

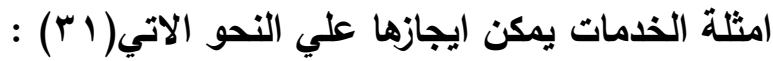
التباين : ويعني ان الخدمات التي تقدما الجامعه تتميز بالتنوع حيث تختلف الذذمات

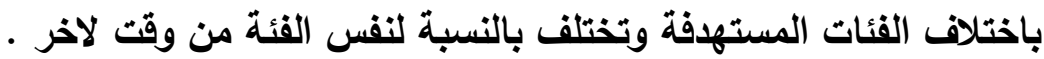

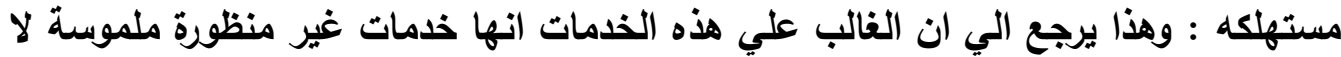
يمكن التعرف علي خصائصها قبل الثراء وتستهلك عقب انتاجها مباشرة (غير قابلة للتخزين ) التلازم وعدم الانفصال: ويعني ان الخدمات ترتبط باسم مقدمها فلا يمكن فصل الخدمات عن منتجها وعلي هذا فان الخدمات التي تقدمها الجامعات بوصفها بيوت خبرة تتميز بالثقة

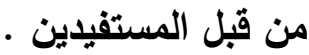
مساهمة المستفيد في انتاج الخدمة: أي ان الجامعات لا تتفرد وحدها بانتاج خدماتها دون

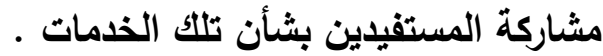

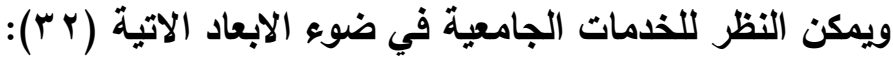
الاتساع : يشير الي عدد خطوط الخذمات المقدمه من المؤسسة لعملائها وتصنف الخدمات لهذا البعد بانها قد تكون ذات مزيج خدمات متسعة (متعدة خطوط الخدمات ) او ذات

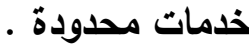
العقق : يشير الي اجمالي عدد الخدمات المقدمه ضمن كل خط من خطوط الذدمات وتصنيف الخذمات التي تقدمها المؤسسة وفقا لهذا البعد الي مزيج خدمات عميق (معقد ) وفيه يتضمن كل خط مجموعه من الخدمات ومزيج خدمات سطحي وفيه يقدم كل خط عدد محدود من الخدمات. الترابط والتكامل : ويشير إلي درجة الارتباط بين كل خط من خطوط 


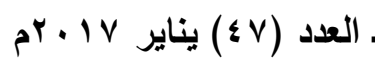

الخدمات المقدمة فمثلا اجراء البحوث الزارعية التطبيةية في مجال معين يتطلب استقراء حاجات المجتمع في مجال الزارعة أولا . تسويق الخدمات الجامعية : عملية ادارية اجتماعية تهدف الي تحقيق الربح بهدف اعادة

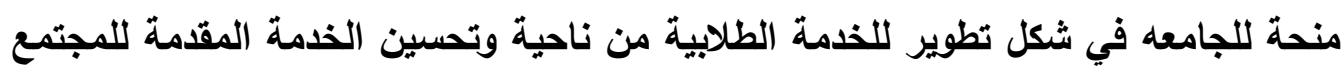
من ناحية اخري(ب (T) وقد وضعت الجامعات المصرية مفهوما محددا للخدمات كما يلي :

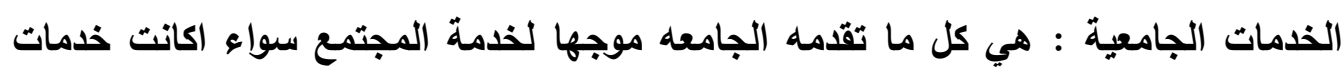
في صورة سلع مادية قابلة للانتقال من مكان لاخر وفقا للاحتياج السوقي ام كانت خدمات غير منظورة تستهلك في مكان ووقت انتاجها وهذا النوع الاخير هو الغالب لخدمات

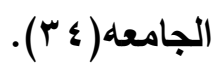

عوامل نجاح تسويق الخدمات التعليمية بـالجامعات : culture : الثقافة

تعد الثقافة العنصر غير الملموس والاكثر اشكالية من عناصر ادارة المؤسسة التعليمية فاكثر المحددات أهمية الثقافة المؤسسة التعليمية هو وجود القيادة التريوية فالثقافة في جوهرها ما هي إلا وظيفية القادة التريوين وخصائص القائد التريوي سوف تنعكس من خلال المؤسسة التعليمية ان لهذه الحقيقة دلائلها المثتبه في مجال الصناعة والتجارة وعلي شاكلتها في المؤسسات التعليمية حيث تمثل قيم واتجاهات وسلوكيات ادارة المؤسسة التعليمية العوامل الاساسية المحددة لمدي قرة المؤسسة التعليمية علي ابراز صورة المجتمع الأي يقع فيه. • القيادة التريوية الايجابية تساعد علي تأكيد حقيقة ان تسويق الخدمات التعليمية الفعالة هي اكثر العناصر اهمية ويجب ان تكون في مقدمة عمليتي التخطيط واتخاذ القرار كما انها عامل اساسي في حياة المؤسسة التعليمية وغاياتها ومدي كونهما اساسا للاداء والتقييم وهذه القيم والاهداف مستمدة من سمة اخري مهمة من سمات ثقافة المؤسسة التعليمية وهي الحساسية تجاه البيئة والرغبة في تغيرها 


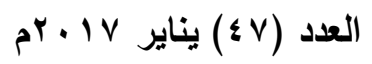

ويقتضي ذلك تحديد نقاط القوة والضعف في المؤسسة التعليمية بحيث تزهو بمناطق قوتها وتكون منتبهة لنقاط ضعفها وتعمل علي تحسينها • الابداع : creativity قورة أي مؤسسة تعليمية علي خلق استجابة فريدة ايجابية فعالة للظروف المتغيرة وهي استجابة تقوم بحل المشكلات عن طريق تحسين الخدمات التعليمية وقيام المؤسسة التعليمية باور حل المشكلات هو احد العناصر الاساسية لنجاح تسويق الخدمات التعليمية ويتطلب ذلك خاصيتين هما : -الخاصية الاولي : هي القدرة علي تشخيص عناصر أي مشكلة بدقة وذلك وفقا لمدركات اطراف هذه المشكلة . الخاصية الثانية : هي القدرة علي ابراز استجابات تخيلية تعيد حل القضية بحيث يتحقى الرضا المتبادل لجميع الاطراف ومن ثم ينتهي الامر • ويكون تسويق الخدمات التعليمية بصدد توقع الاحيتاجات المتغيرة مع الحساسية تجاه المتغيرات الاجتماعية والاقتصادية واعداد استيرايتجيات تدفع المؤسسة التعليمية للامام مع ذلك نجد ان الوسيلة الخلاقة تحتاج الى وسيلة ابتكارية لنقلها ، فالابداع فى ادارة المنهج او المقرر الدراسى لم يوافقه ابداع فى توصيله ، و دائما ما تركز

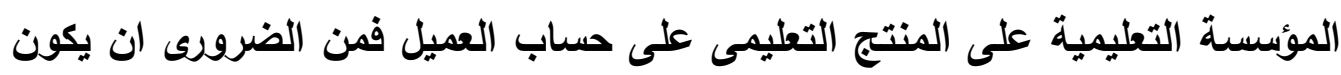
الابداع قادرا على اظهار اكثر الوسائل ملاعمة لتعريف العميل بمصداقية المنتج التعليمى ، على ان يكون العمل انطلاقا من احتياجات و رغبات العملاء بدلا من افتراض ان جميع التغيرات التريوية متسقة ، مفهومة ، شرعية من تلقاء ذاتها ـ

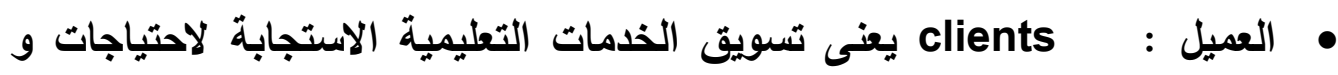
رغبات العملاء و التى يفضل تعريفها من حيث الوفاء بالمتطلبات او الملاعمة للغرض على هذا فان عناصر مواجهة مجموعة محدة من احتياجات و رغبات العملاء سوف تتنوع وفقا للعملاء و ايضا وفقا لاسلوب الاتصال. • الالتزام : ان المؤسسات التعليمية الناجحة فى تسويق منتجاتها و خدماتها التعليمية اعتادت انشاء نوع من الالتزام بلالا من ان تنشر هذا الالتزام من واقع 


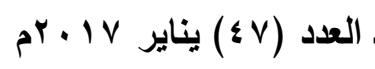

فاعلية عقد الموظف و من ثم هناك تركيز على توصيل قيم المؤسسة التعليمية

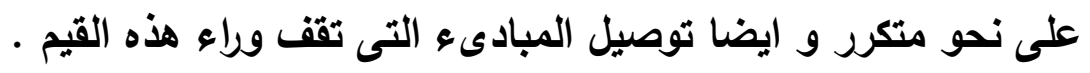
المنافسة : يتأثر برنامج تسويق المنتجات و الخدمات التعليمية للمؤسسة التعليمية

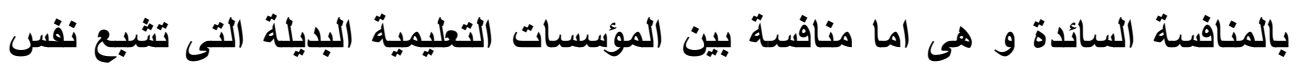

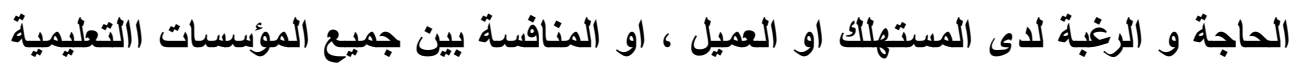

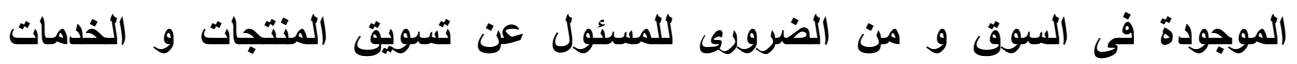
التعليمية الفهم الكامل للبيئة التنافسية المحيطة بالمؤسسة التطليمية و معرفة درجة قوة و ولفئول حدة المنافسة بها و كنلك الحال بالنسبة للمؤسسات التعليمية فى اى مرحلة من مراحل التطليم المختلفة

\section{رابعا :التطلبات اللازمة لنجاح تسويق الخدمات الجامعية}

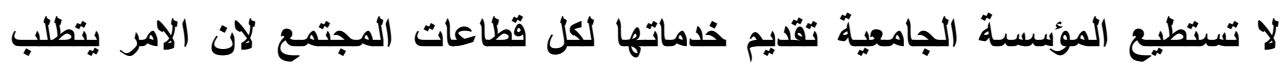

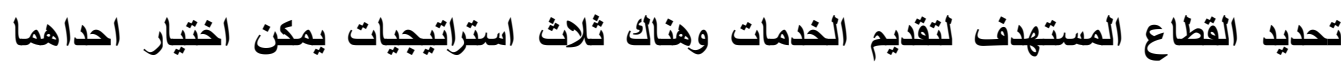

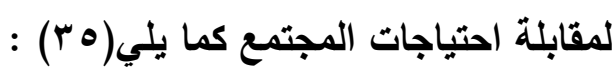

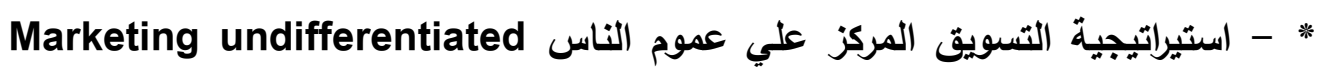
: markets فيما تقوم المؤسسة بتقايم منتج واحد لجميع قطاعات السوق حيث تقوم بالتركيز علي

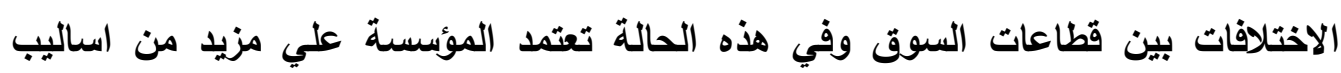
الترويج وقتوات التوزيع لانها تتعامل مع اعداد كبيرة من المستفيدين. differentiated marketing -*

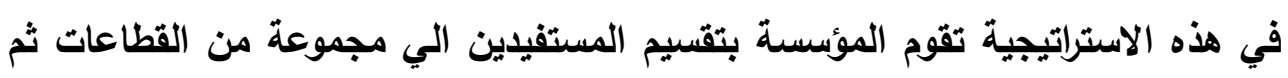

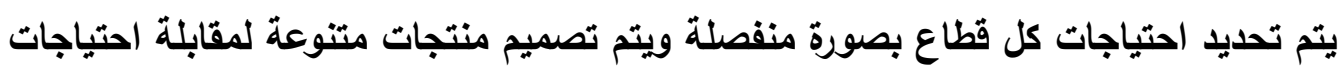
كل قطاع علي حدة وعلي هذا فان هذه الاستراتيجية تزيد من التكاليف لكنها وسيلة لتعظئ فئيم

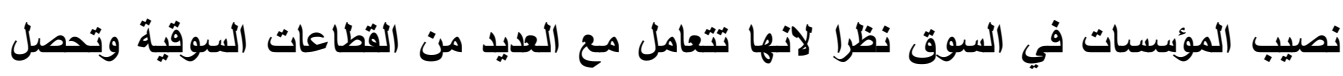
علي رضا فئات متنوعة من المستفيدين . 


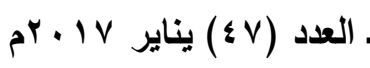

concentrated استثيراتيجية التسويق المركز علي قطاع محدد من المجتمع

marketing

نستخدم هذه الاستراتيجية اذ كانت المؤسسة محدودة الموارد وفيها تقدم المؤسسة خدمة واحدة لقطاع محدد ومن مميزات هذه الاستراتيجية انها تساعد المؤسسة في الحصول علي نصيب كبير داخل هذا القطاع ومن ثم تثمكن من منافسة المؤسسات الاخرى.

اختيار المزيج التسوريقى ( الاسلوب التسويقى )

المزيج التسويقى هو مجموعة من المتغيرات التى تتحكم فيها ادارة المؤسسة و تستخدمها لتحقيق اهدافها فى الاسواق المحدة ، و كان اول من وصف هذه المتغيرات هو " نيل بوردون " Neil Borden عام سه 9 ميث حدد مجموعة من العناصر ( الادوات ) الى

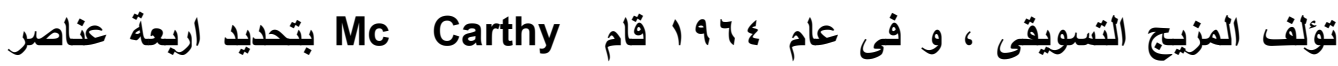
(product , price , 4 PS اساسية لتشكيل المزيج التسويقى لاى مؤسسة ، و هى place , promotion) و على الرغم من التشابه بين عناصر ( ادوات ) استراتيجيات التسويث فى كل من التسويق فى المؤسسات الهادفة للريح ، و التسويق فى المنظمات غير الهادفة للربح الا ان هذه المتغيرات ( الادوات ) الاربع لها مضامين مختلفة نظرا لطبيعة هدف ، و نوعية الخدمات التى تقدمها تلك المنظمات غير الهادفة للربح ( (ب)، و هذه الادوات كالاتى : * المنتج : يعرف المنتج على انه كل ما يقدم للسوق سواء كان سلعا ملموسة ، او خدمات تؤدى الى اشباع حاجات المستهلك(rv) و يعتبر المنتج احد الادوات الاساسية لنجاح النشاط التسويقى ، لألك لابد ان يصمم فى ضوء احتياجات المستفيدين مع الاهتمام بجودة المنتج ، و جودة المنتج لا تقاس من وجهة نظر منتجيها ، و انما تقاس بواسطة المستقيد من خلال درجة تطابقها او اختلافها مع مستوى توقعاته(^)). و يتضح من التعريف السابق ان هناك تطابقا بين مفهوم المنتج ، و مفهوم الخدمات الجامعية الذى حددته الجامعات المصرية حيث ثبنت المفهوم الشامل للخدمات فالخدمات الجامعية لها عدة اشكال فمنها السلع المادية الملموسة مثل المنتجات التى تقدمها بعض الواحدات بكلية الزراعة ، و غيرها و هناك ايضا خدمات غير ملموسة مثل الاستشارات ، الخدمات التعليمية ، و التدريبية، و البحوث العلمية ، و غيرها. 


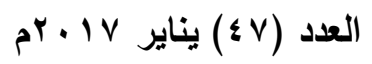

وتمر المنتجات عموما بمراحل مختلفة خلال الفترات الزمنية المتباينة وتعرف هذه المراحل بدورة حياة المنتج وتشمل هذه المراحل مرحلة تقليمها مرحلة نموها مرحلة نضوجها مرحلة

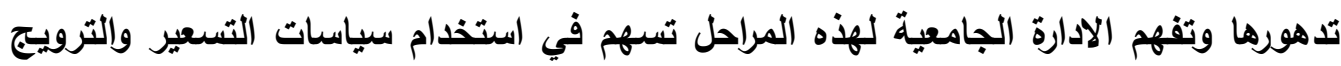
والتوزيع المناسبة لكل مرحلة حتي تتمكن المؤسسة من الوفاء بمتظلبات المرحلة ومواجهة

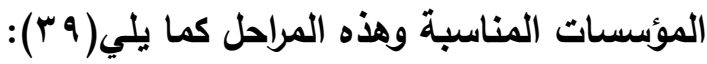
مرحلة عرض المنتج : وتتصف هذه المرحلة بانخفاض المبيعات نظرا لعدم معرفة الفئات المستهدفة بالمنتج الجديد وارتفاع تكلفة التوزيع والترويج لضرورة تعريف الفئات المستهدفة بالمنتج والرغبة في جذب منافة التوزيع لتاول المنتج وتستخدم المؤسسة في هذه المرحلة سياسة الاعلان المكثف مع السعر المنخفض لاعاقة المنافسين عن الاخول في ميدان انتاج ذلك المنتج لقلة الارباح وتثقبل جميع المؤسسات قلة الارباح في تلك المرحلة علي امل تحقيق الارباح في المرحلة التالية. مرحلة تزايد الطلب وتنامي المنتج : وفي هذه المرحلة يبدأ الارتفاع المطرد في حجم المبيعات وينتشر استخدمها بين المستهلكين وعادة ما يظهر عدد من المنافسين في الميدان وللحفاظ علي نمو المنتج في هذه المرحلة فان المؤسسة تبحث عن منافذ توزيع جليدة للحرص علي تحسين وتطوير المنتج تبدأ فى اتباع سياسة التخفيض الطفيف لسعر المنتج على مراحل زمنية معينة لكسب قطاع جديد من المستفيدين.

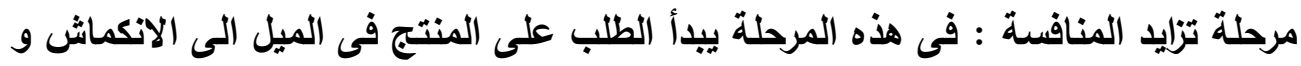
تثتد حدة المنافسة ، و تقوم المؤسسة بتخفيض الاسعار ، و زيادة حملات الترويج ، و و

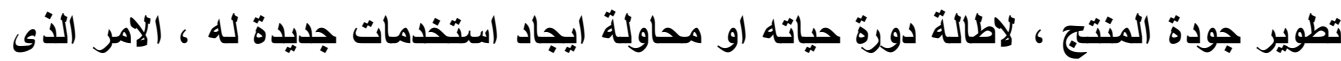
ينتج عنه انخفاض الارياح. مرحلة التهور : تتسم هذه المرحلة بالانخفاض المطرد فى حجم المبيعات ، و قـ يحدث هذا الانخفاض على مدى زمنى طويل او قد يتم بشكل سريع ، و هذا قـ يرجع الى اشتداد المنافسة او لتغير متطلبات المستفيدين( • ؟ ). ونظرا لاهمية المنتجات من حيث جودتها ،ومدى ملاءمتها لاحتياجات المستفيدين تستخدم الجامعات عدة اساليب لتقويم جودة خدماتها ، و فى مقدمة هذه الاساليب : اسلوب تحليل 


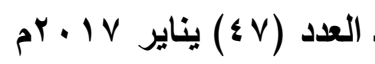

الحافظة، و يتم من خلاله تقويم الخدمات الجامعية من اجل تحسين الخدمات الجيدة ، و استبعاد الخدمات الضعيفة ، و يتم هذا الاجراء بواسطة جهة مختصة بالمؤسسة الجامعية. * التسعير : يعتبر التسعير احد اهم ، و اصعب القرارات التى اتخاذها على مستوى ادارة

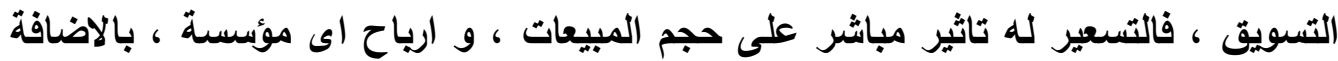
الى انه يعد العامل الحاسم الأى يقر المستهلك على اساسده قبول المنتج او رفضه. التسعير هو فن ترجمة قيمة المنتج للعميل الى وحدات نقدية ، و هو اكثر عناصر الاسترتيجية التسويقية ( المزيج التسويقى ) مرونة حيث يمكن تغييره بسرعة للاستجابة فى هي الطلب او فى حالة المنافسة ، لان تنمية ، و تطوير المنتج يستغرق وقت كبير( أـ). والتسعير فى المنظمات غير الهادفة للربح يتميز بالتسعير الرمزى حيث تحدد اسعار رمزية للمنتجات ليعود بالنفع ، و لو بالقليل يسهم فى تقديم خدماتها ، ولهذا يمكن للوحدات التابعة للجماعات ان تقدم منتجات او خدمات بتكلفة اقل من القطاع الخارجى ، و لهذا تحقق تميزا مع قطاعات المجتمع التى نتعامل معها ، و يزيد عدد المستفدين ، و يهذف تسعير الخدمات

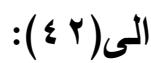

- تحقيق ارياح للجامعة يمكن الافادة منها فى تحسين الخدمات التى تقدمها الجامعة خاصة فى ظل الميزانيات الحكومية المحدودة للجامعات. - المحافظة على العملاء الحاليين ، و العمل على جذب عملاء جدد عن طريق اتباع سياسة تسعيرية مرنة ، و مما يسهم فى المحافظة على الصورة الذهنية للجامعة لدى العملاء. - التصدى للمنافسين من خلال التعديل المستمر للاسعار . - تغطية التكلفة التى تتحملها الجامعة بوصفها مؤسسة غير هادفة للريح فى الاساس.

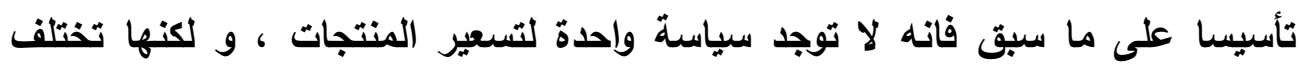
باختلاف نوع المنتج ، لانه يسهم فى خلق الصورة الذهية عن الجامعة لاى العملاء ، فالاسعار العالية تعنى بانسبة للمستهلك الجودة ، و لذلك يتعين على الجامعات عند تحديد الاسعار مراعاة ان تتناسب مع توقع المستفيدين. * الترويج : يعتبر الترويج احد العناصر الاساسية للنظام التسويقى ، و لا يمكن الاستغناء عن النشاط الترويجى ، لتحقيق اهداف الجامعة كمؤسسة تهذف لتعريف المجتمع بما تقدمه من منتجات ، و يعرف على انه العملية التى يتم من خلالها استخدام كافة الجهود ، و 


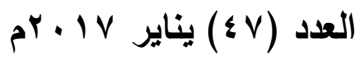

الاساليب الشخصية ، و غير الشخصية لاخبار العميل بالخدمة التى تقدمها المؤسسة ، و و

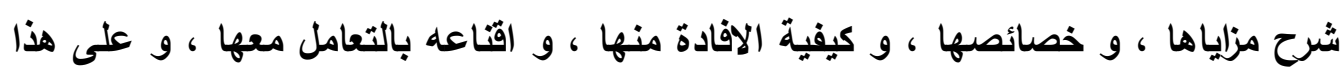

$$
\text { فعملية الترويج تقوم على شقين اساسيين هما(ب ؛ ) : }
$$

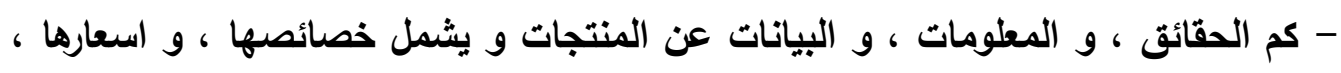
و اماكن وجودها ، و غيرها من المعلومات.

- محاولة التأثير على الفئات المستهدفة ، و اقتاعهم بالمنتج عن طريق تكوين اتجاه ايجابى

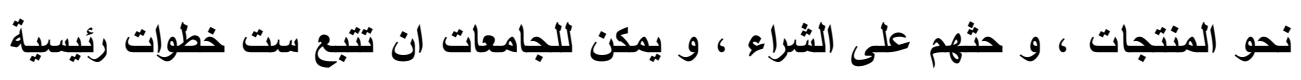

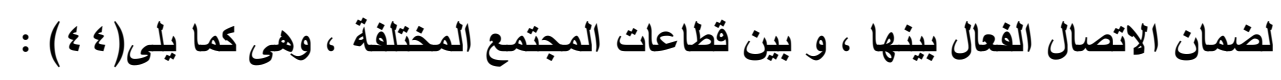

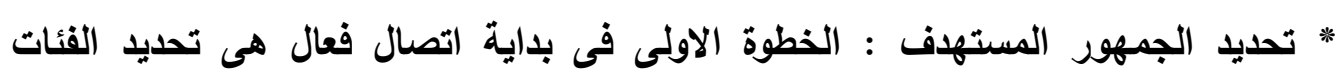

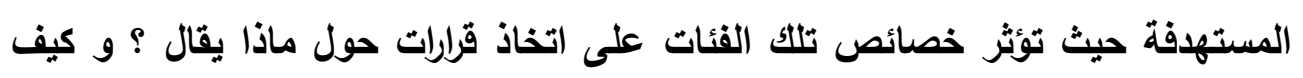

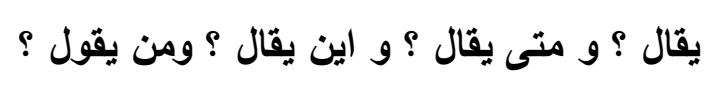

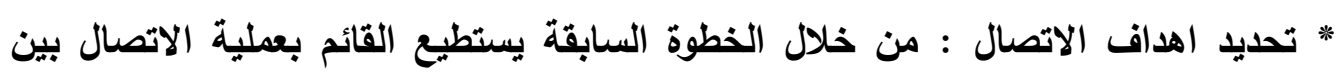
الجامعة و المستفيدين تحديد الهذف الأى يريد الوصول اليه من خلال اتصاله بالمستفيدين ، و فى كثير من الاحيان فان الهدف النهائى هو ان يتخذ الجمهور

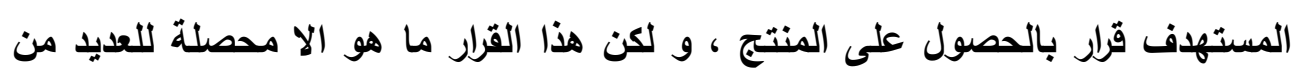

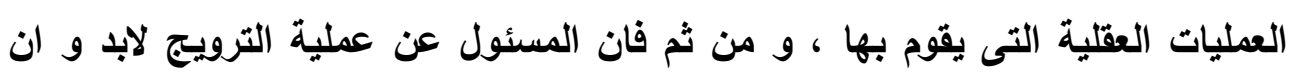
يعرف فى مرحلة يقف الجمهور المستهدف ، وتتمثل المراحل المؤدية الى اتخاذ قرار

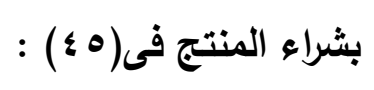

- الوعى : يجب فى البداية التأكد من ان العملاء على وعى بالمؤسسة الجامعية ، فقد يكونوا

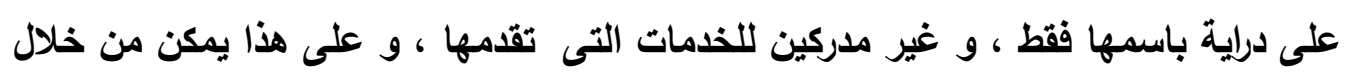

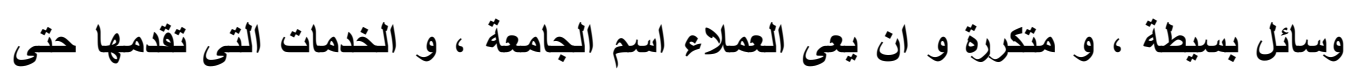

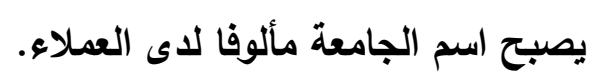
- المعرفة : قد يكون الجمهور المستهذف على وعى باسم المؤسسة الجامعية ، و المنتجات التى تقدمها دون التعرف على خصائصها ، و مزاياها ، الامر الأى يتطلب قيام الجامعات بتقديم كافة المعلومات و البيانات عن المنتجات ، و التى تسهم فى خلق صورة ذهنية للجامعات لاى المستقيدين. 


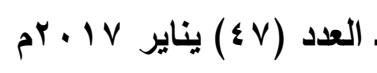

- الحب : لا يقتصر دور المسئول عن ترويج المنتجات الجامعية ان يقوم بتعريف العملاء بهذه المنتجات ، و لكن ينمى لايهم اتجاهات ايجابية نحو المؤسسة الجامعية.

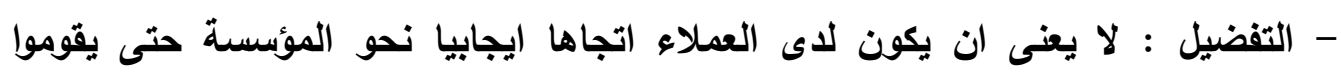

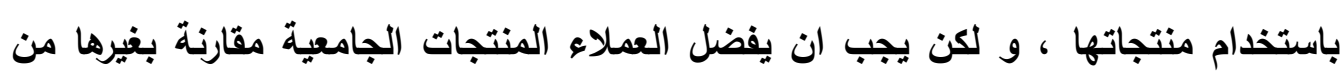
المؤسسات و فى هذه الحالة فان الجامعات تحتاج باستمرار الى تحسين ، و توات تطوير منتجاتها بالاضافة الى التعرف على مدى رضا العملاء عما تقدمه من خدمات.

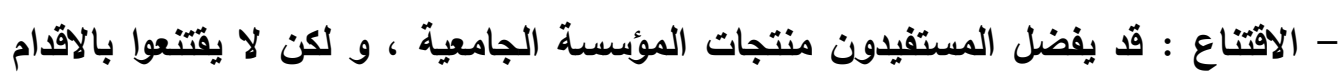
على الحصول على تلك الخدمات ، و هنا يأتى دور القائم على عمل ترويج المنتجات

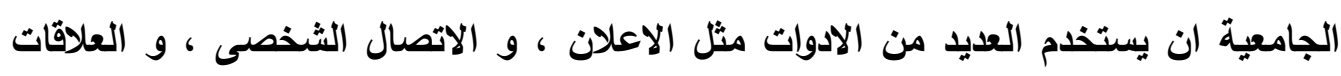

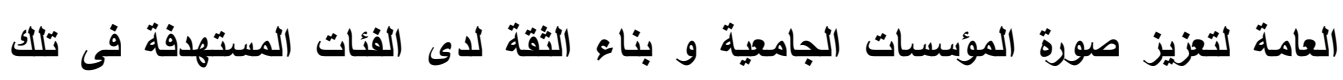

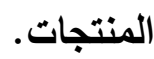
- الحصول على المنتج : قد يصل الجمهور المستهدف الى مرحلة الاقتناع ، و لكنه لم يقدم

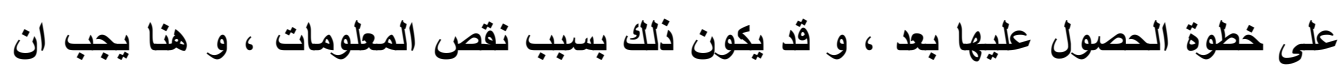

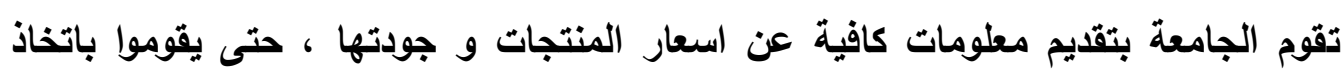
القرار النهائى نحو الحصول على هذا المنتج. * تصميم الرسالة : بعد تحديد المرحلة التى يقف عندها الجمهور المستهدف ، تقوم

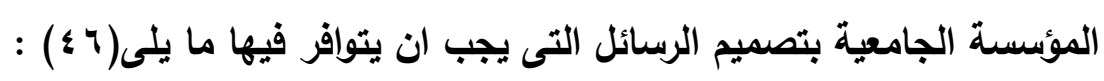
- جاذبة للانتباه لكى تحظى باهتمام الفئات المستهدفة.

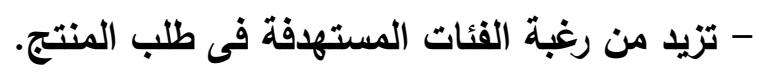
- قد ينتج عنها اتخاذ قرار شراء المنتجات المقدمة من الجامعات. - مراعاة تكلفة الوسيلة الترويجية بحيث يتم اختيار الوسيلة التى تتناسب مع معنداء الميزانية ، الامر الأى يتطلب مراعاة محتوى الرسالة ، و شكلها ، و مصدرها.

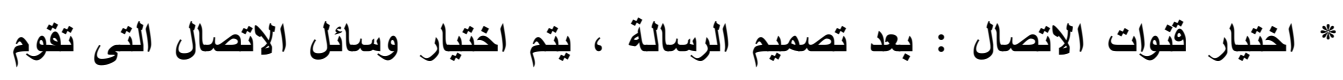
بتوصيلها للفئات المستهدفة ، و هناك نوعان من وسائل الاتصال : شخصية و فيهات التهات

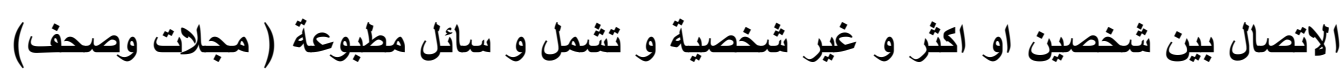

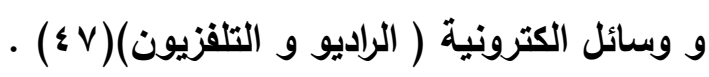




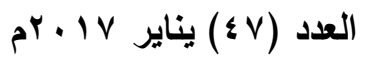

* اختيار مصدر الرساية : ان الرسالة تنقل عن طريق مصدر موثوق فيه كلما كانت اكثر تاثيرا على القئات المستهرفة. * التظذية المرتدة : لا تتوقف عملية الترويج على اقناع الفئات المستهدفة بالحصول على

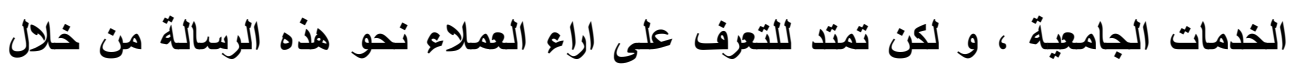
التعرف على اتجاهاتهم الماضية ، و الحالية نحو المنتج ، و هذا يفيد فى اجراء اه تعديل

في البرنامج الترويجى.

وهناك عدة عناصر يمكن للجامعة ان تستعين بها لترويج منتجاتها بالمنتجات التى تقدمها ،

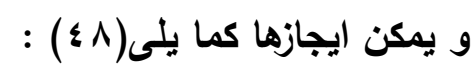

- الاعلان : يعتبر الاعلان من اقدم الادوات الترويجية التى استخدمت فى التسويق ، وعلى

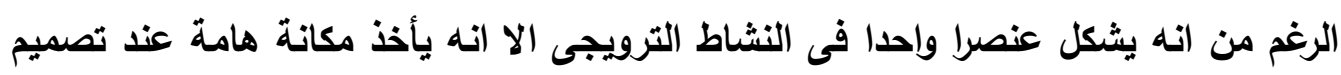
هذا النشاط ، و يعرف الاعلان انه عملية اتصال غير شخصى مدفوع الاجر تستخدمها

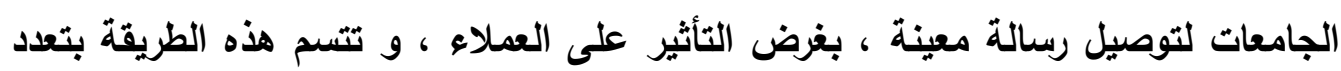

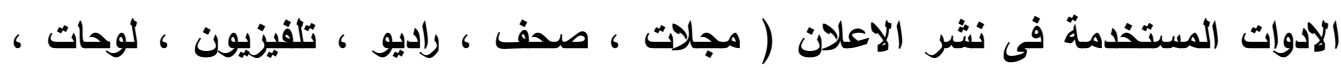
ملصقات ) و من ثم تصل الى قطاعات كثيرة من المستفدين بكفاءة ، و بادنى تكلفة.

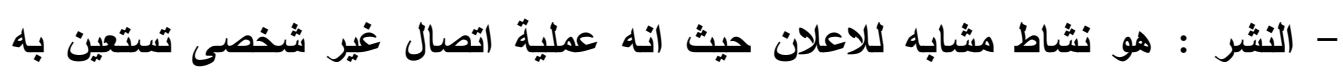
الحامعات تقديم منتجاتها بشكل اختيارى دون مقابل.

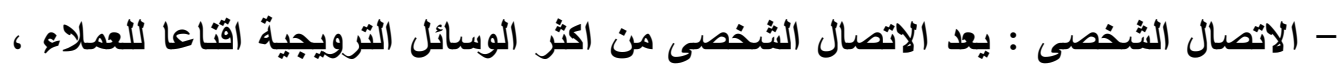

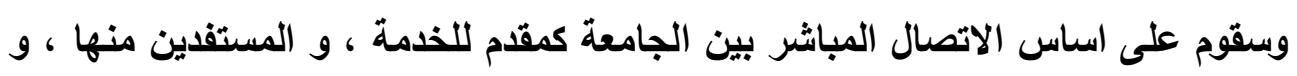
يتيح الاتصال الثخصى الفرصة للتعرف على الاستجابات المباشرة للعملاء بخصوص تلك التك

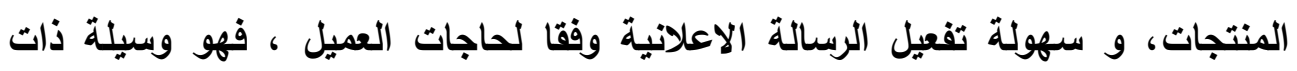

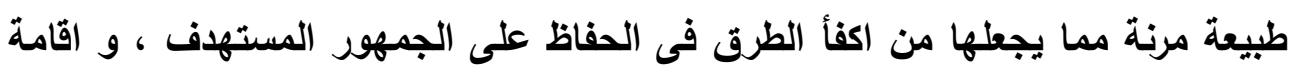
علاقات دائمة معه ، و بصفة عامة يتميز الاتصال الثخصى بامكانية تزويد المستفيدين

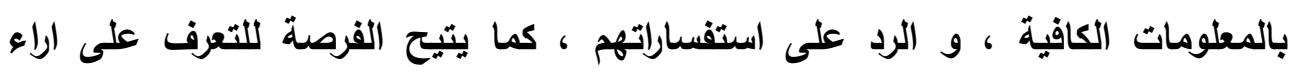

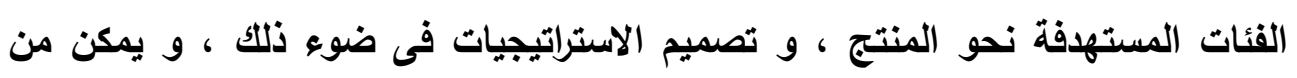

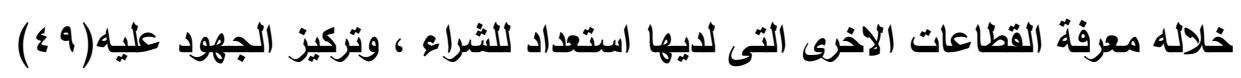




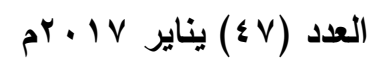

- العلاقات العامة : نشاط يهدف الى ايجاد علاقة ايجابية ، و توطيد الصلة بين الجامعة و

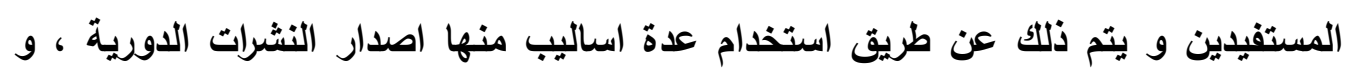
الكتيات ، والندوات ، وورش العمل ، المؤتمرات ، التقارير السنوية ، اقامة المعارض.

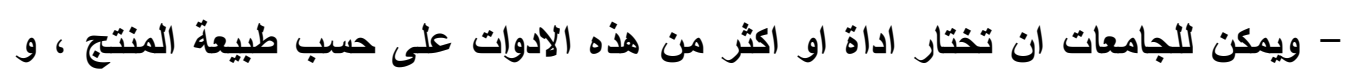
خصائص الفئات المستهدفة ، و الميزانية المتاحة للنشاط الترويجى.

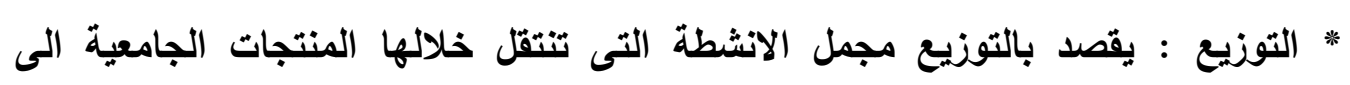
المستفيدين فى المكان ، و الزمان المناسبين ، و يجب ان نفرق بين التوزيع ، و قنوات

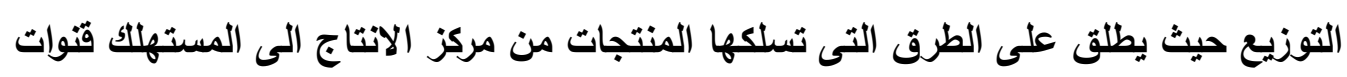

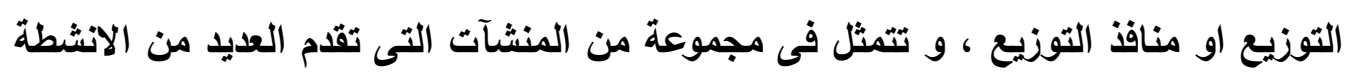

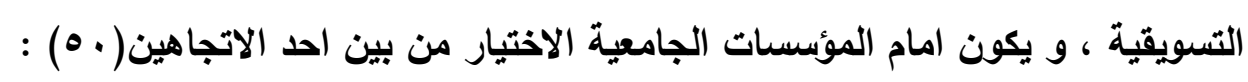

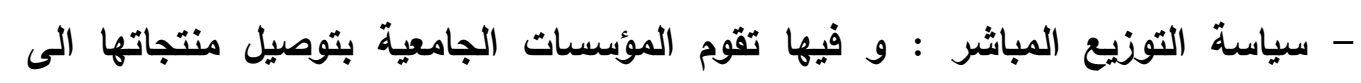
المستفيدين دون تدخل وسطاء ، و تتميز هذه الطريقة بانخفاض التكلفة ، و سرعة توصيل الخدمات الجامعية للمستفيدين ، وسهولة الحصول على التغذية الراجعة.

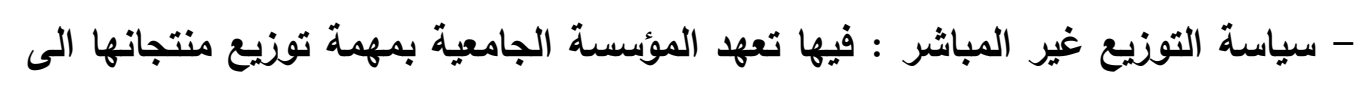
الوسطاء ، غالبا تتم هذه الطريقة فى المنتجات السلعية اكثر من الخدمية.

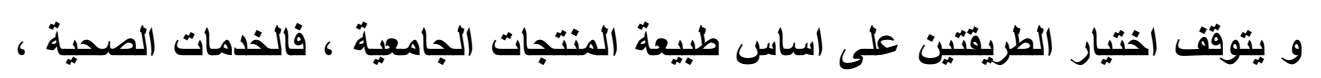

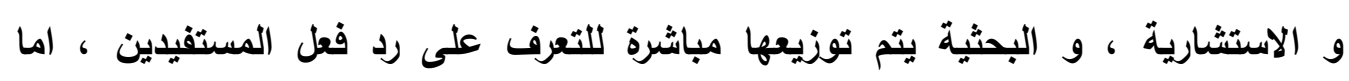

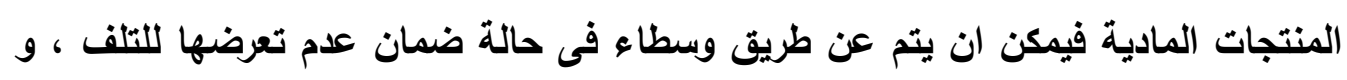

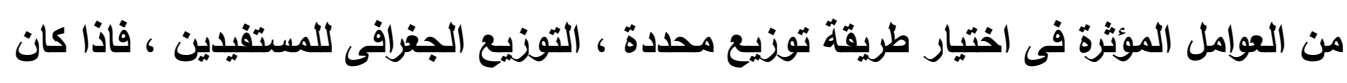

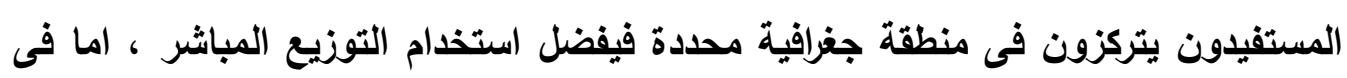
حالة الانتشار الجغرافى للمستفيدين على مساحات واسعة فانه من المفضل ان يتم توزيع الخدمات عن طريق الوسطاء ، مع الاخذ فى الاعتبار الخصائص التنظيمية للمؤسسة الجامعية ، و هى تلك العوامل المرتبطة بالمؤسسة الجامعية من حيث حجمها ، و موارئ مواردها

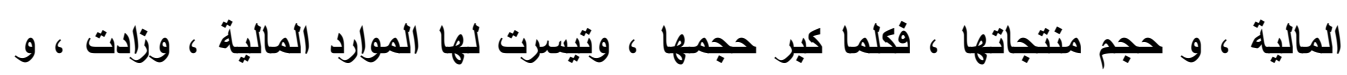

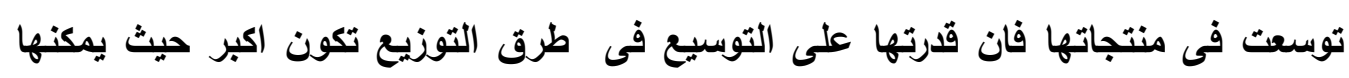

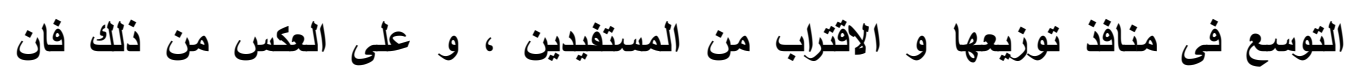




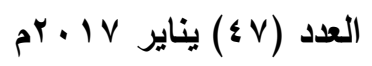

المؤسسات الضعيفة التى تقل مواردها عليها ان تزيد من حجم انشطة التوزيع من خلال الوسطاء.

\section{عمليات تسويق الخدمات التعليمية بـالجامعات.}

تتضمن إدارة تسويق الخدمات التعليمية بالجامعات مجموعة من العمليات، منها:

Marketing Planning in The Universities (التخطيط التسويقي بالجامعات ) يعتبر تخطيط الأنشطة التسويقية للخدمات التعليمية بالجامعات من الاهمية بمكان

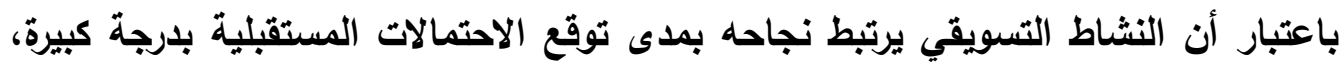
وتخطيط الأنشطة التسويقية يعمل على الاستعداد للغد من خلال وضع الخطط والاستراتيجيات. وتخطيط التسويق مكون أساسي من مكونات التخطيط الاستراتيجي بالمنظمات، "وهو يدعم التخطيط الاستراتيجي للمنظمة بخطط أكثر تفصيلاً لاستهداف الفرص التسويقية المحدد(1)، والثنكل التالي - رقم (1) - ويوضح العلاقة بين التخطيط الاستراتيجي على مستوى الجامعة وتخطيط الأنشطة التسويقية على مستوى وحدة التسويق بالجامعة. مستويات التخطيط بـالجامعات( Or or )

\begin{tabular}{|c|}
\hline 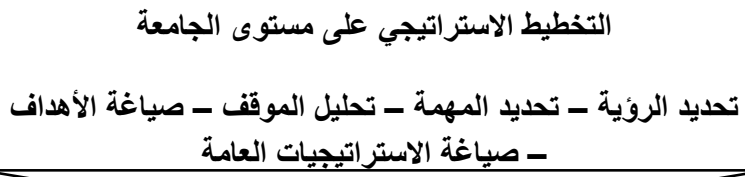 \\
\hline 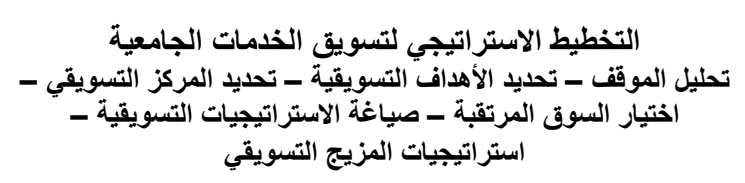 \\
\hline إعداد خطة لكل خدمة التسويق وكل نشاطن، وكل منطقة \\
\hline تنفيذ وتقييم الخطة السنوية \\
\hline
\end{tabular}




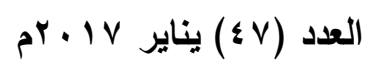

ومن الثكل يتضح أن تخطيط الأنشطة التسويقية بالجامعات يتم على مستويين الأول: التخطيط الاستراتيجي لتسويق الخدمات الجامعية، والثاني: التخطيط السنوي للتسويق بالجامعات.

(أ) التخطيط الاستراتيجي لتسويق الخدمات بالجامعات. ويتم من خلال مجموعة من الخطوات كما يلي(ب هم): ا ـ تحليل الموقف التسويقي الحالي. r. تحليل البيئة الداخلية والخارجية. r. بياغة الأهداف التسويقية. ؛. وضع الاستراتيجيات التسويقية. •. وضع برنامج العمل التنفيذي. 7. تحديد كيفية الرقابة على الخطة. V . تطوير وثيقة الخطة التسويقية. (ب) التخطيط السنوي للتسويق بالجامعات. يعتبر التخطيط السنوي من الأهمية بمكان باعتباره تخطيط على المدى القصير لتسويق الخدمات والأنشطة بالجامعات، وهو المسئول عن تحويل التخطيط الاستراتيجي باتئي للتسويق طويل المدى لخطط سنوية (ـ ه). • تصميم الإستراتيجيات التسويقية: يقصد بالاستراتيجية التسويقية مجموعة من الإجراءات التي تمكن الوحدة من التوصل إلى الأهداف الموضوعة بحيث تتحقق

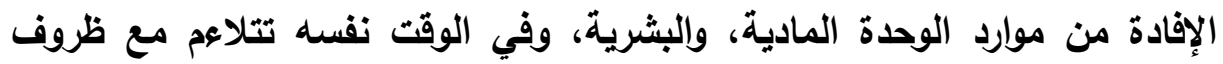
البيئة الخارجية(ه ه) وتوضع في ضوء المعلومات والدراسات عن الفئات المستهدفة، وعن نوعية الخدمات المقدمة من قبل الوحدة، ومدى تلبية لاحتياجات المستفيدين، بالإضافة إلى المعلومات المتوفرة عن المنافسين؛ بهدف تقليم مزايا في مقابل عروض المنافسين تساعد الوحدة في كسب مكانة متميزة بين قطاعات المجتمع

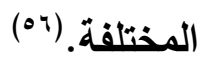
وهناك نوعان من الاستراتيجيات: كل منها تتضمن مجموعة من البدائل، على كل وحدة كأى مؤسسة أن تختار من بين هذه البائل في ضوء تحليل الوضع الراهن لها، 


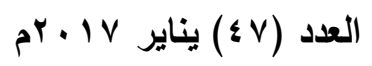

والأهداف المرجو تحقيقها، وهذه الاستراتيجيات تتمثل في مجموعة من الاستراتيجيات لطرح

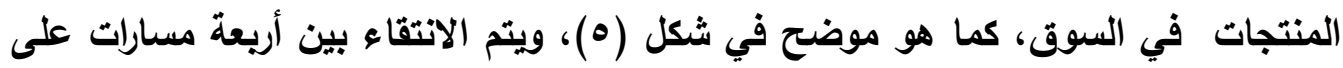

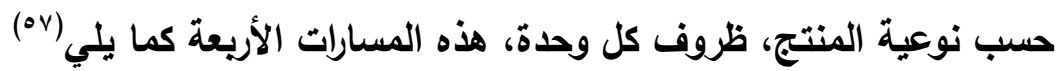

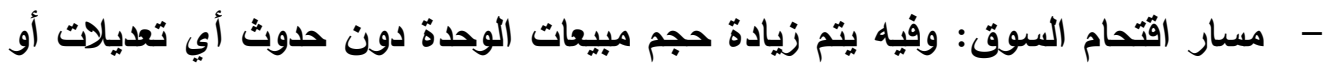
تغيرات في هذه الخدمات. - مسار تنمية المنتج: وفيه يتم تعديل، وتحسين المنتجات وقد يتم إدخال (إضافة) منتجات جديدة لقطاعات السوق الحالية. - مسار تنمية السوق: وتهدف هذه الاستراتيجية لكسب عملاء جدد فضلاً عن العملاء التقليديين أي تسعى للبحث عن قطاعات سوق جديدة للخدمات الحالية. - مسار التنويع: وفي هذا المسار يتم تقديم منتجات جديدة لقطاعات سوق جليدة.

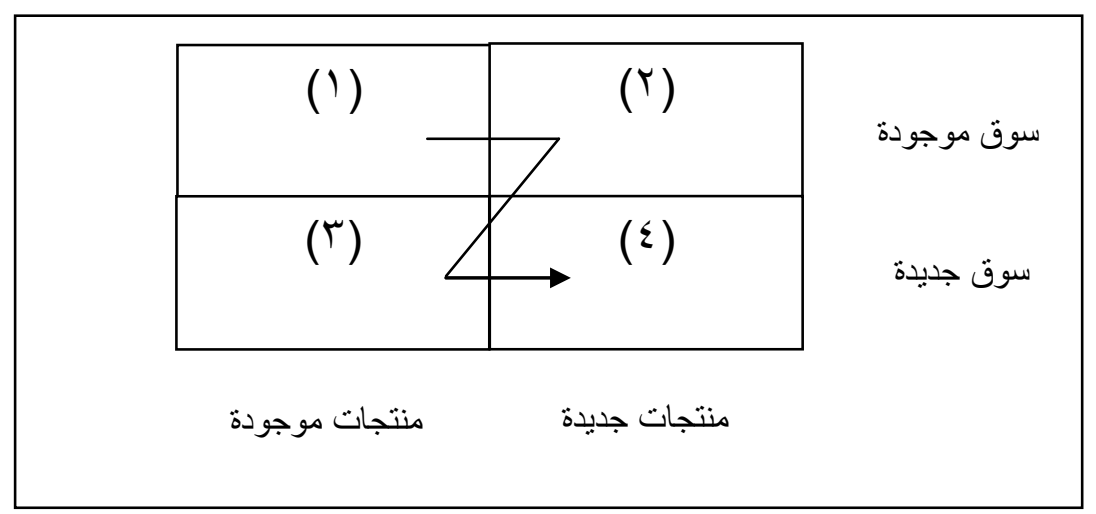

شكل (•) شكل يوضح مسارات تقديم المنتجات للمستفيدين(ه^) والجدير بالذكر أن الكثير من الاقتصاديين ينصح باستخدام هذه المسارات وفقاً لإتجاه حرف Z حتى تكتسب المؤسسة المعرفة الكافية بالسوق، وتكتسب قاعدة عملاء كافية ويرى البعض الآخر أنه لا مانع من التخطي إذا كانت المؤسسة تقوم بلراسات، وتحليلات باته مسبقة للسوق تستند عليها. وينبغي ألا تكتفي الوحدات التابعة للجامعة بتقديم منتجات متميزة أو تقديم منتجات

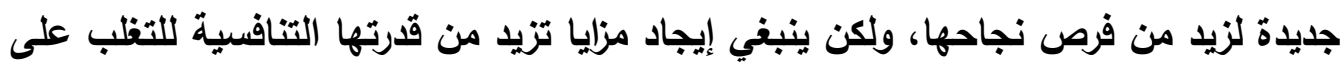

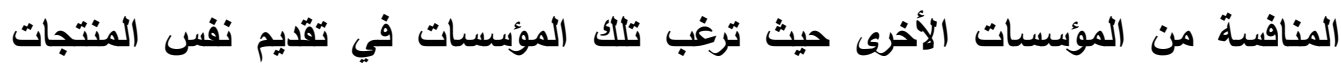
بمواصفات أفضل، ويأسعار أقل للحصول على أكبر نصيب في السوق، لذا ينبغي على كل 


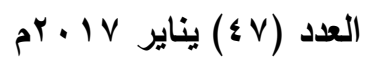

مؤسسة إعداد إستراتيجية تنافسية، ويصفة عامة فإن هناك عدة بدائل يمكن للوحدات أن

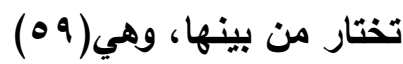

- إستراتيجية الهيمنة على السوق: تعني أن تحظى الوحدة ذات الطابع الخاص بأكبر حصة سوقية للمنتجات التي تقدمها، وهذا يتطلب زيادة الحصة السوقية الإجمالية، والحفاظ على الحصة السوقية الحالية من المنافسين. - إستراتيجية تحدي المنافسين: تستخدم هذه الاستراتيجية لتحسين وقع الوحدة فقد يكون ترتيبها الثاني أو الثالث، وتسعى للوصول لموقع القيادة في سوق الخدمات، ولتحقيق ذلك نتحدى المؤسسة الرائدة في السوق باستخدام سياسات تحدي الأسعار (تخفيض الأسعار)، تكثيف الحملات الترويجية لخدماتها والاهتمام بجودة المنتج، والأداء في تلك الوحدات وتنوع قنوات التوزيع، وهذا يتطلب من العاملين في تلك الوحدات أن يكونوا قادرين على اكتشاف نقاط ضعف المنافسين؛ لاستغلالها في تحسين الخدمات الجامعية التي تقدمها الوحدات. - - استراتيجية مجاراة السوق: تبني هذه الاستراتيجية يعني قبول الوضع القائم وتستخدم من قبل الوحدات التي لا تملتك التي تساعدها في تطوير خدماتها أو تقديم خدمات جديدة، ومن ثم لا تستطيع تلك الوحدات التابعة للجامعة أن تتحدى المؤسسات الرائدة في السوق، ويالتالي تتجه إلى تقلياها بهاف الحفاظ على حصتها السوقية، ومحاولة اكتساب عملاء جدد. - - استراتيجية استهداف قطاع محدد السوق: تهدف هذه الاستراتيجية إلى التركيز على قطاع معين (فئة مستهدفة محدة)، ويتم ذلك عن طريق تحليل احتياجات هذا القطاع، والتعرف على خصائصه، وتحديد كيفية الوصول إليه، وماذا يرضيه ، ومن ينافس عليه، وعلى هذا يمكن تقديم خدمات ذات مزيا عن المنافسين ويتم ذلك من خلال التخصص

$$
\text { في السوق. }
$$

Marketing Organization in The Universities) حيث أن نظام إدارة التسويق بالجامعة نظام فرعي من النظام الإداري بالجامعة ومن ثم فإن التظيم التسويقي بالجامعة جزءاً من تنظيمها الإداري، حيث يختلف تنظيم الأنشطة التسويقية من جامعة لأخرى من حيث هيكل الوحدة التسويقية بالجامعة وعلاقتها بالوحدات 


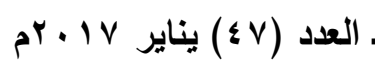

الأخرى، وكذا حجم الإمكانات المادية والموارد البشرية وفقاً لطبيعة التوجه التسويقي للجامعة، وكذلك حجم الجامعة وأنشطتها البحثية والخدمية والتدريسية، وقناعات القائمين على إدارتها بجدوى تسويق تلك الأنشطة ( • (7).

ويصفة عامة يمكن تنظيم العمل التسويقي بالجامعات وفقاً لأحد المداخل التالية:

$$
\text { (أ) مدخل التظيم الوظيفي: }
$$

يعتبر التظيم الوظيفي هو الشكل التظيمي الأكثر شيوعاً لوحدات التسويق حيث

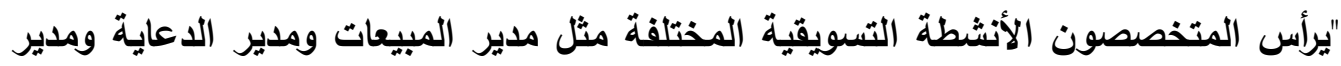
بحوث التسويق ومدير خدمة العملاء ومدير المنتجات الجديدة".(1) ويمكن اقتراح هيكل لوحدة تسويق جامعية وفقاً للمدخل الوظيفي حيث يتم تقسيم النشاطات التسويقية مثل الترويج والتسعير والمبيعات ويحوث التسويق إلى وظائف فرعية تتبع وحدات إدارية متوازنة تقع مسئولية تحقيق أهداف كل منها على عاتق مشرف مستقل (مدير الوحدة)، وتقع مسئولية التسيق بين هذه الوحدات على عاتق مدير عام وحدة التسويق بالجامعة.

(ب) مدخل التظيم الجغرافي (التنظيم على أساس المناطق): يعتمد التقسيم على أساس المناطق على تخصيص قسم مستقل لكل مجموعة من

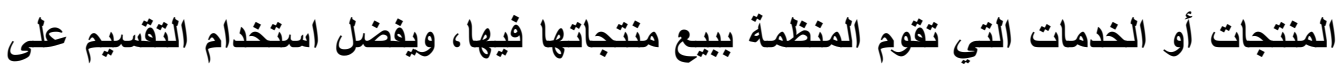
أساس المناطق في حالة المنظمات الكبيرة التي تنتشر أعمالها في مناطق جغرافية متعددة

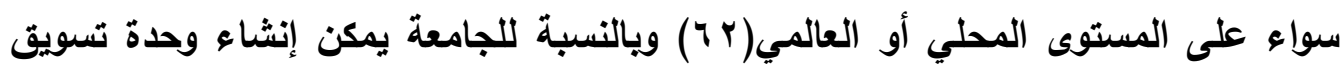
مركزية على مستوى الجامعة تكون مهمتها التسيق بين وحدات التسويق على مستوى

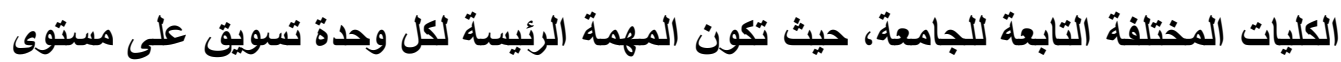
كل كلية تسويث الخدمات النوعية التي تقدمها تلك الكلية. مدخل التنظيم وفقاً للمنتجات (الخدمات):

حيث يعتمد التنظيم على أساس المنتجات على تخصيص قسم مستقل لكل مجموعة من المنتجات أو الخدمات التي تتعامل فيها المنظمة، ويكون هذا الثكل مناسباً في المنظمات

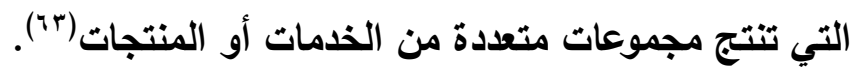




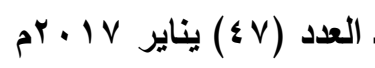

ويحقق التظيم وفقاً للمنتجات مزايا التخصص وتقسيم العمل بين مسئولي التسويق حيث تتراكم الخبرات عن الخدمات الجامعية التي يتم تسويقها وكذلك المشاكل التي تعوق تسويق تلك الخدمات بما يؤدي إلى فعالية أكبر في تسويق تلك الخدمات. (د) مدخل التنظيم وفقاً للعملاء: يعتمد التقسيم على أساس العملاء على أساس تقسيم جهاز التسويق إلى أقسام أو

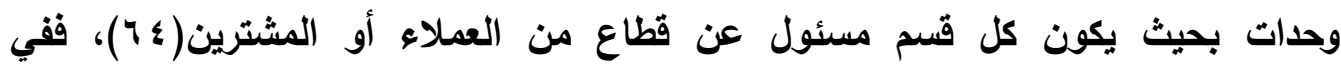

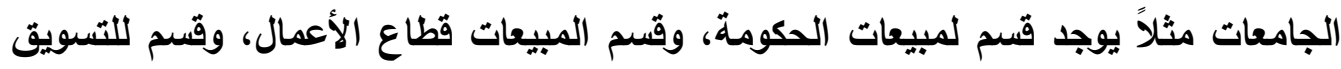
للطلاب والمتدربين.

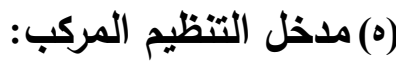

يعتمد التظيم المركب على الجمع بين أكثر من أساس من أسس التظيم السابق، وهو مزيج من عدة أثكال تنظيمية وفقاً لطبيعة وجحم كل جامعة.

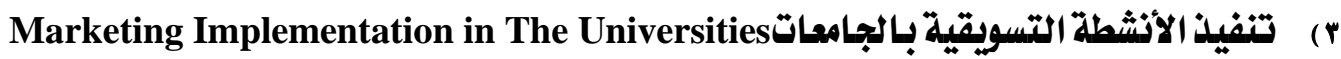
تعتبر عملية تنفيذ التسويق هي المحك في نجاح التسويق بالجامعات حيث يعتبر تخطيط استراتيجيات جديدة باية فقط تجاه تسويق ناجح، ويكون مردود استراتيجية تسويقية ممتازة متواضع إذا فشلت المنظمة في تنفيذها بصورة صحيحة، وتعتبر عملية تنفيذ التسويق معتى العملية التي تحول الخطط إلى إجراءات تسويق كي تحقق أهداف التسويق الاستراتيجي، ويشمل تنفيذ الأنثطة من يوم ليوم، ومن شهر لشهر وفقاً لخطط العمل، فبينما يتناول

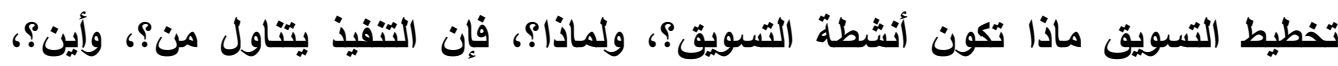

$$
\text { ومتى؟، وكم؟". (70) }
$$

ويعتمد تنفيذ التسويق الناجح على مدى جودة مزيج الأفراد، والتهيكل ونظم القرارات

والمكافآت، والثقافة السائدة في برامج العمل التي تدعم استراتيجيات المنظمة، وينبغي أن أن يتمتع العاملون في المنظمة على جميع المستويات بالمهارات اللازمة للعمل، والعمل على

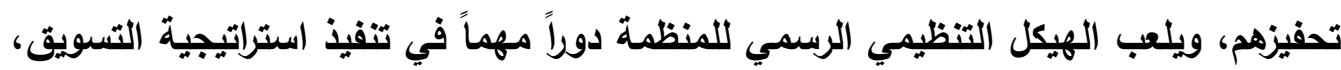
وكذلك نظام القرارات والمكافآت، وأخيراً فالتنفيذ الناجح يتطلب أن تتفق استراتيجيات التسويق

مع ثقافة المنظمة ونظام القيم والمعتقدات الذي يشترك فيه أفراد التظظيم. (rاب) 


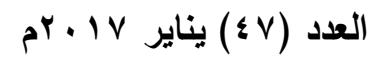

عarketing control in The Universities الرقابة التسويقية بالجامعات إن الجهود الإدارية المبذولة في سبيل تحقيق الأهداف التسويقية للجامعات لا يمكن

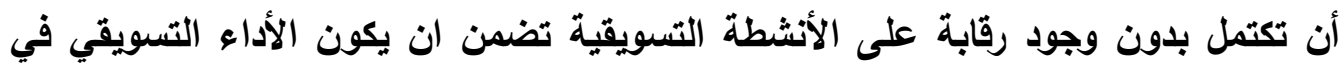

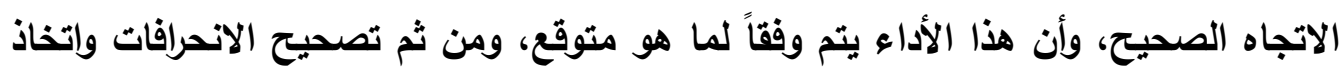
الإجراءات التصحيحية المناسبة. ويقصد بالرقابة على الأنشطة التسويقية للجامعات "عملية قياس وتقويم نتائج الاستراتيجيات والخطط التسويقية، واتخاذ الإجراءات التصحيحية التي تضمن تحقيق الأهداف التسويقية"( آن للجامعات.

وتمر عملية الرقابة على الأنشطة التسويقية بالجامعات بأريعة مراحل أساسية وهي كما يلي(1 7):

وضع المعايير الرقابية: يمثل المعيار الأداء المتوقع لتسويق خدمة تعليمية أو أكثر، وهو بمثابة المستوى الذي ينبغي أن يصل إليه الأداء التسويقي بالجامعة، مثل

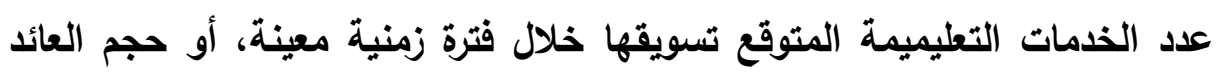
(الدخل) المطلوب الوصول إليه خلال فترة زمنية محددة. (ب) قياس الأداء الفعل: "يعد وضع المعايير، وتتفيذ الأعمال أو القيام بالأنشطة التسويقية، يتم قياس الأداء التسويقي الفعلي في المجال موضع الاعتبار"(9 ؟)، فعلى سبيل المثال إذا كان المجال هو تسويق البرامج التعليمية، فإن قياس الأدئ الأداء

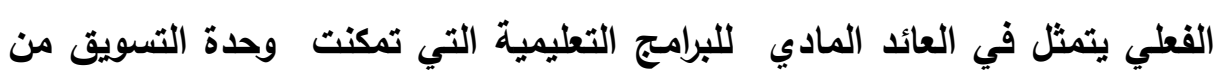
الوصول إليه بالفعل. تقييم الأداء(·): في هذه المرحلة يتم المقارنة بين الأداء الفعلي والمعيار (الأداء المتوقع)، ويترتب على هذه المقارنة الوصول إلى إحدى النتائج التالية:

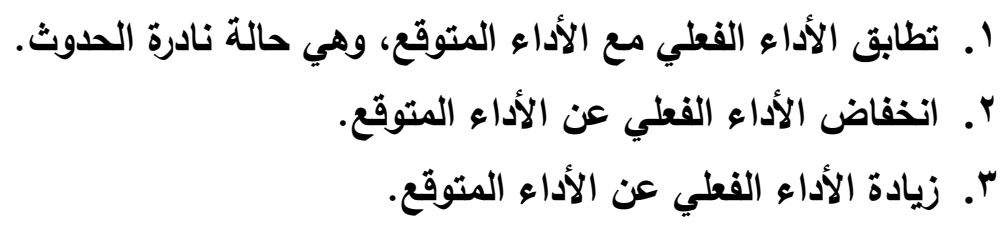




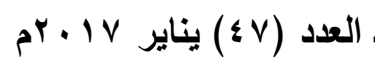

اتخاذ الإجراءات التصحيحية: في المرحلة الأخيرة ، يتم إتخاذ ما يلزم من إجراءات لتصحيح الانحرافات، فقد يأخذ الإجراء التصحيحي معالجة أسباب الاتحراف، وريما

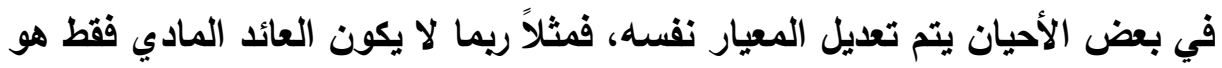
المعيار الملائم لقياس تسويق الخدمات التعليمية بالجامعات.

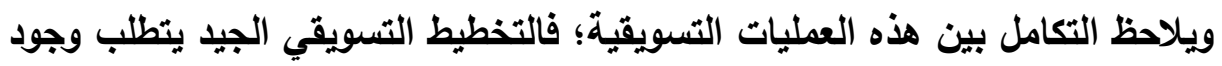
تنظيم تسويقي قادر على تفعيل الخطط والاستراتيجيات الموضوعة، وعملية تنفيذ الأنشطة التسويقية هي المحك في نجاح الخطط التسويقية باعتبارها العملية التي تحول الخطط إلى إجراءات تنفيذية، ويعتمد تنفيذ التسويق الناجح على مدى جودة مزيج الأفراد، والهيكل التنظيمي، ومدى تمتع العاملون بالجامعات بالمهارات اللازمة للتسويق، ومن ثم يأتي دور الرقابة التسويقية لضمان كون الأداء التسويقي في الاتجاه الصحيح، وأن هذا الأداء يتم وفقاً لما هو متوقع.

د - وضع آليات لقياس مدى رضا الفئات المستهدفة: قياس رضا المستفيدين من أبرز آليات التقييم والمتابعة، وهي خطوة أساسية لتحديد مواطن القوة والضعف في الاداء، ووضع تصورات لتحسين، وتطوير العمل بحيث تصبح تلك من الترئ الخدمات أكثر استجابة لاحتياجات أفراد المجتمع الذي تخدمه، ويعبر رضا المستفيدين عن

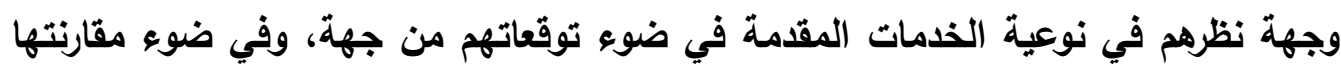

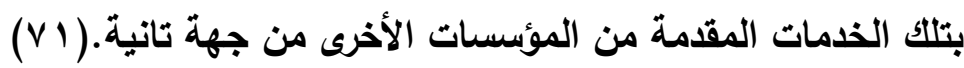
وهناك نوعان من الفئات المستفيدة: الفئات المستفيدة داخل المؤسسات (العملاء الداخليون)، وهم العاملين داخلها، فكل منهم يتلقى خدمة أو نتائج أعمال من الآخرين، وفي

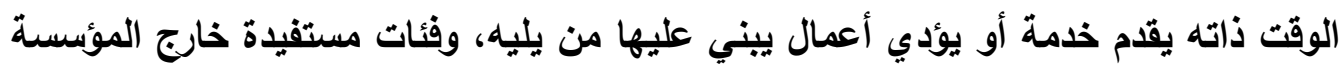
(العملاء الخارجيون)، وهم الجمهور التلقى او المستخدم لتلك المنتجات، وهناك صلة وثيقة بين النوعين، فالعملاء الداخليين هم وسيلتنا الى العملاء الخارجيين لذا يجب الاهتمام بهم الهم

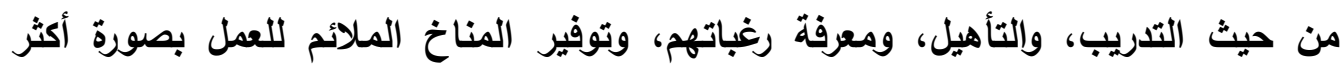

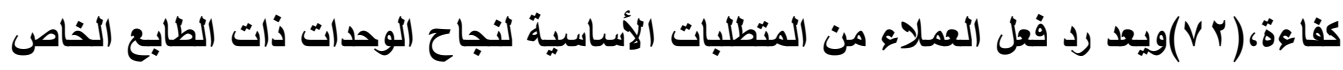

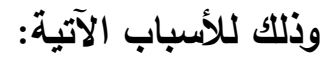




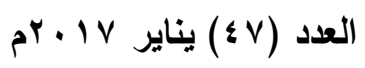

• معرفة ما إذا كاتت الفئات المستهدفة قد استفادت بالفعل من الفوائد المتوقعة

من الخدمة.

• هم احتياجات وتوقعات المستفيدين (العملاء).

• معرفة مدى إمكانية توسيع نطاق الخدمات لتشمل فئات أخرى.

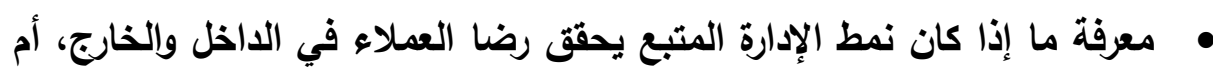

أن الأمر يحتاج إلى مراجعة.

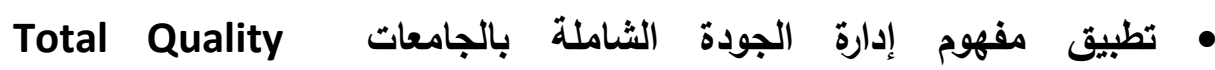

هذا المفهوم السعي نحو التحسين المستمر للخدمات من خلال تضافر جهود العاملين بالمؤسسات بما يضمن تحقيق توقعات الفئات

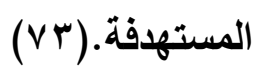

وفي ضوء الاهتمام الجاري الآن للتعرف على مدى رضا العملاء وضعت أدوات

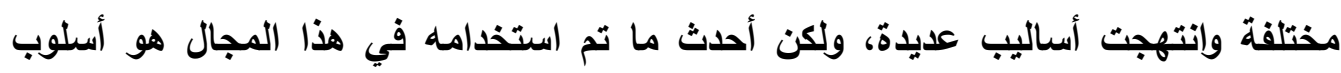
الفجوة بين إدراكات وتوقعات الأفراد لقياس جودة الخدمة (Servqual Of Quality Gaps) حيث طور Parasuraman \& Others 1988 اداة تعتمد على فكرة تحديد الفجوة بين واقع

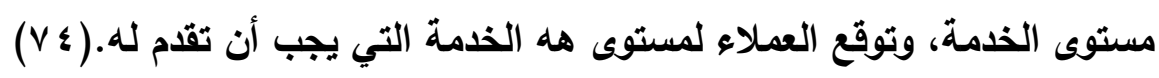

\section{الجزء الثاني:الاتجاهات العالمية المعاصرة لتسويق الخدمات التعليمية بـالجامعات}

أ- نموذج جامعة ويسكونسن الأمريكية بملينة ماديسوز Aniversity Of Wisconsin (At)

Madison)

تعد جامعة ويسكونسن جامعة بحثية عامة مقرها مدينة ماديسون بولاية ويسكونسن،

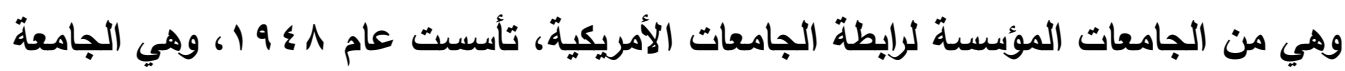

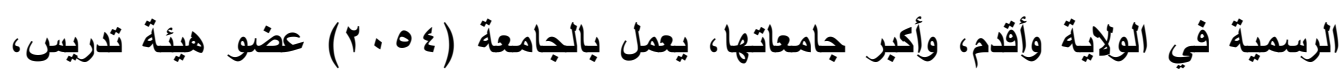

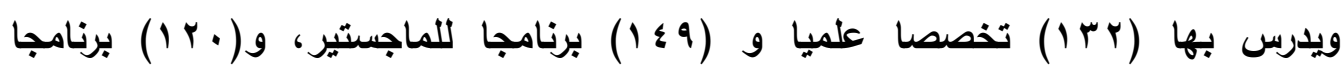
للاكتوراه(P (V)، تصنف جامعة ويسكونسن بوصفها جامعة ذات نشاط بحثي عالي الجودة وفقا لتصنيف كارنيجي لمؤسسات التعليم العالي، وقد بلغ إنفاق الجامعة على البحث العلمي عام بونه

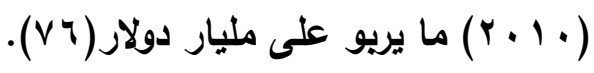




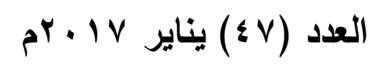

وتتمثل رسالة جامعة ويسكونسن في توفير بيئة تعلم تساعد الطلاب، وأعضاء هيئة

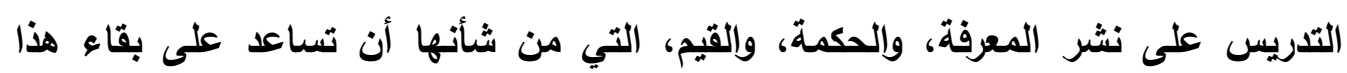

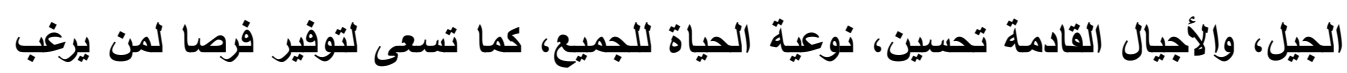
في الالتحاق بها، إذ تسعى لاستقطاب الطلاب من خلفيات اجتماعية، واقتصادية، وعرقية

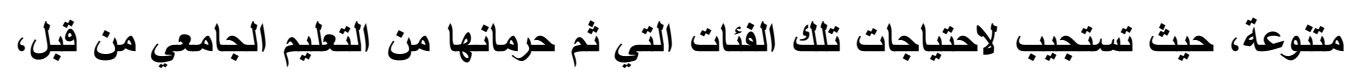
ولإنجاز هذه الرسالة تقوم الجامعة بما يلي( VV)

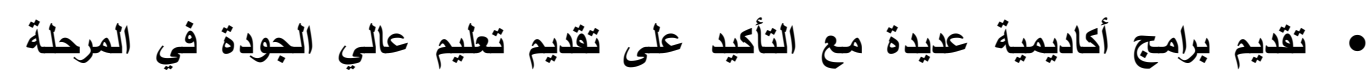
الجامعية الأولى والدراسات العليا، وكذلك برامج التنمية المهنية. إنتاج معارف جديدة من خلال التشجيع على إجراء البحوث المرتبطة بحل المشكلات وكات براه المجتمعية التي تستجيب لاحتياجات المجتمع على المدى الطويل.

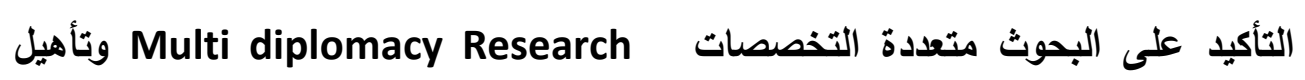
الارسين ليصبحوا متخصصين في مجالاتهم، وذلك من خلال تطوير قدراتهم على استخدام المعارف، لمنفعة المجتمع.

إتاحة إمكانيات الجامعة، وخبراتها للمجتمع المحلي، والمؤسسات العامة بالولاية مثل المثل

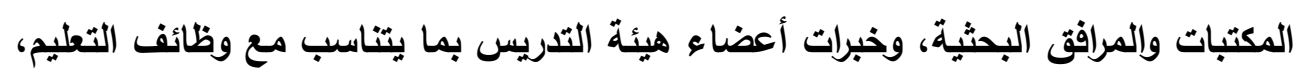
والبحث العلمي التي تقوم بها الجامعة. • المساهمة في التنمية الثقافية، والاجتماعية، والاقتصادية للولاية، والدولة، والعالم أجمع، وذلك من خلال تقديم برامج متميزة في مختلف المجالات استجابة لاحتياجات الولايات المتحدة، والعالم ككل بصفة عامة.

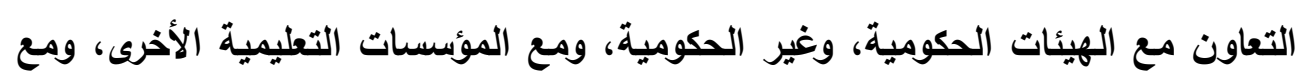
المؤسسات الصناعية، والاقتصادية.

وعليه يلاحظ أن جامعة وسكونسن تتبني في إطار رسالتها الوظائف الجامعية الثُلاث

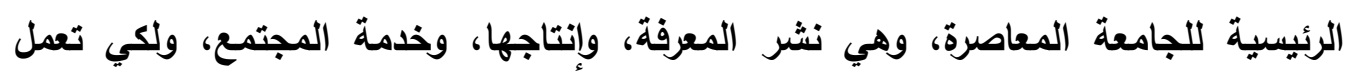

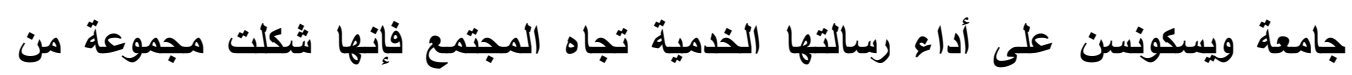
التنظيمات التي تمكنها من تقديم خدماتها، ومن بين هذه التنظيمات ما يلي: 


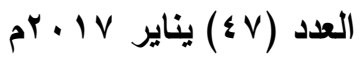

ا- مركز تنمية المشروعات الصغيرة: Small Business Development

\section{Center (SBDC)}

يقلم المركز خدماته لأصحابه المشروعات الصغيرة، والمستثمرين منذ عام (9 9

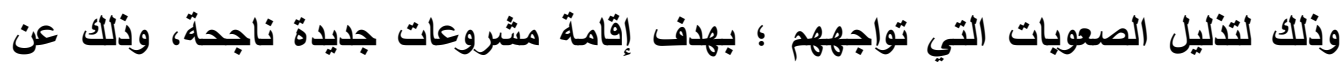
طريق تقديم استشارات ، ويرامج تدريبية مخفضة التكاليف في العديد من المجالات المرتبطة

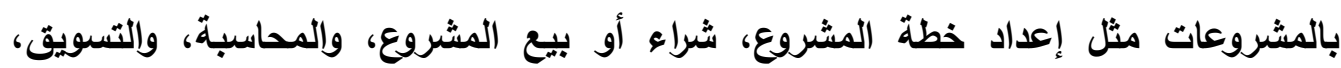

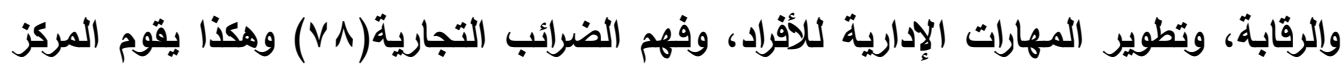
بتظوير المشروعات الصغيرة، ويربط بين رأس المال، والمعرفة النظرية.

rechnology Support Center (TSC) مركز دعم التكنولوجيا: Te

يقوم هذا المركز بتقديم مجموعة متنوعة من الدعم التكنولوجي للمؤسسات الاخرى

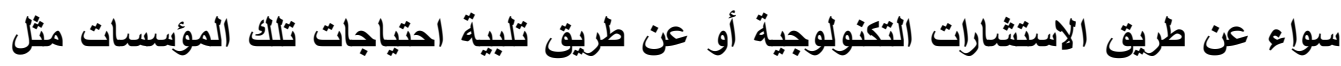

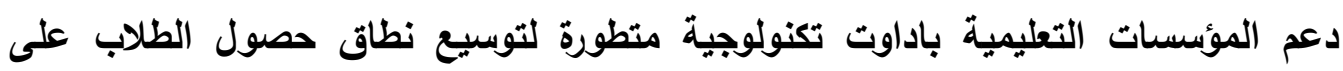

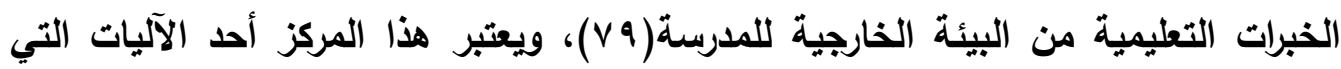
تستخدمها الجامعة لنقل نتائج والتكنولوجيا من الجامعات الى قطاعات المجتمع المختلفة. ب- رابطة خريجي ويسكونسن: Wisconsin Alumni Association (WAA)

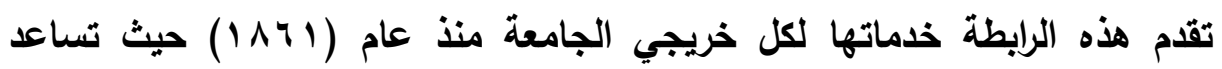
الطلاب إكتثاف الفرص الوظيفية التي تتماشي مع قدراتهم، واهدافهم من خلال إتاحة

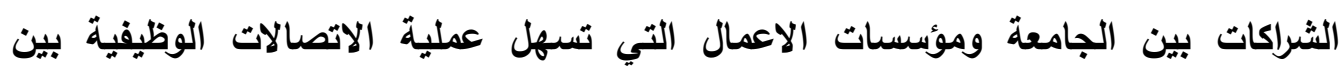

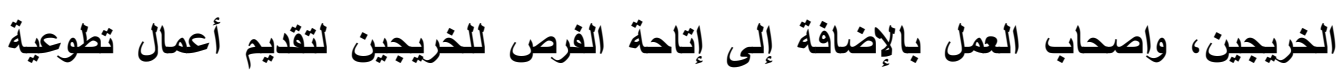

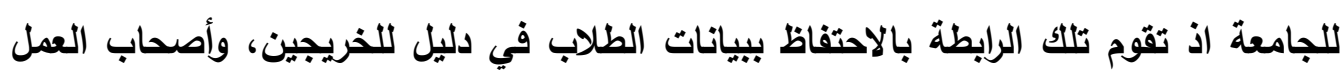

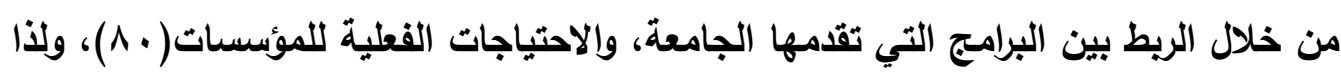
فإن الجامعة تحظى بمكانة متميزة بين المؤسسات الجامعية، وسمعة طيبة في سوق العمل،

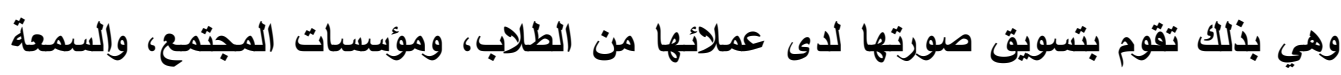

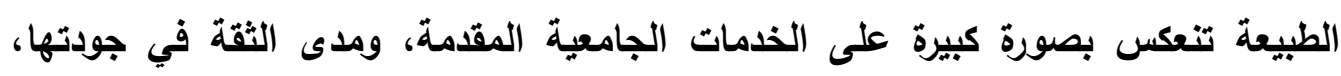
On Wisconsin بالإضافة إلى ذللك تقوم هذه الرابطة بإصدار مجلة عن الجامعة Magazine بهدف نشر الوعي العام عن الجامعة وهي من أكثر المجلات تداولا في الولايات 


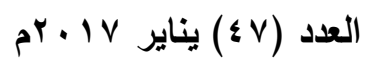

المتحدة الأمريكية وتحتوى على معلومات عن الحياة داخل الجامعة ويرامجها وما تقدم من خدمات، وتصدر هذه المجلة أربع مرات سنوياً(')'، وتعتبر هذه المجلة إحدى الوسائل التي تستخدمها الجامعة لتسويق صورتها.

\section{ع - مكتب تحسين الجودة: Office Of Quality Improvement}

تتمثل رسالة هذا المكتب في التحسين، والتميز المستمر للخدمات الجامعية؛ بهدف بناء الثقة بين المستفيدين والجامعة، وتحقيق رضا العملاء في الحصول على خدمات جيدة في ضوء توقعاتهم وهذا يساعد الجامعة على المنافسة، والنجاح في أداء مهامها، ويمكن لهذا المكتب تحقيق رسالته من خلال القيام بالمسئوليات الآتية(r ب): - - إنشاء نظام لجمع البيانات لتحديد الاحتياجات التعليمية أو الخدمات للقطاعات المختلفة بالمجتمع ثم تصنيفها، وتوزيعها على المراكز الخاصة بشئون خدمة المجتمع للمساهمة في الوفاء بها. - - تقليم خدمات استشارية في المجالات الآتية: التخطيط الاستراتيجي للمشروعات، وتصميم، وتتفيذ المشروعات، وإداراتها. - تحسين إجراءات العمل في الجامعة، وهذا يعني معاونة الجامعة على مواجهة

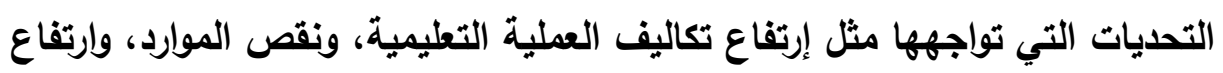
مستوى الخدمة المتوقعة، وغيرها. - مراجعة الهيكل التظيمي للوحدات التابعة للجامعة، ومهام كل وحدة، والأدوار، والمسؤوليات؛ لتحديد فرص التوسع في السوق، ويتم ذلك بمساعدة فريق عمل متخصص، وياستخدام عدد من الأدوات منها (SWOT) الذي يساعد في تقييم الوضع الحالي لتلتك الوحدات؛ لتحديد التوجه المستقبلي لها. ه - مكتب الاتصالات المركزية لجامعة ويسكونسن:

Central Communication Office for University of Wisconsin يقدم هذا المكتب خدمات الاتصالات، والتسويق لوحدات الجامعة المختلفة، ويضم مجموعة من المتخصصين في إدارة التسويق، فهم المسئولون عن تصميم الاستراتيجيات التسويقية بوحدات الجامعة المختلفة، واختيار المزيج التسويقي المناسب الأي يتضمن تحديد المنتجات، وتسعيرها، واختيار أساليب نرويجها (كتابة الإعلانات، وتصميمها، وتصميم مواقع 


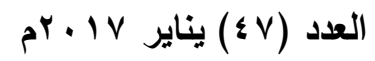

الانترنت، والعلاقات العامة، وتصميم المطبوعات، وغيرها من المهام والأنثطة)، وتحديد

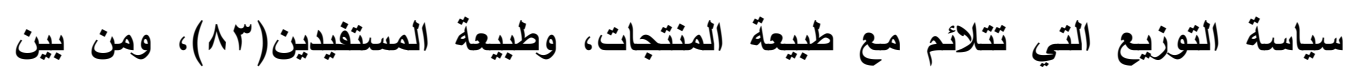
اختصاصات هذا المكتب أيضا تصميم العلامة التجارية Brand Names وهي شعار المؤسسة الذي يجب أن يستخدم في أى مشروع داخل الجامعة.

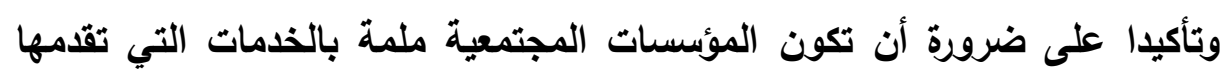
الجامعة فقد حددت الجامعة فريقا لإدارة العلاقات بين الجامعة، وعملائها من المؤسسات المجتمعية Corporate \& Foundation Relation (CFR)، ويقوم هذا الفريق بتحديد المؤسسات التي يمكن للجامعة أن تقدم لها خدماتها في مجال تزويد هذه المؤسسات بالقوى

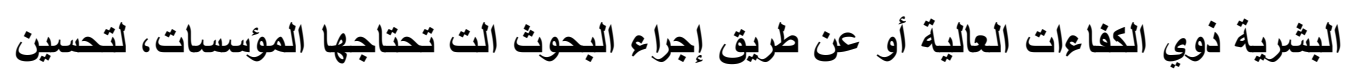

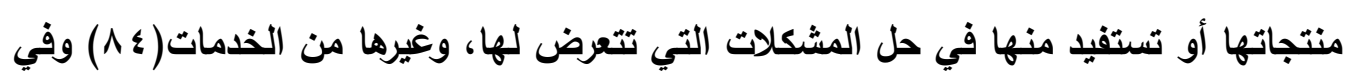
المقابل تقوم هذه المؤسسات بدعم المشاريع، والبرامج ذات الصلة بالجامعة ولتحديد شراكات ناجحة طويلة الامد بين الجامعة، والمجتمع المحلي فإن هذا الفريق يقوم بتقديم من الخدمات كما يلي(^): • يمثل (CFR) وسيط لتحديد احتياجات المؤسسات، وغايات الجامعات.

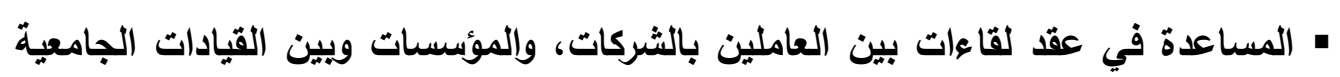
واعضاء التدريس، والموظقين للمساهمة في نقل خبرات الجامعة للمجتمع المحلي من بن جهة، والتعرف على احتياجات، ومشكلات تلك المؤسسات من جهة أخرى.

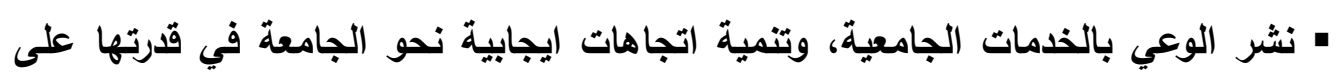
تحقيق التطوير في المجتمع. • تقديم معلومات مفصلة عن البحوث التي تقدمها الجامعة، وتحفيز الشركات، والمؤسسات على زيادة الدعم المقدم للجامعة (توفير مصادر تمويل لمشروعات محددة). ج - مكتب علاقات الجامعة Office of University Relations يقوم هذا المكتب بتدعيم علاقة الجامعة مع الخريجين، وأولياء الأمور، ومؤسسات المجتمع المحلي، ووسائل الإعلام، ويرأس هذا المكتب نائب رئيس الجامعة للعلاقة العامة Vice Chancellor For University Relation منهم مسئولية الوظايف الآتية( ( م): 


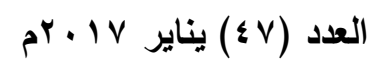

• الاتصالات الجامعية: حيث يختص بالإشراف على الحملات الإعلامية؛ بهرف التغطية الإعلامية للجامعة.

Executive Director Of التسويق: وتتمثل مهمة المدير التنفيذي للتسويقه Marketing تجارية نظير حصول الجامعة مقابل مادي مثل(^v):

خدمات الإعلانات المقدمة للمؤسسات، وللحفاظ على سمعة الجامعة وصورتئ مادي مئها، وضع نائب رئيس الجامعة للعلاقات العامة قواعد، وشروط لهذه الإعلانات، حيث تمتلكانك الجامعة في رفض الإعلانات التي ترى أنها غير مقبولة.

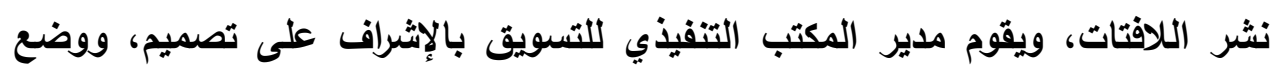
اللافتات في الحرم الجامعي. • تأجير مرافق الجامعة للمؤسسات الأخرى، وذلك نظراً لما يتمتع به الحرم الجامعي

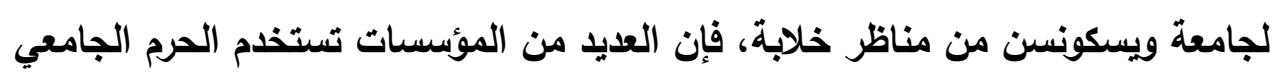
لأغراض تجارية مثل التصوير الفوتوغرافي، وصناعة الأفلام التعليمية والوثائقية، وترويج فئيج المنتجات والتسويق، والعلاقات العامة.

الأثراف على التعاقدات مع المؤسسات الحكومية، وغير الحكومية: يقوم بهذه المهمة مساعد نائب رئيس الجامعة Associate Vice Chancellor وذلك إنطلاقا من أهمية فتح سبل العمل بين الجامعة، والهيئات المجتمعية لتحقيق فائدة متبادلة.

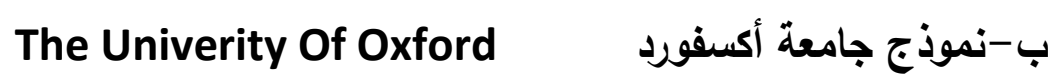

تعد جامعة أكسفورد من اقدم جامعات العالم وتصنف الجامعة الاولى في المملكة المتحدة

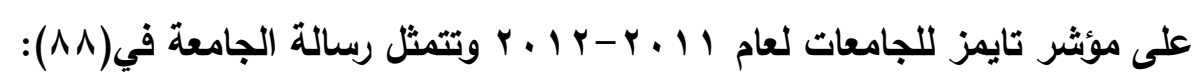

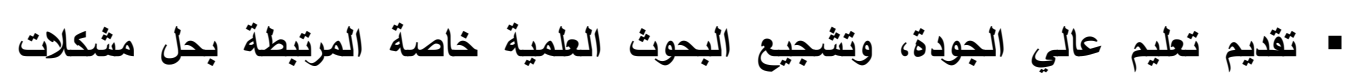
المجتمع.

ه التعاون مع مؤسسات المجتمع المحلي للمساهمة في تلبية احتياجات المجتمع.

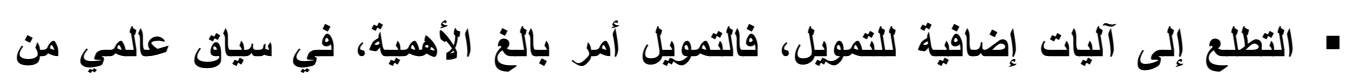

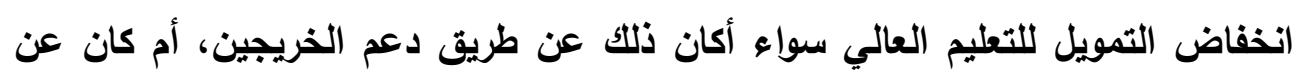
طريق الحصول على المنح، والهبات من المتبرعين، وغيرها. 
العدد (V)

- استقطاب أفضل الطلاب من مختلف دول العالم للاراسة في الجامعة بغض النظر عن

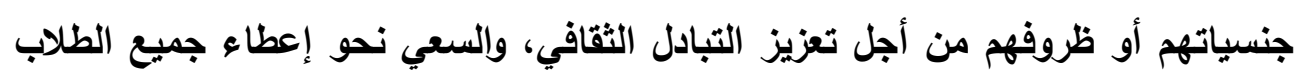

$$
\text { الفرصة للإفادة من التعليم الجامعي. }
$$

وعليه نجد ان جامعة أكسفورد، تولى اهتماما بتطوير المعرفة، من خلال جودة جمدة

التدريس، والبحث، وتولي إهتماما ملحوظا بترجمة تلك المعارف إلى واقع عملي من خلال

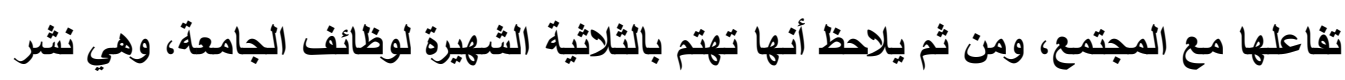

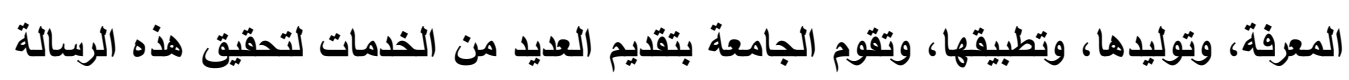
كما يلي:

ا-خدمات البحوث بجامعة اكسفورد Research Services

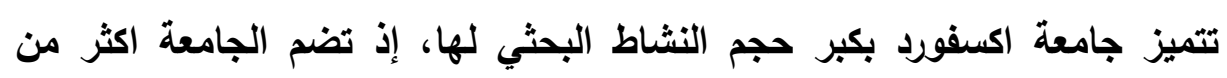

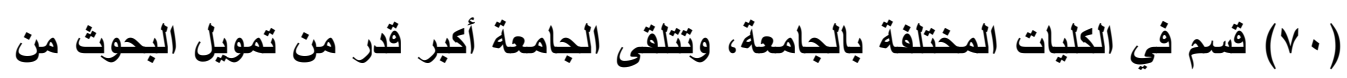
مجلس تمويل التعليم العالي في إنجلترا (HEFCE) بالإضافة إلى المنح، والعقود الممولة خارجيا سواء عن طريث مجالس البحوث والمفوضية الأوروبية الجية Councils and the European Commission المجتمعية(^)، ولكي يتم رفع مستوى البحث العلمي ففن الجامعة تسعى جاهدة لتوفير ظروف وييئات عمل جاذبة للباحثين بما في ذلك المختبرات، والمكتبات والاهتمام باعداد الباحثين الجدد في كل مراحل حياتهم المهنية، ومساعدة الباحثين في توفير التمويل التلازم لهذه البحوث من خلال مساعدة الباحثين في تحديد الجهات المستفيدة في تطبيق نتائج أبحاثهم ، وتسعير المشروعات البحثية( • (9)، وهذه الترتيبات التظيمية تلجأ إليها لجامعات لتسويق الأبحاث العلمية لتشجيع القطاع الخاص على تمويل البحث العلمي للخروج بنتائج الأبحاث لحيز التطبيق إيمانا بدور البحوث العلمية في إحداث التنمية.

\section{Yxford University Consulting (OUC) الخدمات الإستثارية}

إن الاستشارات هي الانشطة أو الخدمات الاعتيادية التي يقدمها عضو هيئة التدريس للمؤسسات وإلهيئات بناء على طلب منها، فقا يدعى أحد اعضاء هيئة التدريس لتقديم المشورة لحل مشكلة معينة وقد يساعد استاذ في الإدارة مؤسسة ما في تطوير نظام جديد في أحد القطاعات ، وقد يعمل أحد علماء الكمبيوتز مع شركة معينة لتطوير العمل بها 


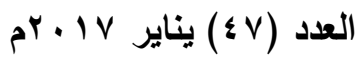

بالإضافة إلى أن يقوم باختبار فرضياته، وتطبيق نظرياته في الميدان، في مقابل حصول هؤلاء المستشارين على دخل إضافي لهم( 9 (9).

وتشغل الخدمات الاستشارية مكانة متميزة بجامعة أكسفورد حيث تمنح الجامعة الحرية لأعضاء هيئة التدريس للعمل كمستشارين بالشركات ، وتقوم بتصميم بيان مفصل

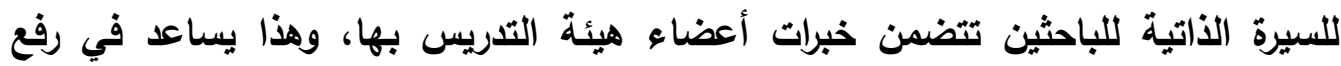
مستوى تفاعل الاساتذة مع القطاعات المختلفة وتحسين الإنتاج وتحقيق النمو والإزدهار الاقتصادي للمجتمع(ب و).

كما يشجع مركز الحدمات الاستثارية (OUC) أعضاء هيئة التدريس على الانضمام إلى المجالس الاستثارية للعلوم Science Advisory Boards، وتهذف هذه المجالات إلى هئ مساعدة المؤسسات في تقييم خططها التنموية عن طريق تزويدها بآخر التطورات في مجالات عملها، كما تقدم رؤى موضوعية للباحثين حول خططهم البحثية للتأكيد عليها أو تغييرها. Isis Enterprise مشروع آى زيس

هذا المشروع هو مؤسسة فرعية مملوك لجامعة اكسفورد يتم عن طريق نقل التكنولوجيا Technology Transfer إذ يساعد الباحثين، وإلمخترعين في نقل وتسويق التكنولوجيا التي تنتجها الجامعة إلى المجتمع الخارجي، ويتم ذلك عن طريق: • تقديم خدمات تتعلق بتسجيل براءات الاختراع، ووسائل حماية الملكية الفكرية. • منح التراخيص التكنولوجية License Technology From Oxford إذ تحدد الدهات المستفيدة من التكنولوجيا التي تتتجها الجامعة، بهدف مساعدة الباحثين في البحث عن منافذ تجارية للمعرفة للخروج بأفكارهم لحيز التطبيق، ومن ثم يتم عقد اتفاقات مع هؤلاء الشركاء من خلال مدهم بالتكنولوجيا التي تتطلبها مؤسساتهم نظير الحصول على مقابل مادي، وهذا يحقق النفع للجامعة، ويساعد المؤسسة على تحسين، وتطوير منتجاتها،

$$
\text { ويعود بالنفع على المجتمع(ب و ه). }
$$

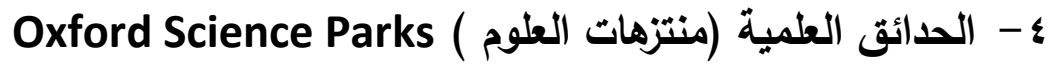
هي كيان يضم عدد من المباني، والمختبرات التي يمكن للشركات الصناعية، والتجارية استئجارها، وهدفها إنشاء، واحتضان بيئة عمل محفزة للصناعة، والخدمات القائمة على المعرفة إذ تقوم بتوفير بيئة عمل متميزة ترتكز على قدرات، وخبرات الجامعة، وقد تم 


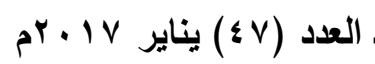

افتتاح أول مبنى على تلك الحديقة عام 991 199، تلي ذلك افتتاح مختبرات أبحاث شارب

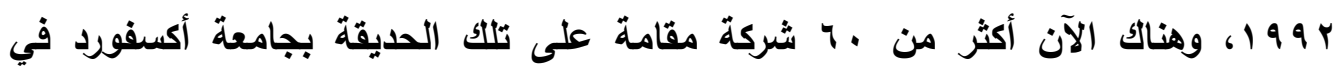

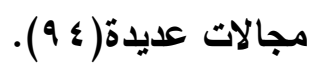

ه - خدمات توظيف الخريجين The Careers Services

تقوم جامعة أكسفورد بتقديم مدى أوسع من الخدمات لطلاب ، وخريجي الجامعة

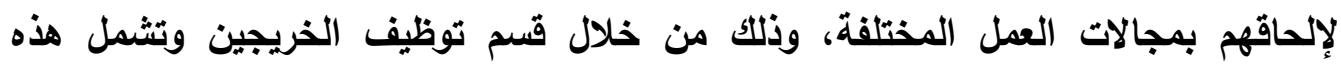

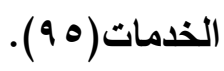

مساعدة الطلاب في إتخاذ القرارات الخاصة بمجالات العمل ، وحياتهم المهنية، وذلك عن طريق تقديم معلومات عن مجالات العمل المختلفة، والقدرات والمهارات التي تطلبها Recognize your abilities and ومساعدة الطلاب في تعريف قدراتهم ، ومهاراتهم skills العمل الأي يقدم المشورة لهؤلاء الطلاب. • إعطاء الطلاب الفرصة لتطوير مهارات جديدة إذ لزم الأمر، وذلك من خلال تقديم برامج التدريس Internship Programme وهذه البرامج تقدم مدى واسع من برامج الاعداد الوظيفي للطلاب المصممة لمساعدة طلاب الجامعة في الإعداد لسوق العمل. تقديم خدمة الوظائف الثاغرة - على شبكة التواصل الاجتماعي - للطلاب الحاليين، والخريجين Online Job Listings وتتضمن قائمة من فرص العمل الثاغرة المخصصة للخريجين، وتتضمن تجميع مجالات العمل سواء العمل التظوعي أو الوظائف المؤقتة بنظامي نصف الوقت Part-time والوقت الكامل Full-time في العديد من مؤسسات وقطاعات العمل المختلفة، ويمكن الاطلاع على هذه القوائم عبر شبكة الانترنت حيث يقوم الطلاب والخريجين بتسجيل بياناتهم على الموقع، وإرسالها، عبر الإكتروني. يقلم خدمة لأصحاب العمل Employer Service حيث يقدم لهم فرصة للإعلان عن

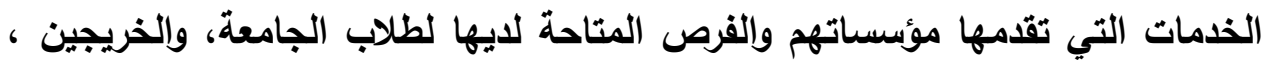
ويمكن تحديث تللك المعلومات بثكل مستمر ، وهذه الذدمات تعتبر وسيلة لترويج خدمات تلكك المؤسسات، كما يحتفظ القسم بملفات تضم أدبيات المؤسسات، وفرص العمل الثاغرة لايها، والتقارير السنوية لها والدورات التدريبية التي تقدمها تلك المؤسسات. 
العدد (\& ) يناير IV

V

ونظراً لما تمتلكه جامعة أكسفورد من مرافق تصلح لإقامة العديد من المناسبات فإن

University Events Office موسيقى وحدائق وغيرها لإقامة مختلف المناسبات مثل الندوات ، والمؤتمرات ، وحفلات الاستقبال، ومهرجانات جمع التبرعات، وغيرها نظير عائد مادى مناسب للجامعة حيث يقوم هذا المكتب بتسعير تلك المرافق حيث تختلف من مكان إلى آخر، ولا يقتصر دور خدمات تسويق مرافق الجامعة على الريح المادي الأي يعود على الجامعة، ولكن هذه الأحداث تترك إنطباع دائم في ذاكرة الأفراد( 9 (9). وتأكياً على حرص الجامعة على التمتع بصورة جيدة لاستقطاب أفضل الطلاب،

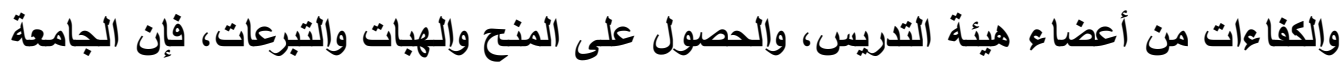
أنشأت مكتب الشئون العامة Public Affairs Office لكي يقوم بالمهام الآتية(9v):

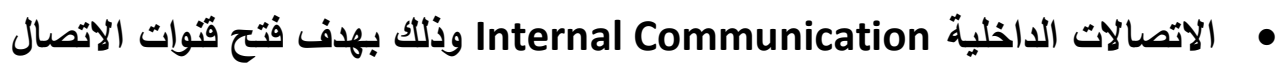
بين وحدات الجامعة، لتحقيق المنفعة المتبادلة، كما يقوم المكتب بتقديم المشورة لوحدات الجامعة، لمساعدتها في التخطيط لأنشطتها، وهذا يساعدها على القيام بأنشطتها المختلفة على نحو أكثر كفاعة. • تدعيم العلاقات المجتمعية Community Relations وذلك عن طريق توفير

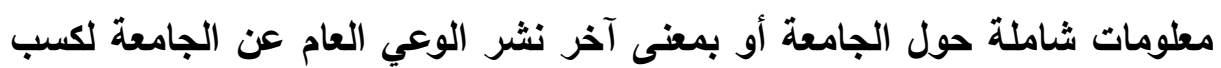
تأييا المجتمع. /deciding-right -for-you ولكي تتحقق هذه المهام فُإن هذا المكتب يتعاون ميع مكتب التصميم، والنشر Design \& Publications Office والخدمات الجامعية المقدمة من خلال وحداتها، ويقوم العاملين في هذا المكتب بتصميم المواد

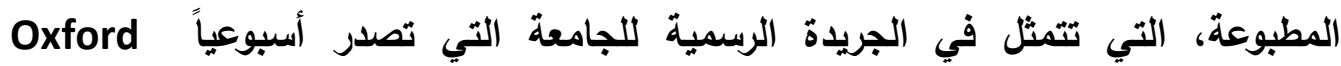
University Gazette خريجي الجامعة - بالإضافة إلى كتيبات عن أعضاء هيئة التدريس، وخبراتهم كما يوجه القائمون على العمل في هذا المكتب اهتمامهم بتصميم، وتطوير المواقع الإكترونية، 


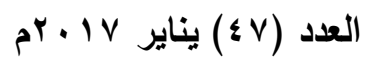

وتتضمن صور للجامعة ( ... (†) صورة، ولقطات فيديو وهي متاحة للبيع، ويسمح هذا المكتب للمؤسسات بالإعلان عن أنثطتها في المطبوعات التي تصدرها الجامعة نظير مقابل مادي من هذه المؤسسات( 91 ). بالإضافة إلى ذلك فإن جامعة أكسفورد تحرص على التغطية الإعلامية لخدماتها في News \& Information وسائل الإعلام، ويتم ذلك من خلال مكتب الأخبار، والمعلومات ويقوم فريق العمل في هذا المكتب بعقد اللقاءات الإعلامية، نشر نتائج البحوث عبر Office النشرات الإخبارية، كذلك يقوم المكتب بمتابعة الأخبار، والمعلومات في وسائل الإعلام، ويقوم

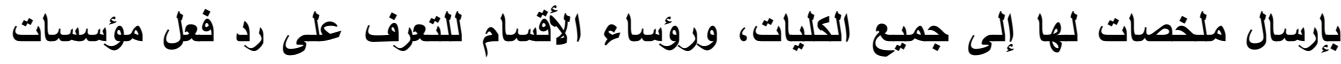
المجتمع المختلفة، بهذف الاستجابة لاحتياجات الفئات المستفيدة، والعمل على إرضائهم، ولا يقتصر دور هذا المكتب على التعامل مع العملاء من خلال وسائل الإعلام فقط ، بل يمكن للمستفيدين التعامل مع هذا المكتب بصورة مباشرة للرد على استفساراتهم يساهم في فتح قنوات إتصال بين الفئات المستهدفة والجامعة.

\section{ج- نموذج جامعة ملبورن الاسترالية University of Melbourne}

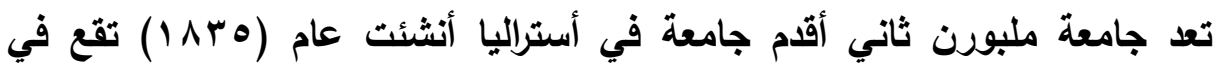
فيكترويا في مدينة ملبورن، وتعد أحد الجامعات الرائدة في التعليم العالي في أستراليا، والعالم، ومما يؤكد على ريادة وتميز الجامعة تصنيفها في المركز الأول بين الجامعات الاسترالية، والمركز الرابع والثلاثون على مستوى العالم، والمركز العاشر على مستوى العالم في توظيف الخريجين(9 9)، وتتحدد رسالة الجامعة في المساهمة المتميزة في تنمية المجتمع، وتحسين وضعها التنافسي بين الجامعات الأسترالية من جهة ، وبين جامعات العالم من جهة اخرى، وذلك من خلال الاعتماد على ثلاث دعائم رئيسية متكاملة هي التميز في التعليم والتعلم،

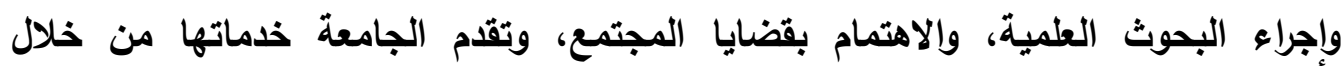

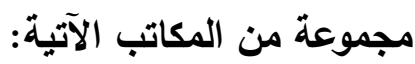
ا-مكتب ملبورن للشراكة Melbourne Engagement and Parent ships office (MEPO)

يعد هذا المكتب أحد الترتيبات التنظيمية التي تساعد في تسويق المعرفة الجامعية

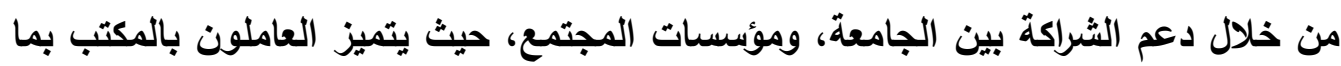




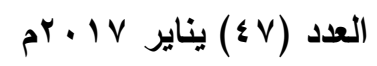

لايهم من خبرة واسعة مجال العقود، والاتفاقات، فضلا عن قدرتهم على إقامة علاقات ناجحة مع الفئات المستفيدة، ويقوم فريق العمل بدوره من خلال قيامه بوظيفة "السمسرة" حيث يقوم العاملون بالمكتب بالتعرف على احتياجت المؤسسات المجتمعية التي تتطلب خبرات أكاديمية معينة ثم يقوم هذا الفريق بتحديد أعضاء هيئة التدريس القادرين على تقديم خبراتهم لهذه بأهن المؤسسات، أى ان هذا المكتب يقوم بعملية وساطة بين الطرفين ليتم إبرام تعاقد بينهما يتضمن مهام كل طرف نحو الآخر، وعائد تلك الوساطة تساعد المكتب في توفير التمويل اللازم للمشروعات الجديدة من خلال مساعدة أصحاب المشروعات الجديدة في إجراء العقود بينهم، ويين أصحاب رؤوس الاموال، حيث يتم تحديد سبل التعاون المشتركة( . . 1 ).

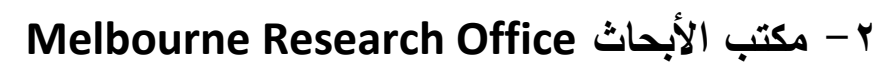
يتمثل دور هذا المكتب في دعم البحث العلمي بالجامعة من خلال الخدمات

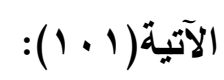

• خدمات متعلقة بتمويل الأبحاث من خلال معاونة الباحثين في البحث عن الجهات

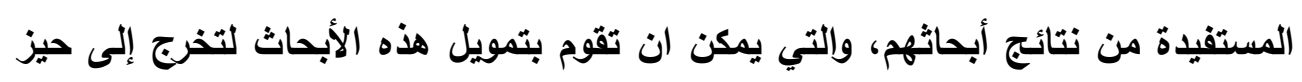

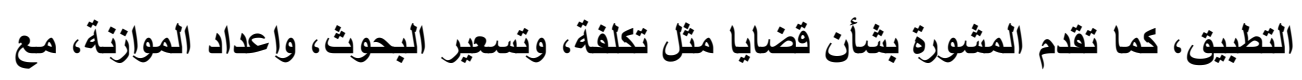
الاخذ في الاعتبار أن دور هذا المكتب لا يقتصر على عقد شراكة بين الجامعات الاسترالية

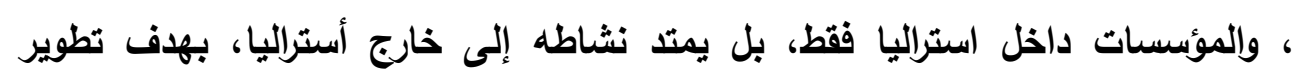

$$
\text { الأبحاث واكتساب خبرات أخرى. }
$$

• امكانية استخدام مرافق الجامعة من معامل، ومكتبات، ومختبرات بالإضافة إلى تقديم الخدمات الاستشارية للباحثين كما يقدم هذا المكتب خدمات تتعلق بمجالات منح الترخيص، وحقوق حماية الملكية الفكرية.

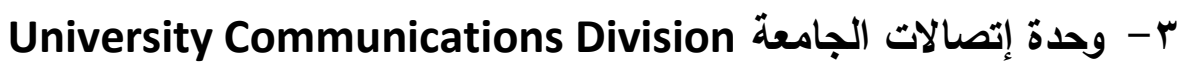

إن الجامعة في حاجة لتسويق صورتها من خلال تعريف المجتمع بمكوناتها، وانجازاتها ، ويطبيعة ما تقدمه من خدمات، ويتم ذلك من خلال وحدة إتصالات الجامعة التي

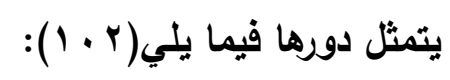

• إختيار القتوات التي يتم من خلالها عرض الأبحاث، أحداث الجامعة، أنشطة الجامعة، سواء كان ذلك من خلال التليفزيون، او المواقع الإكترونية، أو صحيفة الإنة 


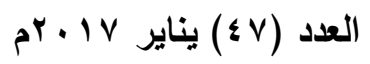

الجامعة "Voice" التي تصدر شهريا وهذه المسئولية يختص بها وحدة الاعلام، والعلاقات العامة بالجامعة إذ تعمل كحلة وصل بين وسائل الاعلام، والعاملون بالجامعة.

يقوم فريق عمل من أعضاء هذا المكتب باستطلاع آراء المستفيدين (أصحاب

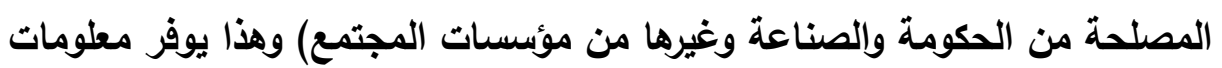

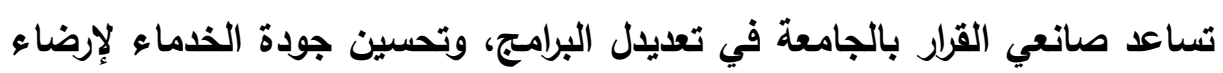
المستفيدين، وهذا يجعل وحدات الجامعة أكثر قدرة على القيام بانشطتها المختلفة، كما يوسع دائرة الثراكات بين الجامعة، والمؤسسات ، ويعاون وحدة وحدات الاتصالات مكتب التسويق Marketing Office الأي يساعد في تحقيق الأهداف الآتية (س + (1):

الاشراف على تصميم، وتطوير العلامة التجارية.

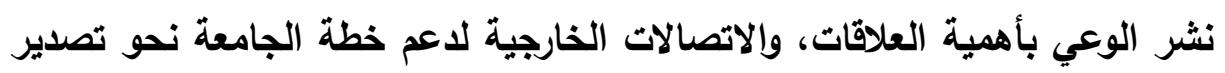
التعليم الجامعي، تنمية وعي الجمهور بالجامعة.

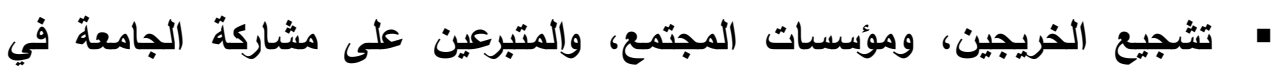
تحسين العملية التعليمية والبحثية. ولإنجاز هذه الرسالة بنجاح فإن المكتب يقدم مجموعة من الخدمات تتمثل في التعريف بالعلاقة التجارية، وتصميم الحملات الدعائية عن المنتجات ، والتتواصل مع التهات العملاء

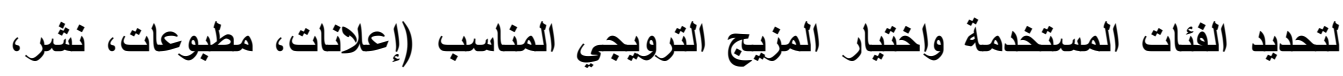
تصميم مواقع إلكترونية)، وتحديد الخدمات الجامعية التي يمكن تسويقها (بحوث، برامج تعليمية، مرافق، ..... وتخطيط وتثفيذ الاستراتيجيات التسويقية، واجراء بحوث التسويق.

ع - وحدة التوظيف، ومجالات العمل Career and Employment Divison يعمل بهذه الوحدة فريق متخصص يساعد الطلاب ، والخريجين في التنمية المهنية، ومساعدتهم في التوظيف بعد التخرج من خلال تقديم الخدمات الآتية( ـ ـ 1) : • خدمات للطلاب: تهدف الخدمات المقدمة للطلاب من هذه الوحدة إلى مساعدة الطلاب على تقييم انفسهم للتعرف على قدراتهم من خلال إتاحة الفرصة لهم بإجراء مقابلات، ومناقشات تساعدهم في اختيار الوظيفة المناسبة (خدمات التوجيه المهني 


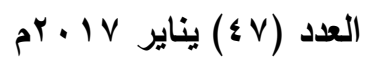

للطلاب) بالإضافة إلى مساعدة الطلاب في تنمية مهاراتهم من خلال عقد ندوات، ورش عمل، وتتظيم دورات تدريبية تساعدهم في الحصول على فرصة عمل (الإعداد (المهني للطلاب).

خدمات لأصحاب العمل: توفر وحدة التوظيف ، ومجالات العمل فرص التواصل بين الطلاب، والخريجين من جهة واصحاب العمل من جهة اخرى من خلال اتاحة الفرصة لرجال الاعمال، والقطاع العام وغيرهم بتوزيع مواد ترويجية تحول العلامة التجارية

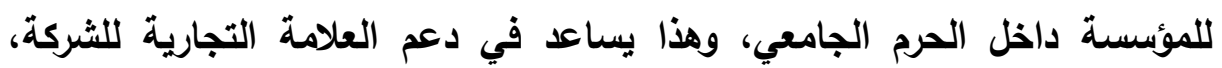
وترسيخها في أذهان المستفيدين من خدمات الجامعة، كما يقوم فريق العمل بتنظيم معارض التوظيف التي يتم من خلالها إعلام الطلاب والخريجين بفرص العمل الشاغرة داخل المؤسسات والمهارات المهنية، والثخصية التي تثطلبها تلك الوظائف، والمعلومات اللازمة عن المؤسسة، ومميزات العمل بها، بالاضافة إلى ذلك يسمح إلى لئ

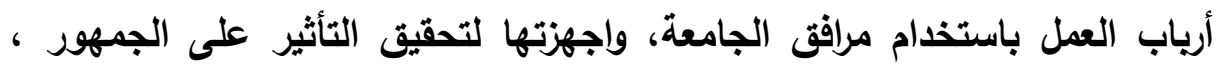

$$
\text { وجذب انتباههم. }
$$

• خدمات للخريجين (توظيف الخريجين): تهدف هذه الخدمات لنجاح خريج الجامعة في مجال العمل التي يختارونها من خلال الاتصال الائم بين فريق العمل، واصحاب العمل، حتى يمكن تزويد الخريجين بالاحتياجات المتغيرة في سوق العمل كما يزود فريق العمل الخريجين بمهارات كتابة طلبات التوظيف، وكتابة السيرة الذاتية للخريجين ، ويتيح لهم التعرف على الاسس التي يمكن اتباعها في المقابلات

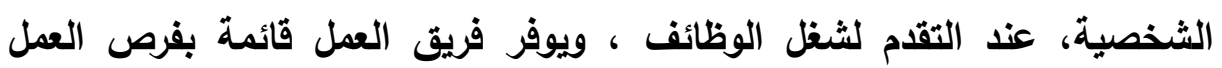

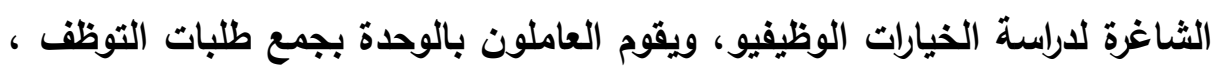
وتوزيعها على أصحاب العمل بالإضافة إلى دور هذه الوحدة في تنظيم البرامج

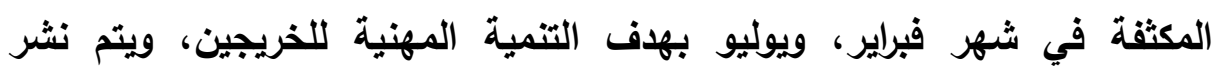
معلومات عن هذه البرامج بالتفصيل على الموقع الإكتروني.

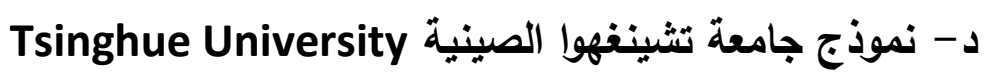
تعد جامعة تشنغهوا إحدى أقدم الجامعات الصينية أنشئت عام 1911 19، تقع بضاحية

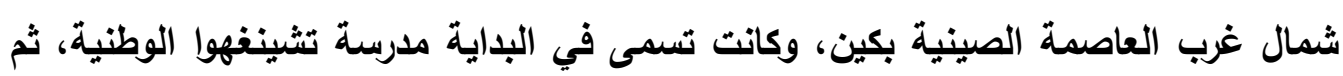




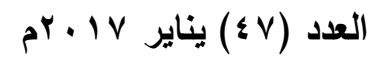

تحول عام 9 r^ إلى جامعة تثينغهوا الوطنية، واصبحت اليوم إحدى الجامعات الأكثر

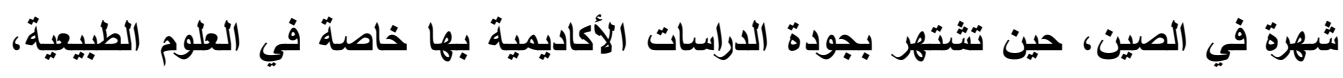

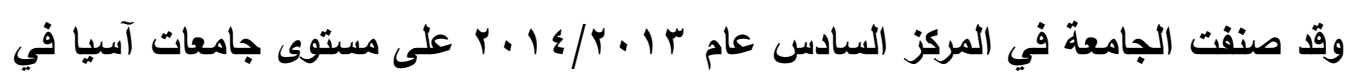
تصنيف التايمز للتعليم العالي، وهي الجامعة الصينية الأولى في تصنيف أفضل ( • (ه) جامعة

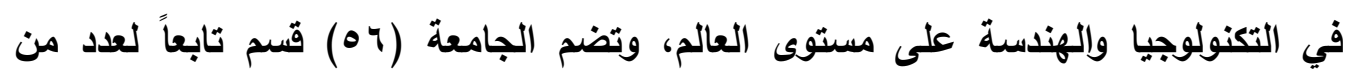

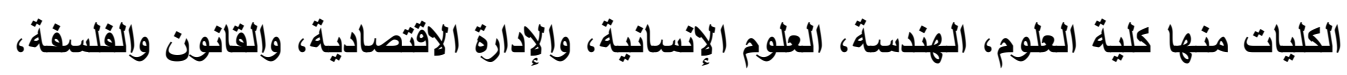
بالإضافة إلى عدد من مراكز البحوث، والمختبرات العلمية، ويدرس حاليا في الجامعة أكثر من الإن

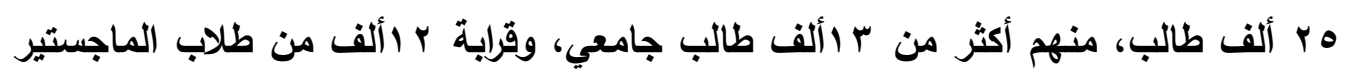
وإلاكتوراه، بالاضافة للعديد من الوافدين الأجانب، ويعمل بالجامعة عدد كبير من الأساتذة في وني

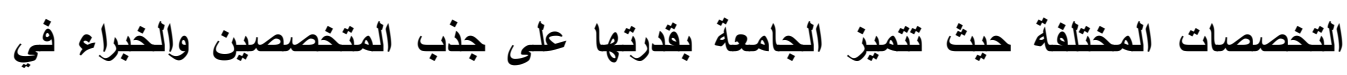
المجالات المختلفة للعمل بها مما ساعدها في الحصول على مكانة مرموقة ، وسمعة متميزة كمؤسسة بحثية شاملة (1 م 1 ). وتتمثل رسالة جامعة تشينغوا في تحقيق التكامل بين التعليم والبحث والصناعة وهذه الرسالة تعبر عن التزام الجامعة بمسئوليات تجاه المجتمع لذا نجد أن جامعة تثينغوا الصنينة إبتكرت طرقا لتحويل المشروعات البحثية إلى قوة إنتاجية ومن هذه الآليات التي يمكن من خلالها دعم العلاقة بين الجامعة والمجتمع إنشاء "قسم الخدمات" في بداية

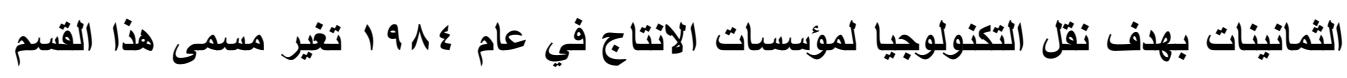
إلى "قسم تطوير العلوم، والتكنولوجيا" ليعس إسهامات الجامعة وتهيئة الوسيلة التي يمكن بواسطتها تقييم المشروعات التكنولوجية، والتقريب بين النظرية ، والتطبيق بالإضافة إلى ذلك التك تم إنشاء مكاتب خاصة تسمى مكاتب التعاون Cooperation office لتقوم بدور الوسيط بلتيط

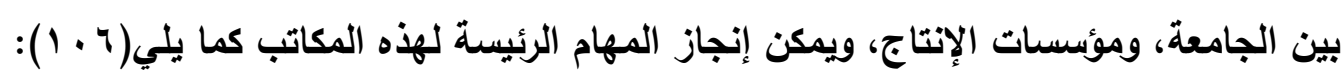

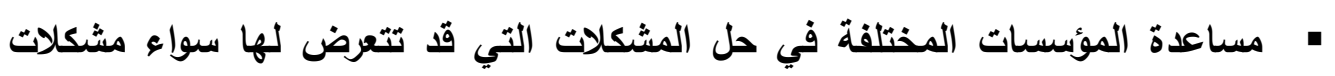
تكنولوجية إدراية بهدف تعزيز قدرتها على التنافس في سوق العمل.

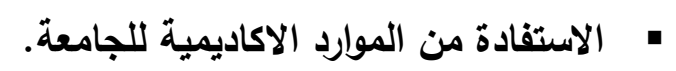

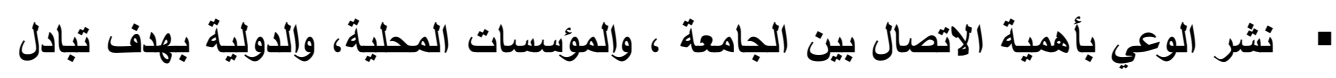
الخبرات في التخصصات والمجالات المختلفة. 


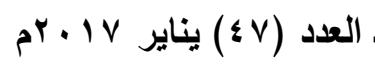

• إرسال خبراء للمؤسسات لإجراء مسح شامل للمؤسسة لتحديد احتياجاتها، وقدرتها على

$$
\text { التنمية المستقبلية. }
$$

• شثد الثراكات التجارية لزيادة الموارد المالية للجامعة من خلال الخدمات المقدمة، والهبات والتبرعات حيث يعمل هذا التمويل على سد العجز عن عدم كفاية التمويل الموجه للتعليم العالي وهذا يساعد في تطوير برامج الاراسة، وتوفير التمويل التلازم

$$
\text { للبحوث العلمية. }
$$

وريما للتدليل على حجم الخدمات المقدمة من خلال هذه المكاتب وزيادة الطلب الاجتماعي عليها فإن عوائد الجامعة من تلك الخدمات قد قدرت بحوالي . . م مليون يوان 300 Million Yuan للمجتمع، واستثمار خبراتها للمشاركة في خطط التنمية، وذلك عن طريق تكوين لجنة للتعاون مع المؤسسات الصناعية university Industry Cooperation (UICC) اللجنة نظام عضوية الجامعة في إدارة المؤسسات وهذا يعني قيام الجامعة بإدارة مؤسسات

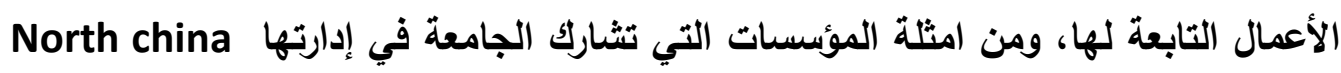
grid company ltd , china telecom , bao steel group المحلية، بالإضافة إلى بعض المؤسسات الأجنبية مثل "توشيبا"، وهيتاشي , Toshiba

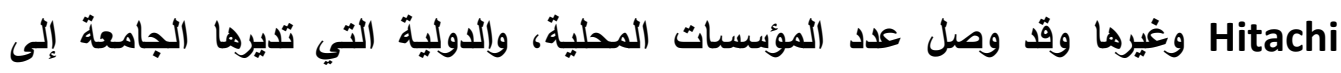
(9.9) مؤسسة حيث تقدم الجامعة خدمات مميزة لهذه الشركات مثل تحديد الاحتياجات المتفيرة للسوق، تقييم خصائص الخدمات والمنتجات المقدمة، بحوث حول إمكانية تحقيق تلمات التميز في المنتجات، وفي المقابل تستفيد الجامعة من عائد إدارة هذه المؤسسات في تحسين

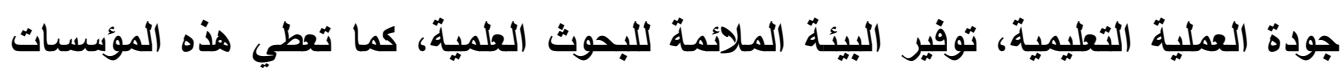

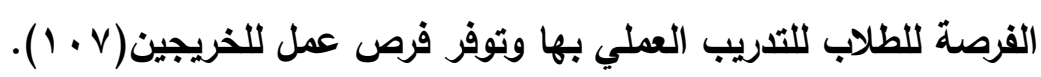

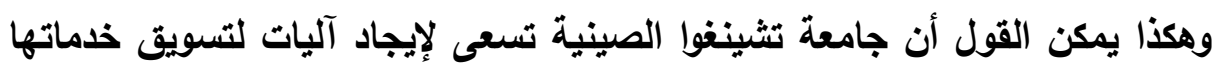

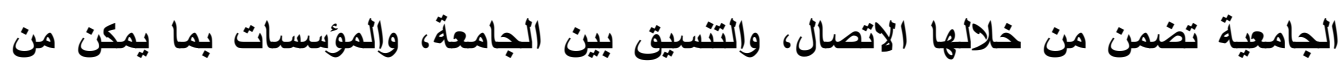

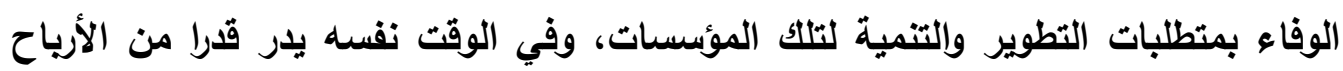
ل اللجامعة. 


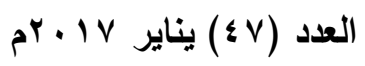

ومن استقراء العرض السابق يمكن القول: إن هناك مجموعة من العوامل المحلية،

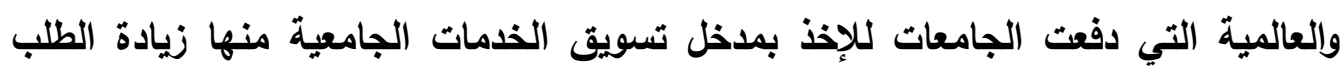

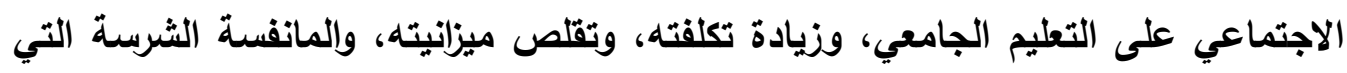

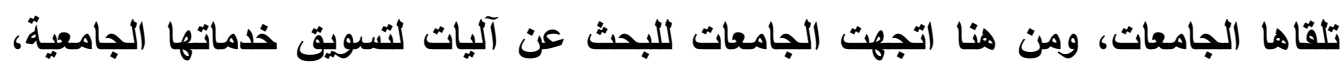

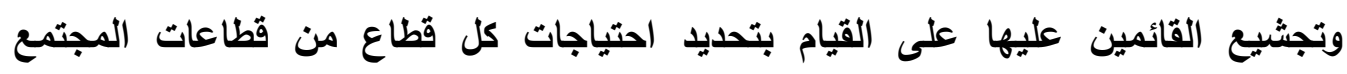

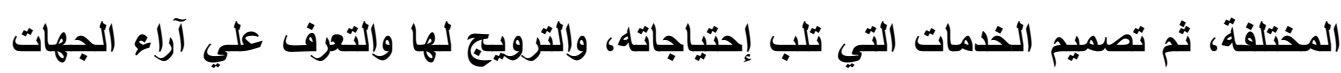
المستفيدة من اجل تطوير الخدمات.

وهكذا يمضي بنا عرض، وتحليل النماذج السابقة في التسويق الاجتماعي للذدمات

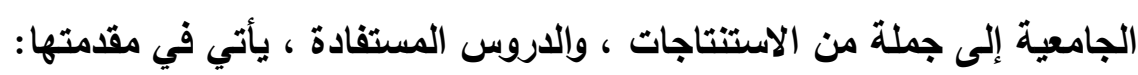

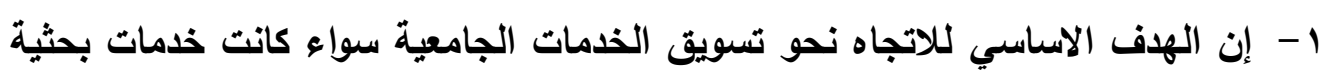

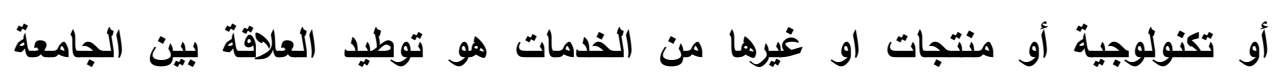

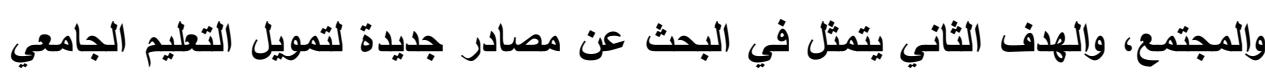

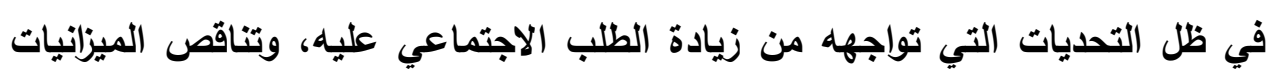

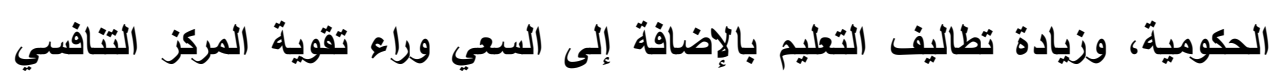
للجامعات خاصة بعد دخول التعليم مجال التصدير.

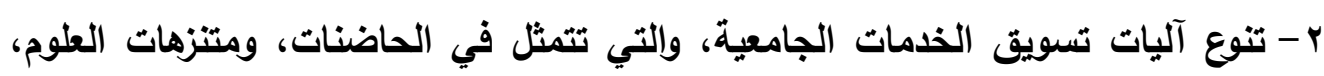

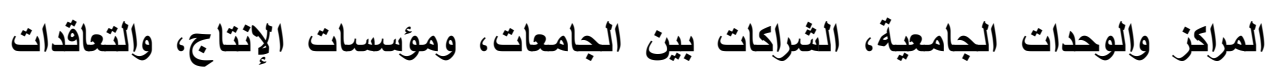

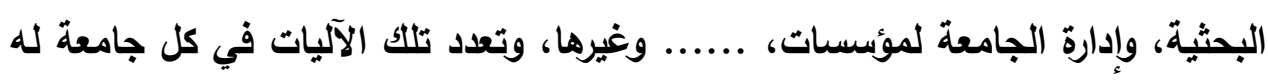

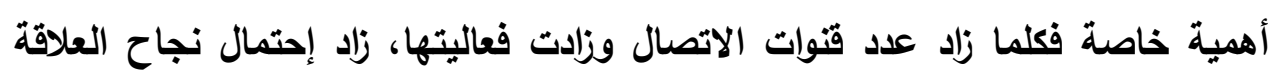

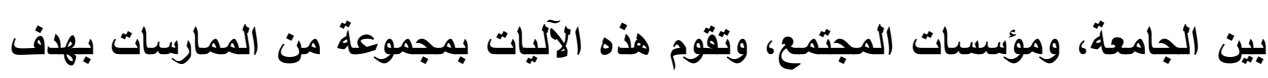

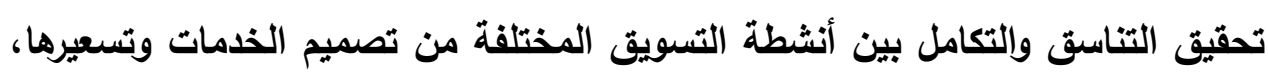
وترويجها وتوزيعها وصولاً للكفاءة القصوى في الأنثطة التسويقية.

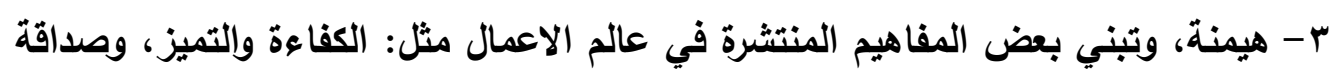
المستهلك إلى غير ذلك تمشياً مع تغيرات البيئة الجديدة، وإستجابة لتعاظم قوى الاعثى السوق.

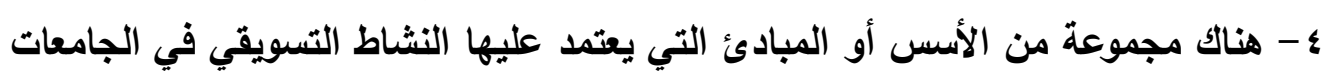

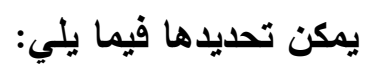




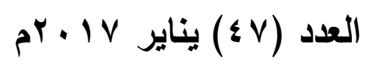

أولاً: الإهتمام بتحديد إحتياجات الفئات المستهدفة، والعمل على إشباعها، فالتحدي الحقيقي للجامعات ليس مجرد تقديم مجموعة من الخدمات للمستفيدين، ولكن القدرة على لإنى الإشباع المستمر لهذه الحاجات والرغبات المتغيرة، والتجديد والإبداع، ويتم ذلك عن طريق دراسة السوق لكي تتمكن الجامعة من تقديم الخدمات بما يتفق مع رغبات،

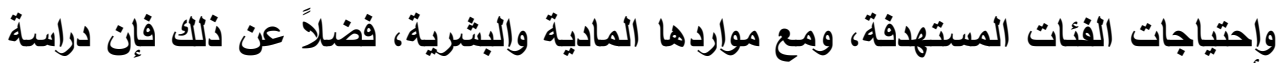
السوق تساعد الجامعة في اختيار المزيج التسويقي المناسب.

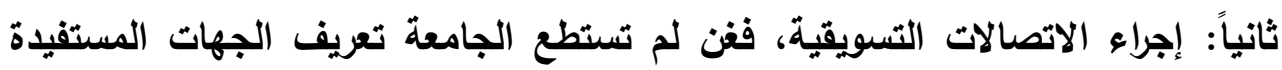
بخدماتها ومنتجاهاته فتنها لن تستطيع تحقيق الهذف من إنتاجها، وهذه الإتصالات ترمي إلى تحقيق الأهداف التالية: الإخبار: بمعنى تعريف الفئات المستهذفة بالمنتجات التي تقدمها الجامعة خاصة بالنسبة للمنتجات الجديدة التي لا تعرفها الجهات المستفيدة. • توعية الأفراد بالعلامة التجارية وتثبيت الصورة الذهنية عن الجامعة في أذهان المستفيدين. • أكير الفئات المستهدفة بالمنتجات الجامعية، وخصائصها، ومميزاتها خاصة في ظل وجود منافسين. إقناع الفئات المستهدفة بالمنتجات الجامعية من خلال تعظيم، وإبراز مزايا المنتجات. وقد قامت الجامعات - موضع الدراسة - بإنشاء وحدات ، أو مكاتب تتلخص مسئوليتها في - - تقديم إرشادات للباحثين لضمان إرتباط أفكار ومشروعات البحث بإحتياجات مؤسسات المجتمع. - الحصول على مصادر خارجية للتمويل من خلال تسويق قدرات وإمكانيات وتسهيلات الجامعة وقرتها البحثية والتكنولوجية. - - إدارة عملية التعاقدات، والترتيبات التعاقدية والقانونية للمشروعات التعاونية مع الجهات الخارجية المستفيدة. - - تصميم ويناء نظم المعلومات، وقواعد البيانات عن الجامعة، وأقسامها وتخصصاتها وإلباحثين وقدراتهم وخبراتهم . 


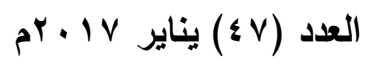

وتتقق النماذج السابقة على إسناد هذه التظيمات (أقسام - وحدات - مكاتب) إلى فريق متخصص من رجال الاتصال يتميز بقدرات، ومهارات خاصة مثل مهارات التفاوض، ومهارات تسجيل براءات الإختراع، وإلتراخيص، ومهارات بناء قواعد البيانات، واستقطاب المنح والمساعدات، ومهارات إدارة المشروعات التعاونية، والمهارات التسويقية. ثالثا: قياس مدى رضا المستفيدين: وهذا الامر غاية في الاهمية بالنسبة للجامعات سواء العملاء الخارجيين (الجهات المستفيدة خارج الجامعة) أو العملاء الداخليين (العاملين داخل الجامعة، ويتوقف على أدائهم نجاح النشاط التسويقي)، ومن ثم تسعى الجامعات الى تقديم خدمات جامعية عالية الجودة بحيث يكون هناك إتفاق بين المستوى الفعلي للخدمات المقدمة، والمستوى المتوقع لهذه الخدمات من قبل العملاء، وتستخدم الجامعات مقاييس محددة تعتمد على رد فعل العملاء تجاه جودة الخدمات لتحسين الخدمات،

$$
\text { وتطويرها. }
$$

هكذا يشير العرض السابق لبعض التجارب والخبرات العالمية في التسويق الاجتماعي للخدمات الجامعية أن هناك إهتماماً على المستوى العالمي بممارسة النشاط التسويقي في المؤسسات الجامعية لتحسين أدائها، مما يدفع إلى الأخذ بهذا النظام في تحسين أداء المؤسسات الجامعية بمصر ، ولا سيما بعد ثبوت نجاحها في الارتقاء بمجتمعاتها، الامر الأي يتطلب إجراء دراسة ميدانية يمكن من خلالها التعرف على واقع تسويق الخدمات الجامعية بجامعة الإسكندرية، وصولاً إلى روئية مقترحة لتفعيل دور الوحدات ذات الطابع الخاص بوصفها آليات لتسويق الخدمات الجامعية بما

$$
\text { يتفق مع واقعنا التنموي. }
$$

\section{الجزي الالثالث :- - تسويق الخدمات التعليمية بـالجامعات}

\section{المصرية (دراسة نظرية مانة}

فى هذا الجزء من البحث و فى حدود منهجية البحث سيتم تحليل الوضع الراهن فى الجامعات المصرية من خلال البحوث و الاراسات و التقارير التى صدرت بهذا الثان و ذلتك لبيان نقاط القوة فى الجامعات و التى من الممكن ان تسمح لها بالتوجه بالسوق و نقاط 


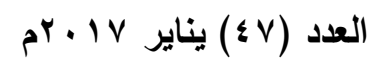

الضعف بالجامعات التى من الممكن ان تمثل تعديات تواجه المدارس فى سبيل توجهها • بالسوق

و على ذلك سيتم تناول ما بليى : بالكوق مراحل النشاط التسويقى بـالجامعات :

لقد مر النشاط التسويقي بأربعة مراحل أساسية وذلك منذ أواخر القرن التاسع عشر

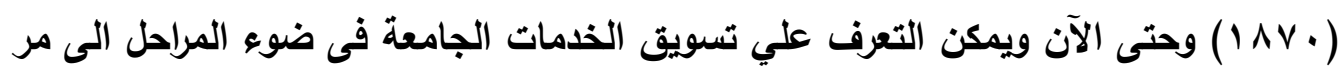

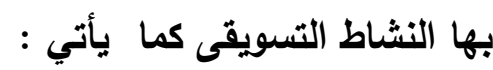
production orientation أ) مرحلة التوجه نحو الانتاج"

بدأت هذه المرحلة عام NVY واستمرت حتى الثلاثينات من القرن العشرين ومن أهم خصائص هذه المرحلة التركيز علي أنتاج أكبر قدر ممكن من المنتجات ورفع الكفاعة الإنتاجية لتلبية الطلب المتزايد علي هذه المنتجات ونتيجة الطلب المستمر علي المنتجات فلم

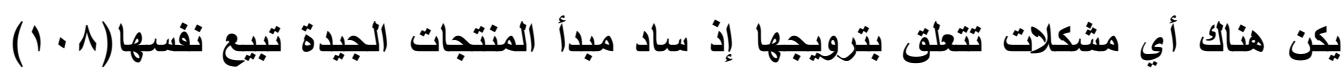
وترتب علي ذلك عدم الاهتمام بحاجات المستهلكين مقابل الاهتمام بجودة المنتجات .

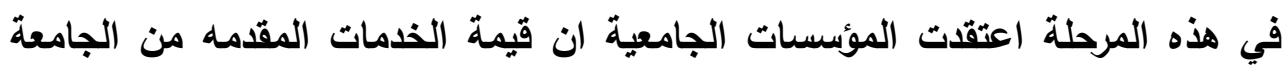
معروفة وان قطاعات المجتمع المختلفة سوف تقدم علي التعامل معها دون الحاجة الي جهود ترويجية وعلي هذا كان التركيز في هذه المرحلة علي تفويض الجامعات بانشائها (زيادة اعدادها ) واعادة اللائحة التنفيذية الخاصة بها واقتصر دورها علي لترهي انتاج الخدمات الجامعيه دون ان يتم الافادة منها في تنمية قطاعات المجتمع المختلفة ويبدو ان في تلكك الفترة قد تم

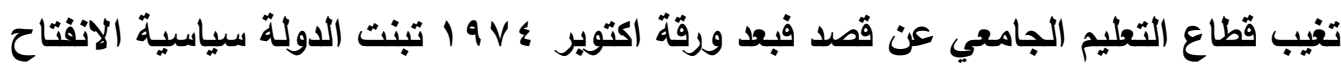
كما سبق ايضاحه والتي تريب عليها اضمحلال راس المال الوطني في الاقتصاد المصري لعدم قدرته علي منافسة راس المال الاجنبي وخاصة في المجال الصناعي مما ادي الي قلة الموارد المالية للاولة وكان من المفترض اشترالك الجامعة وقطاعات المجتمع وذلك لدارية واستة النتائج المترتبة علي سياسية الانفتاح الاثتصادي وكيفية توجيهها بما يكفل المصلحة العامة

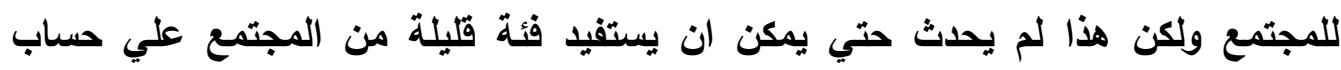
الاغلبية ويالفعل تضخمت ثروات هذه الفئة الراسمالية التي افرزتها سياسية الانفتاح مما لفات

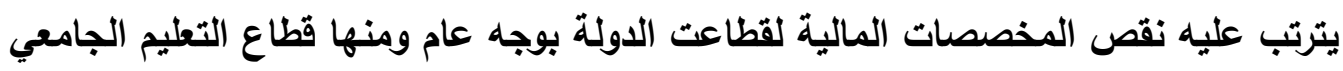




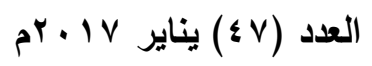

هذا ما دفع مؤسسات التعليم المفتوح الي البحث عن طريق لتعريف المجتمع بالخدمات الجامعية المقدمه منها الافادة للطرفين.

ب) - مرحلة التوجه نحو البيع sales orientation: بدأت هذه المرحلة منذ نهاية الثلاثينات من القرن العشرين وحتى نهاية الخمسينات من نفس القرن ومن أهم ما يميز هذه المرحلة حدوث طفرة إنتاجية بسبب تقدم الأساليب التكنولوجية وأساليب الإنتاج الأمر الأي أدي إلي ظهي ظهور مشكلة توزيع هذا الكم من

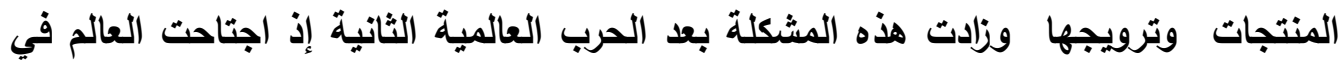
هذه الفترة أزمة اقتصادية وكساد عالمي(9 + 1) هذا ما دفع المؤسسات إلي التركيز علي نشاط البيع والترويج بشكل اكبر حتي يمكنها التخلص من فائض الانتاج فظهر نشاط الاعلان كما شهدت ايضا هذه المرحلة الاهتمام بتدريب رجال البيع وتحليل المبيعات وذلك لترغيب

$$
\text { المستهرلك في شراء المنتجات( • (1 ) ). }
$$

واجهت الجامعات المصرية في تلك الفترة تحديات تمثلت في تضاؤل التمويل الحكومي للجامعات بالاضافة الي عدم قرة الجامعات علي الوفاء باحتياجات المجتمع نتيجة لضعف الاتصال بين الجامعات ومؤسسات المجتمع أو عدم مرونة الإجراءات الادارية بها بلاضافة الي ضعف الموارد المتاحة لها مما نتج عنه تراجع جودة الخدمة او تاخرها ومنافسة المؤسسات الخاصة الاكثر قرة علي القيام بالعديد من هذه الخدمات الامر الذي دعا لوجود قطاع تنظيمي يكون من مجالس ووظائف مرتبطة بهذا القطاع للاشراف علي تسويق الخدمات الجامعية مع مراعاة ان يضم كل مجلس في تثكليه بعض الاعضاء من الخارج ذوي الخبرة في مجالات الانتاج والخدمات ويمكن القول : ان هولاء الاعضاء يعدوا مندوبين يقدموا بلاتصال بين الجامعة ومؤسسات المجتمع لتعريفها بالخدمات الجامعية بوصفها وسيلة لترويج تلك الخدمات .

ج- مرحل التوجه نحو التسويق marketing orientation : تبأ هذه المرحلة منذ نهاية الخمسينات وحتي بداية الستتيات ومن اهم ما يميز هذه المرحلة هو التركيز علي تحديد الاحتياجات ورغبات العملاء واصبح المبدأ السائد في هذه المرحلة هو انتاج ما يتم بيعه بدلا من بيع ما يتم انتاجه وهذا يتطلب دراسة احتياجات

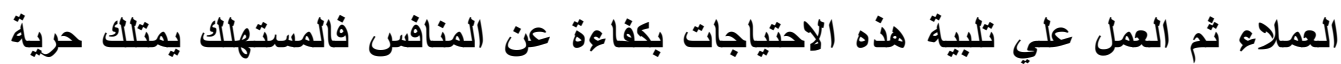




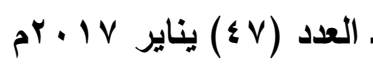

الاختيار بين بدائل كثيرة علي اساس امكاناته المادية وما يمتلكه من معلومات عن هذه

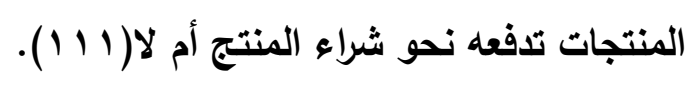

\section{دمرحلة التوجه نحو التسويق الاجتماعي Social marketing:}

بأت هذه المرحلة منذ الستينات لاعتناقه وتطبيقه كفلسفة لنشاطهم الا ان الكتابات الحديثة تنادي بتعديل المفهوم التسويقي ليتّلاءم مع احتياجات المجتمع والمسئولية الاجتماعية للمؤسسة فقد تثبع المؤسسة احتياجات ورغبات العملاء (طبقا للمفهوم التسويقي

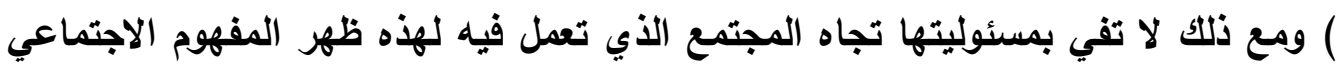
للتسويق الذي يعتبر التسويق عملية اجتماعية تمكن الافراد من تلبية احتياجاته مع الاخذ في الاتئي

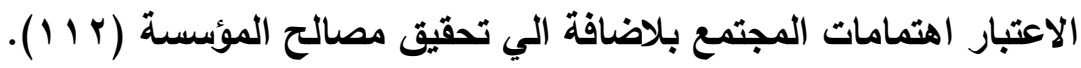
أي ان التسويق الاجتماعي يسعي لتحقيق التكامل بين الجوانب الاتية :

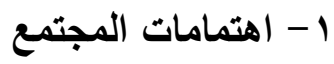

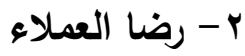

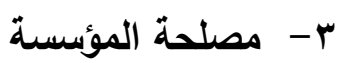

مما سبق يمكن تحديد الملامح الرئيسة لمفهوم التسويق كما ياتي : *- التوجه الاجتماعي( التسويق الاجتماعي للمنتجات ) هو التوجه السيائد في المنظمات.

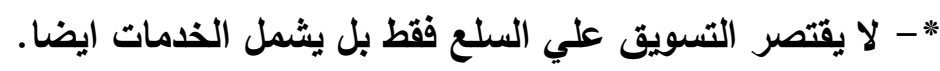

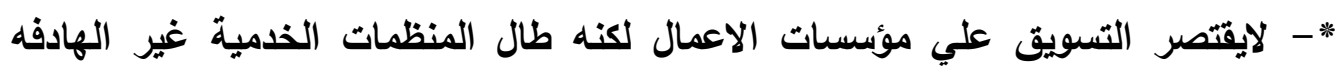

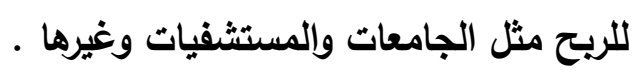
" يعتمد التسويق الاجتماعي علي نفس عناصر التسويق وهي التعسير والترويج والتوزيع . والمكان.

لقد صاحب محاولات تطوير الذدمات التعليمية بالجامعات المصرية تحولها من التوجه

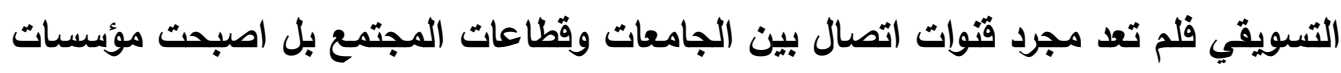

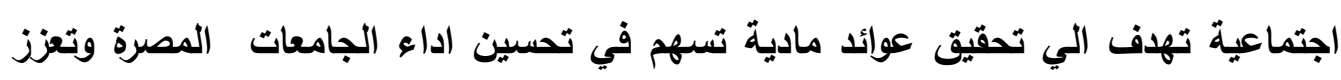

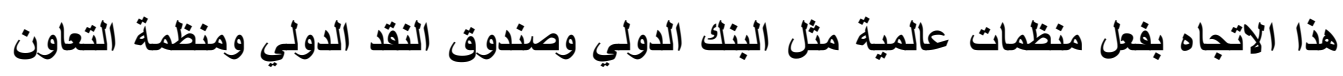

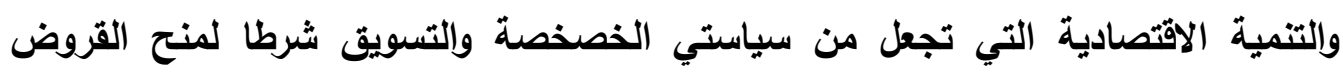




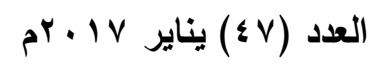

والمساعدات ومن ثم اصبحت تلك التطورات ظاهرة عالمية كما تبنت المؤسسات التعليمية

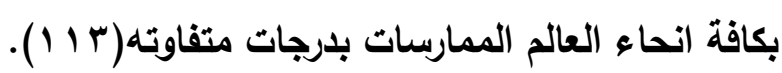

وهناك عديد من الفرص التسويقية (المميزات التي تتمتع بها المؤسسة) منها : توافر الخبرة والموارد البشرية النادر والصورة الذهينة لبعض الجامعات والكليات والاساتذة ومعرفة التكنولوجيا الحديثة(ع 1) الميما ان الجامعه مؤسسة اجتماعية فانها تهدف من تسويق

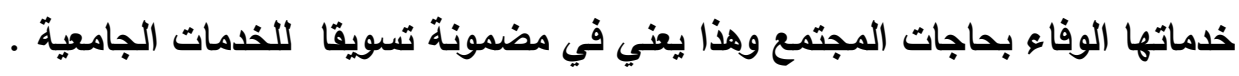
وتجدر الاثارة ان مفهوم تسويق الخدمات الجامعية لم تظهر الا في الاونة الاخيرة في

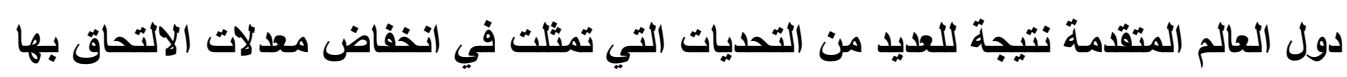
وإنخفاض المنح والهبات التي تعتمد عليها في التمويل في الوقت الذي تزايدت فيه تكاليف التعليم مما ادي الي تعرضها لضغوط مالية الامر الذي يترتب عليه عجز في تثفيل هذه

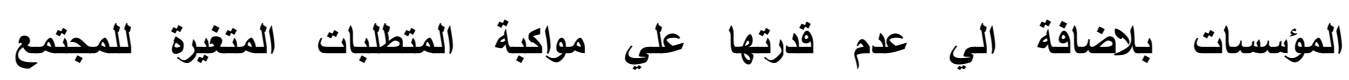
والطلاب(10) - (10).

ويالفعل اخذت بهذا الاتجاه عديد من دول العالم المتقدم مثل جامعه يورك في انجلترا وجامعه اتونت في هولندا ويالفعل ساعد ذلك علي التقليل من اعتماد تلك الجامعات علي التمويل الحكومي ورفع مستوي الاداء الجامعي فيما يرتبط بخدمة المجتمع . أهمية تسويق الخدمات التعليمية بـالجامعات المصرية : أ- يسهم التسويق في مواجهة بعض التحديات التي تواجه الجامعات المصرية ومن هذه

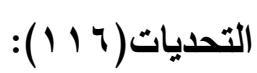

* تحدي التمويل حيث يساعد تسويق الخدمات علي جذب موارد ذاتية للجامعات في ظل

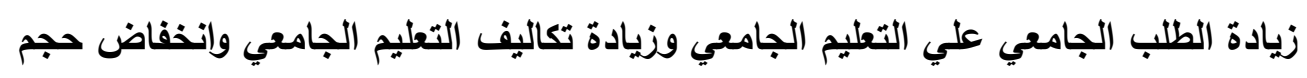
الدعم الحكومي للجامعات وتزويد الجامعات بتلك الموارد الإضافية يساعدها في في الجيادي القيام بوظائفها المختلفة في التعليم والبحث العلمي وخدمة المجتمع .

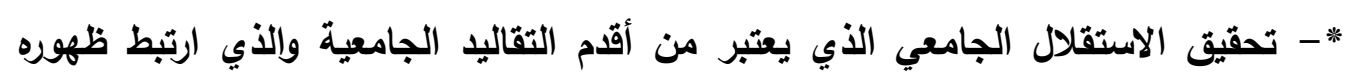
بنشأة الجامعات في اداء رسالتها كمؤسسة ينبع منها الفكر الحر وتقوم بالبحوث العمئية العملية

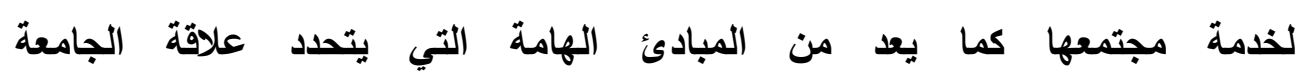
بالدولة(I V V)ويعني استقلالية الجامعه حق الجامعه في اتخاذ القرارت الخاصة بشئونها 


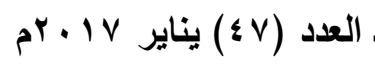

الاكاديمية والادارية والمالية دون رقابة خارجية من قبل القوي الاخري خارج الجامعه

$$
\text { خاصة القوي السياسية . الاديه }
$$

ويعد الاستقلال المالي اول خطوة نحو تحقيق الاستقلال الكامل للجامعات اذ يعد هذا الجانب من اقوي الضمانات لاستقلال الجامعه ويقدر ما تتمتع به الجامعه من استقلال مالي تتحدد مدي كفاعتها في اداء وظائفها ودورها في تقدم المجتمع والعمل علي نموه وازدهاره(1 ا 1 (1).

وتعاني الجامعات المصرية من القيود التي تكبل استقلالها المالي والإداري وترجع احدي الدراسات هذا الضعف الي اعتماد الجامعات المصرية علي التمويل الحكومي بشكل شبه كامل(19 1 1) ومن هنا يصبح فتح فنوات تمويل غير حكومية امرا ضروريا وعلي هذا تم التفكير في تسويق الخدمات الجامعية اذ يمكن ان تدر عائدا علي الجامعه الامر الذي يترتب عليه تحقيق استقلال الجامعات . ب- يساعد تسويق الخدمات الجامعية بوصفه احد مصادر التمويل الأتي للجامعات في التظلب علي بعض المشكلات التي جعلت الجامعات تتنازل يوما بعد يوم عن مستواها

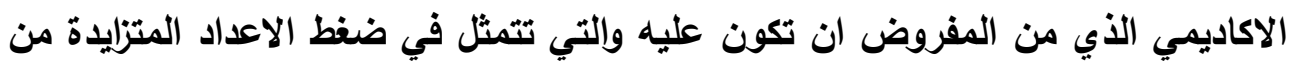
الطلاب والنقص فى الامكانات المادية والبشرية وافتقار المعامل الي التجهيزات الحديثة مما يؤدي الي تناقص فرص الطلاب في التدريب والتأهيل.

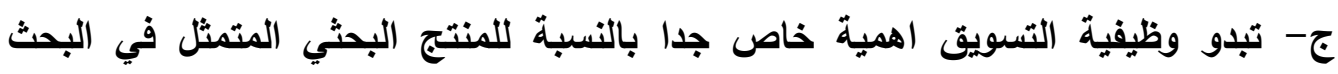
العلمي لانها خدمات غير ملموسة من الصعب عرضها فهي افكار تحتاج الي مسوق جيد يقوم بتسويقها لاستكمال الحلقة الطبيعية للبحث العلمي الأى تقل قيمته دون وجود

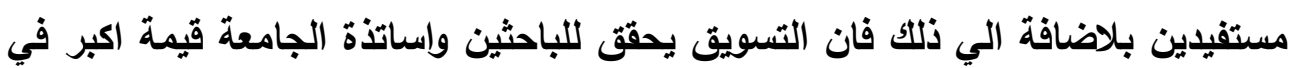

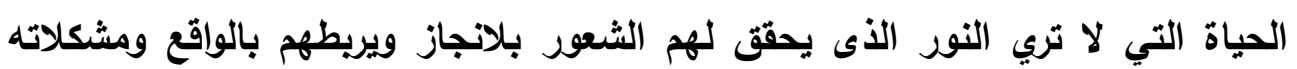

د - نظرا لان الوظائف الثلاث للجامعه متكاملة فان تسويق الخدمات بالطبع يساعد علي تأدية

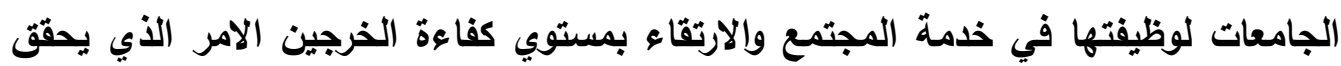

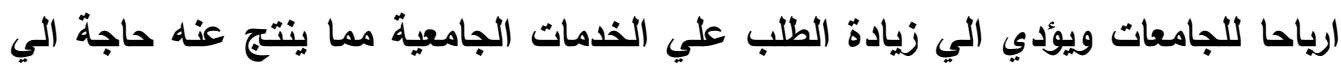
تثنيل ايدي عاملة جليدة وهذا يسهم في خفض معدلات البطالة في المجتمع . 


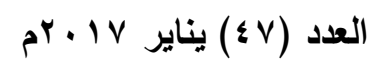

انطلاقا مما سبق يمكن القول : ان الاخذ بمفهوم تسويق الخدمات الجامعية يعد أمرا حتميا

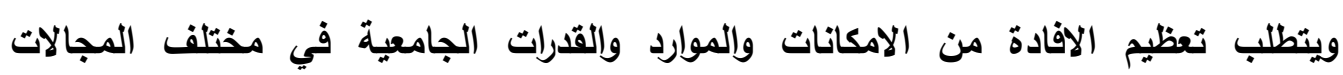
الاستشارية والبحثية والتدربية وغيرها حتي تتكمن الجامعات من المشاركة بفاعلية في التنمية الثاملة للمجتمع وحتي توفر مصادر التمويل الازم لاجراء عمليات التطوير والتحسين من

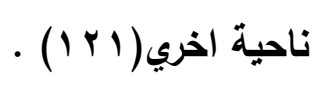

نواحى القوة بـالجامعات و التى تسمح لها بالتوجه بـالسوق: تجلت فى سياق التعليم الجامعى فى ج.م.ع بعض نواحى القوة التى تسمح للجامعات

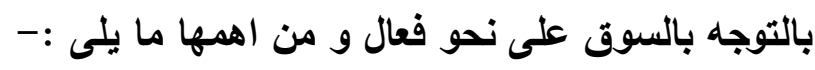

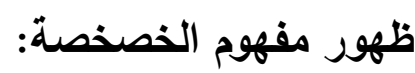
شهر المجتمع المصرى فى بداية التسعينات مجموعة من المستجدات التى كان لها تأثير على شكل العياة بمختلف مجالاتها ، و خاصة فى مجال التعلم الجامعى ، و يمكن لتهن

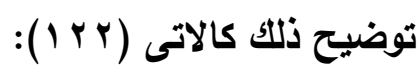
مع نهاية الثمانينيات اصبحت مصر إزاء ازمة اقتصادية سياسية حادة تحت تأثير مجموعة من العوامل ، معظمها خارجية مثل : " الركود الاقتصادى العالمى ، المقاطعة العربية

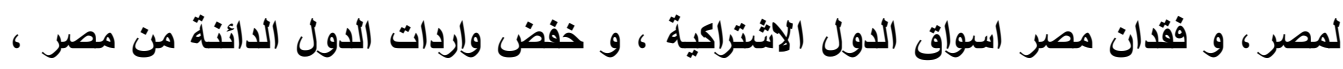
و انخفاض ايرادات قناة السويس " ، كما واكبتها عوامل داخلية مثل : اتباع سياسات خاطئة

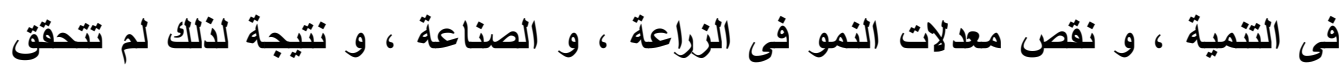
الاهداف الاقتصادية المرجوة. و مما زاد من حدة اختلال الاقتصاد القومى الزيادة المتوصلة فى نسبة الانفاق الكلى

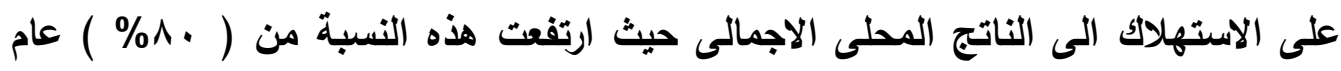

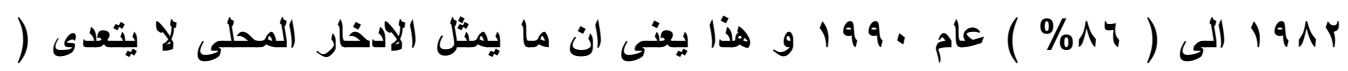
• .

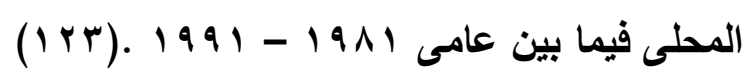

و ازاء هذه الاوضاع قامت الحكومة المصرية فى منتصف 1991 بتوقيع اتفاقيتين مع

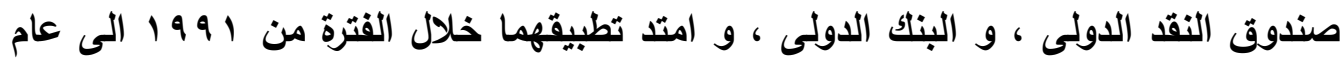

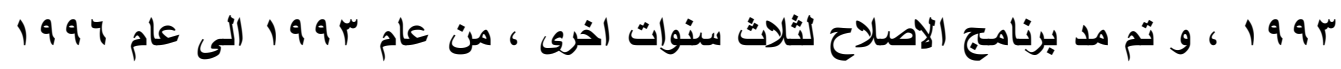




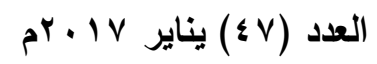

( ع r 1)، و تهذف المرحلة الاولى من الاصلاح الى الانتقال من اقتصاد مخطط مركزيا يلعب

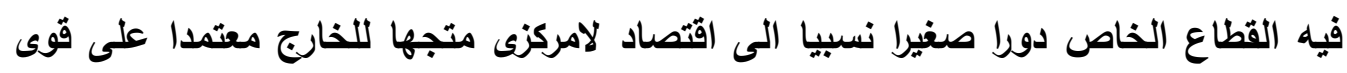

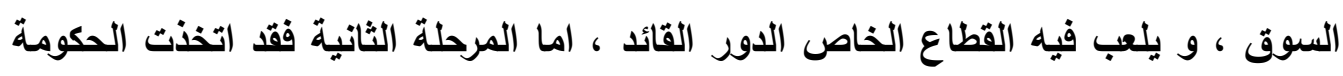
خلالها عدد كبير من الاجراءات التى تهدف الى تحقيق كل من : الاستقرار الاقتصادى الكلى ،و الاصلاحات المالية.

و قد بدأت عملية التحول نحو القطاع الخاص ( الخصخصة ) فى مصر بصدور القانون

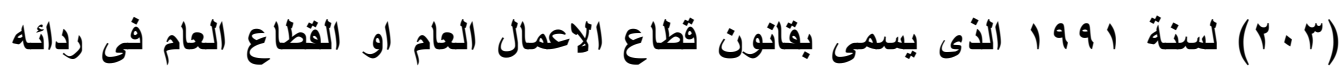
الجديد ، و الخصخصة عملية تثير الى حدوث تغيرات وإسعة المجال فى السياسة العامة يكون من شأنها التقييد من تلخل الحكومة او القطاع العام فى الانشطة الاقتصادية ، و و الخدمية ، سواء تم ذلك من خلال التصفية ام الايجار ام الاستثمار الخاص ( محلى، اجنبى) ام عقود للادارة.

والخصخصة ليست غاية فى حد ذاتها، لكنها وسيلة لتحقيق عدة اهداف منها ( Y / ): * رفع كفاءة المؤسسات الخاصة من خلال تحقيق الحجم الامثل للانتاج الذى يؤمن للمنتجين

$$
\text { اقصى ربح ممكن. }
$$

* توفير وظائف ، و مجالات عمل جيدة ، و التخفيف قر الامكان من نسبة البطالة المنتشرة

$$
\text { بين مختلف فئات المجتمع. }
$$

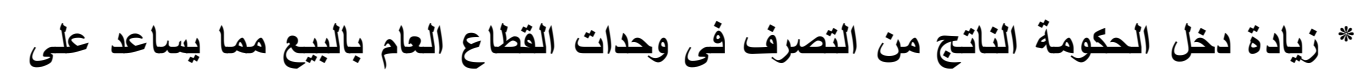

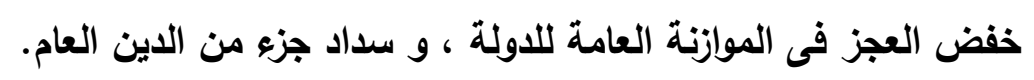

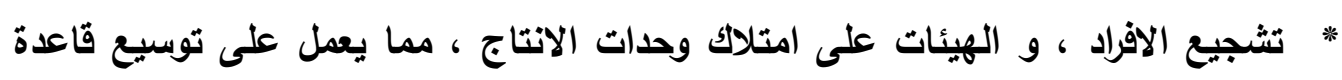

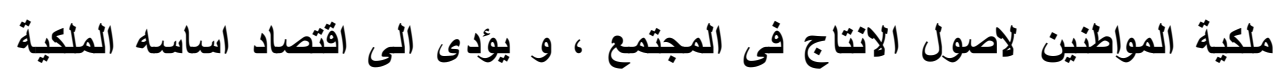

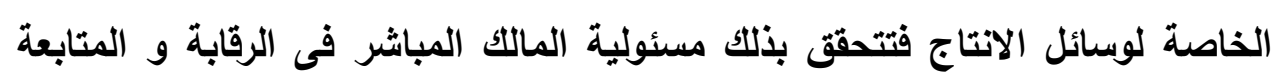

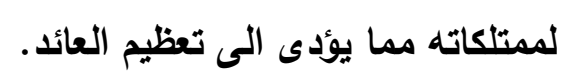

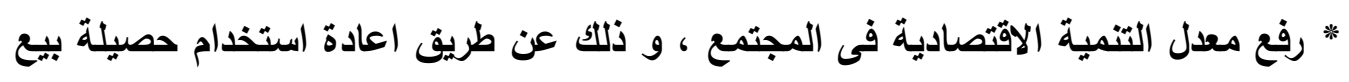

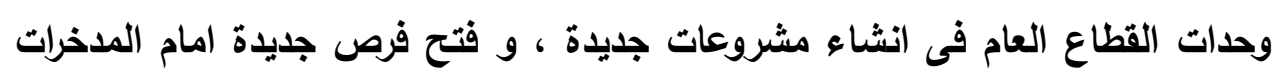
الخاصة لتستثمر و تملك مشروعات قائمة او جديد. 


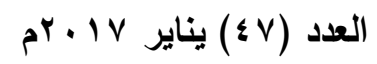

* تشجيع المنافسة عن طريق التخلص من جميع اثكال الاحتكار التى تكونت فى ظل التخطيط المركزى للحكومة.

و لم يكن التعليم الجامعى بمنأى عن هذه التغيرات ، فقد ادت هذه التغيرات اللى تخلى

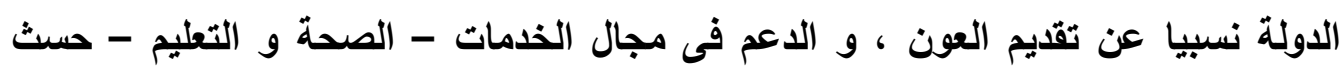

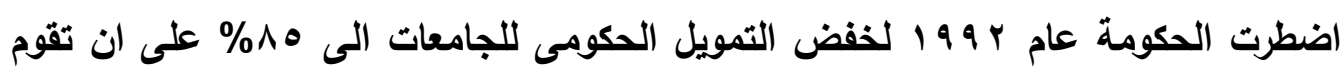
الجامعات بتوفير نسبة ه 1\% من مورادها الأتية ، الا ان الحكومة لم تستطع الاقتراب من

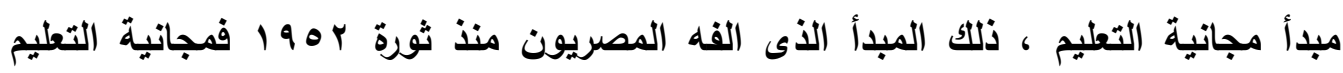
بجميع مراحله حق نص عليه الدستور ، و اقرته القوانين ، و مبدأ مقدس لا ينبغى المساس

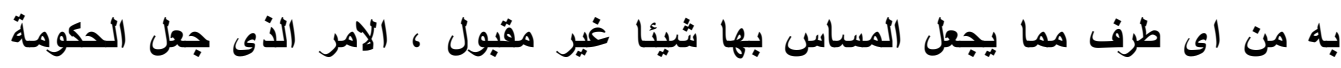

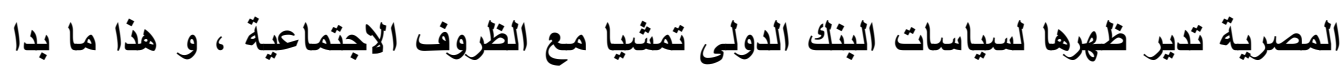

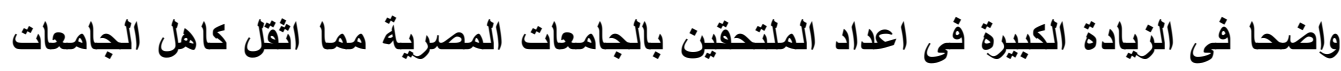

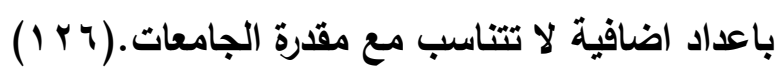
و قد حرصت القيادة السياسية من خلال الخطاب السياسى على التوجه نحو رفع الدعم

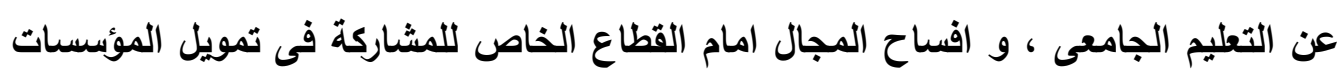
التعليمية.

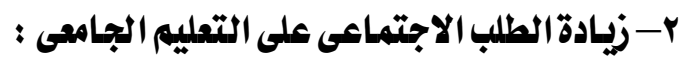

زيادة الطلب الاجتماعى على التعلم ظاهرة صحية لانها ستسلم فى تنمية العقول البشرية

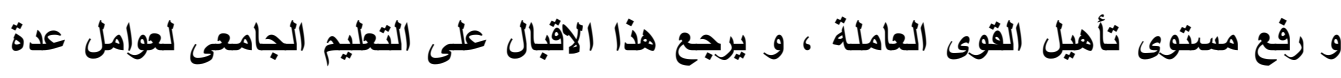

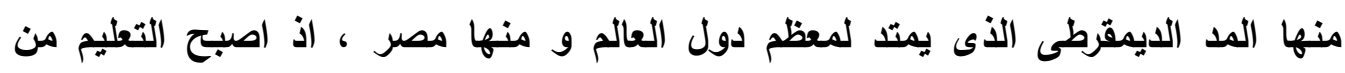

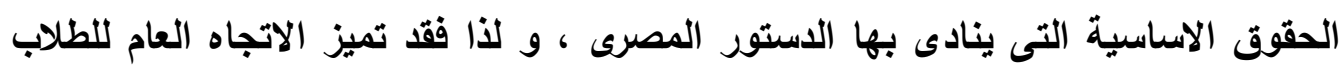

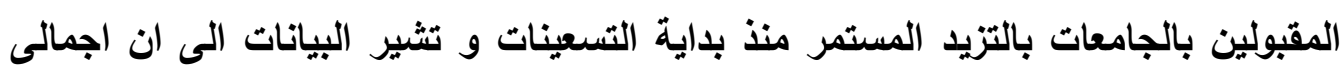

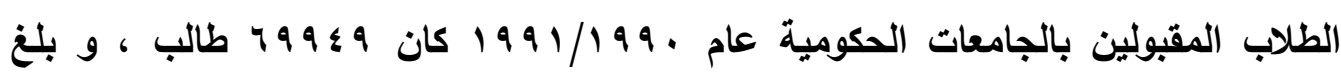

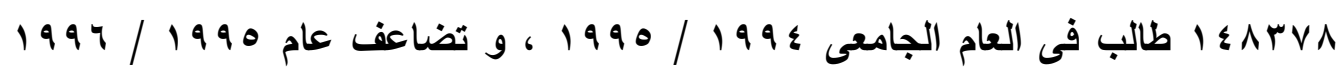

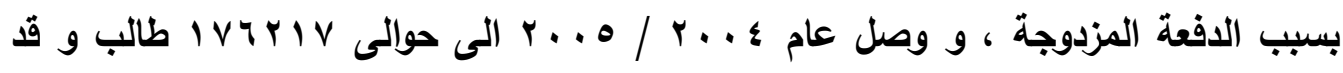

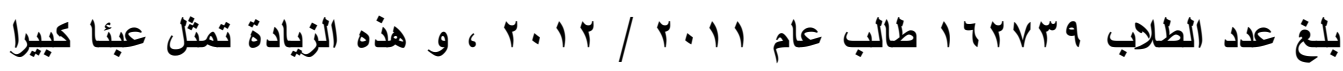
تنوء به الجامعات ، و يعوقها عن تحقيق بعض الهافها. ( I rV) 


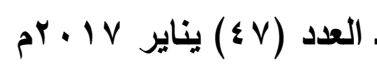

و الجدير بالذكر انه يوجد عدة عوامل تسبيت فى زيادة الاقبال على التعليم الجامعى منها

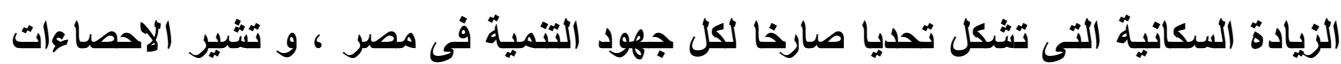

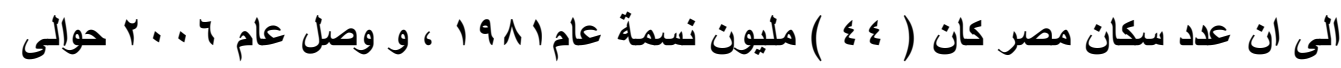

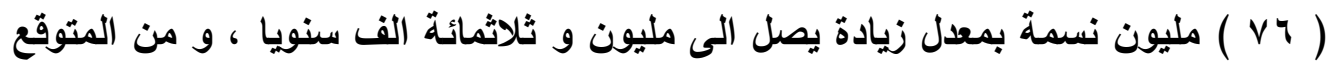

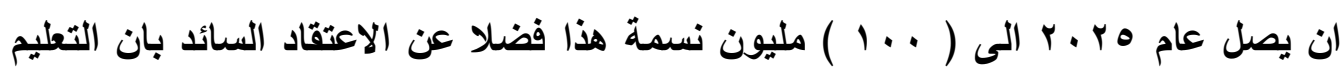

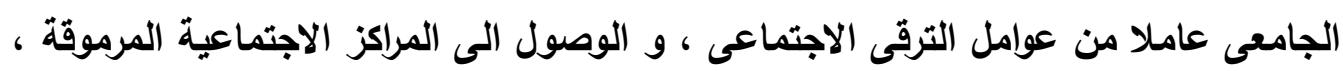

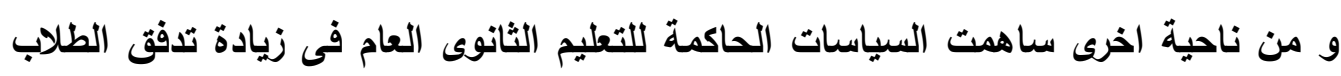

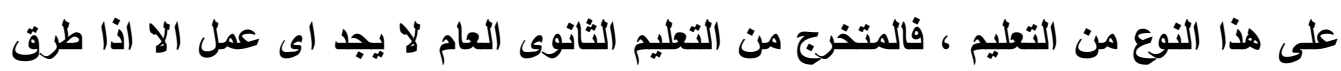

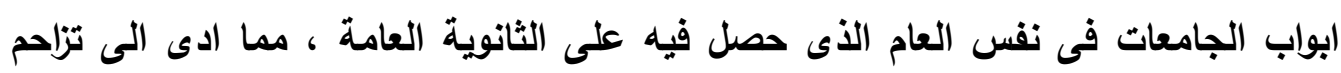

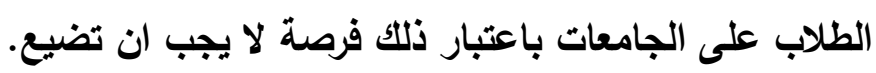

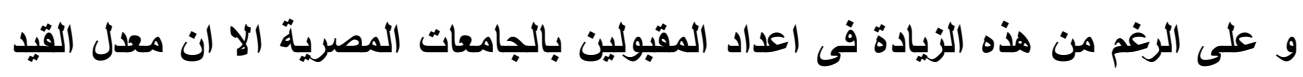

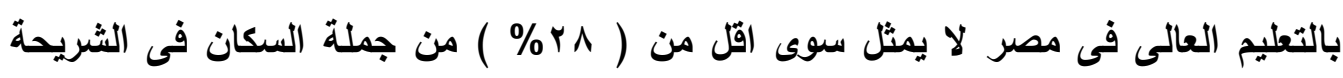

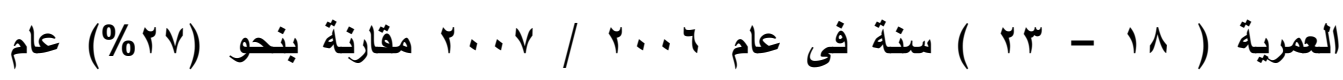

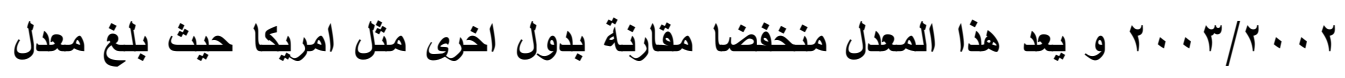

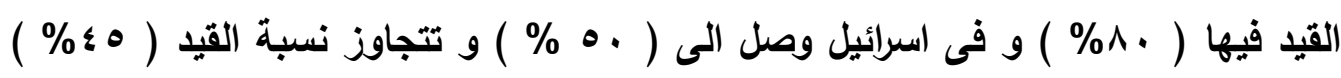

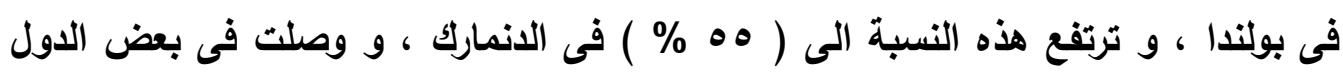

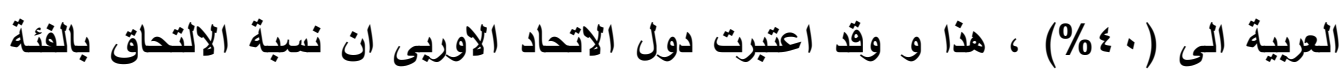

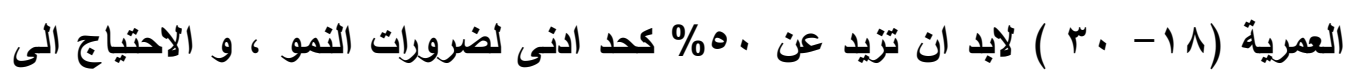

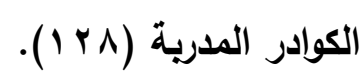

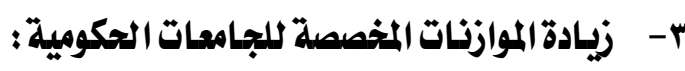

يعد التعليم من مرحلة التعليم الاساسى ، و حتى الجامعة خدمة مجانية تقام من قبل

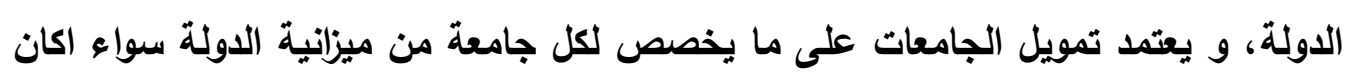

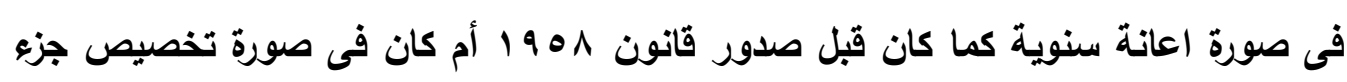

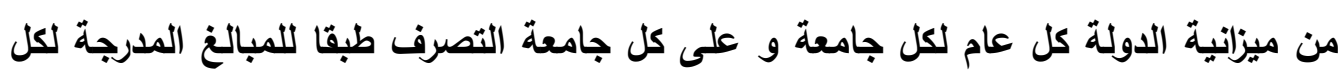

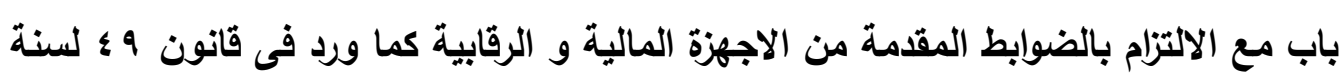

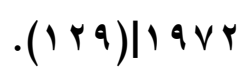


العدد (\&) يناير IV

و عندما قام مسئول البنك الدولى بعرض وجهة نظر تطلب تخفيض الدعم الموجه لقطاع التعليم فانه قد تناسى الأثير السلبى على فرص التعليم من خلال زيادة تكلقة المستلزمات

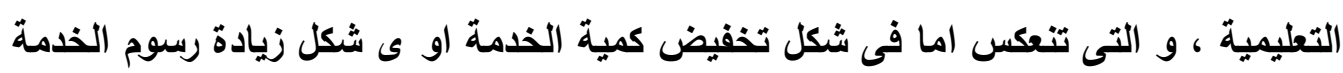

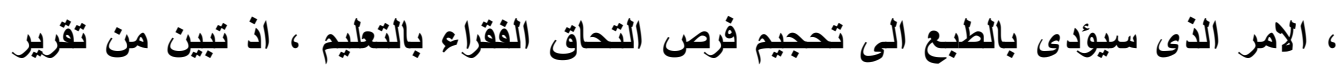

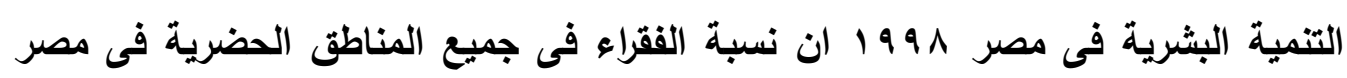

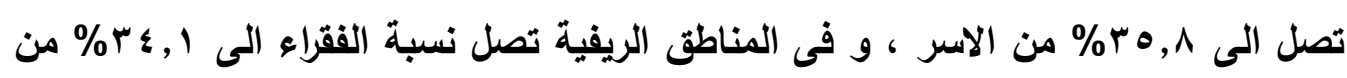
اجمالى الاسر التى تعيش بها ، و تحمل هذه الاسر تكلفة اضافية من خلال زيادة تكلفة ولافية

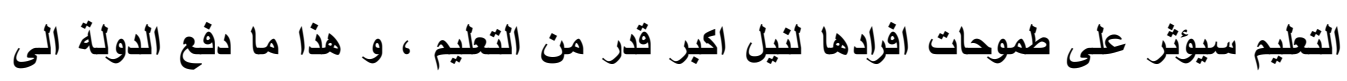
عدم الالتزام بسياسة البنك الدولى بتخفيض الانفاق الحكومى على التعليم.

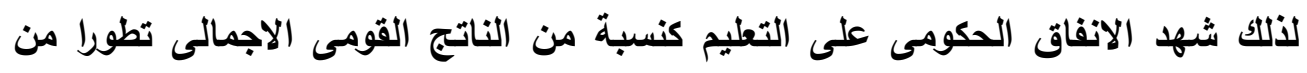

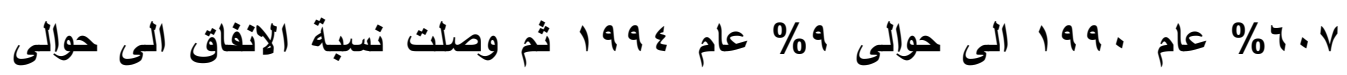

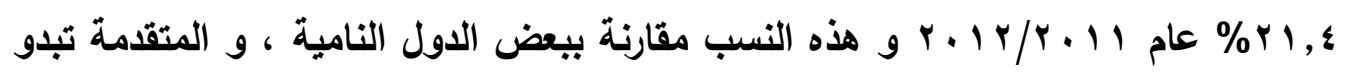
معقولة ، و لكن مع الاخذ فى الاعتبار ان الناتج المحلى فى مصر يقل عن مثيله فى الدول

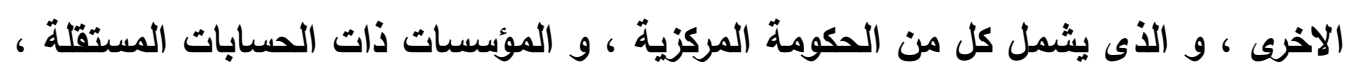

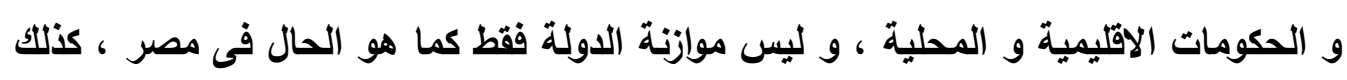

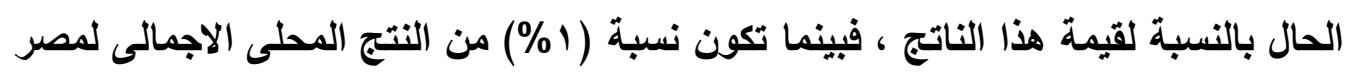

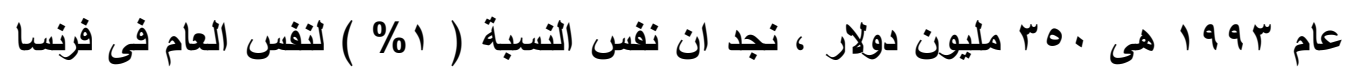

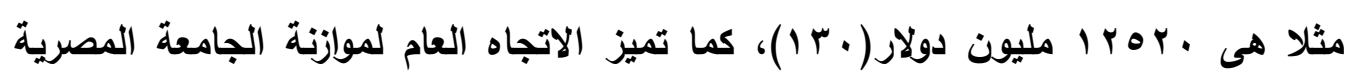

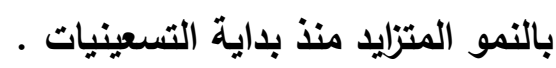

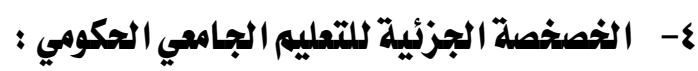

للخصخصة الجزئية عدة اشكال تتدرج تحت ما يسمي "سياسية استرداد التكاليف " والتي

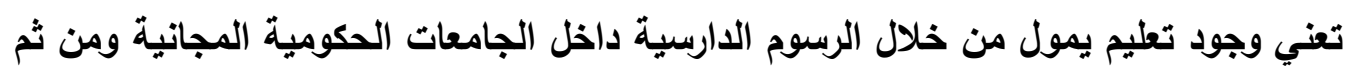
تقوم هذه الجامعات باستعادة تكاليف العملية التعليمية والتي كان من المفترض اندي ان تكون

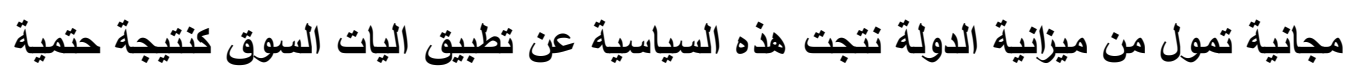
لضغوط العولمة وانتثار ثقافية السوق مع تفشي ازمة التمويل وعدم القدرة علي انثاء

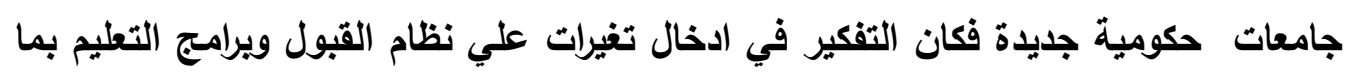




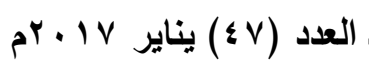

يسمح بتوفير مصادر اضافية لتويل الجامعات الككومية واتاحة الفرصة لعدم متزايد من الطلبة في الجامعات مع تحملهم تكلفة تعليمهم بالكامل .

وقد تكون هذه الاجزاء مركزا للتطليم المفتوح الذي بدأ ظهوره بمصر في العام الجامعي

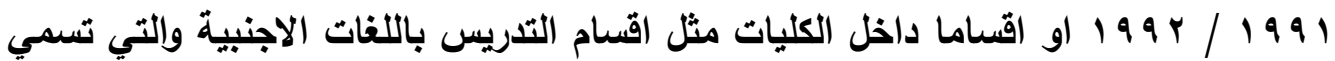

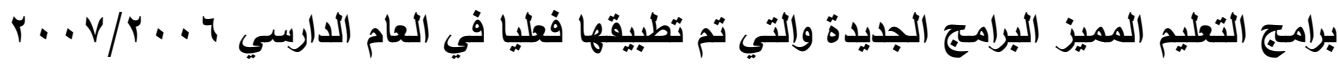
بموجب قرار المجلس الاعلي للجامعات وكان عدد تلك البرامج (Y^) برنامجا كمرحلة تجريبة وهذه الانماط يتم خضوعها لكافة لوائح وقوانتين الجامعات الحكومية مع وجود لوائح داخلية خاصة بها سواء بالقبول ام الدارسة بها ويقوم بالتريس فيها اساتذة الجامعات الحكومية ذاتها ويطبق في بعضها نظام الساعات الدارسية المعتمدة ( اب أ).

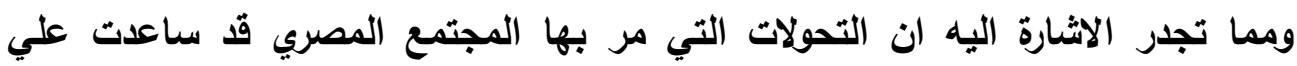

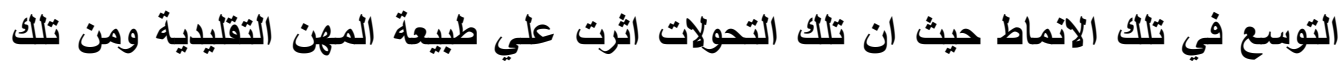
المهن التي ظهرت ما هو خاص بمجال اللغات والترجمة واللسياحية والبنوك والتهندسة

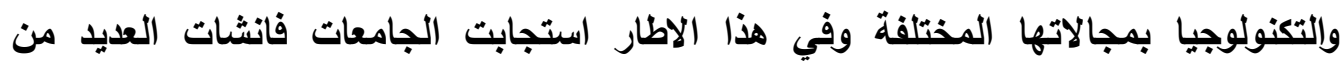
البرامج لمقابلة التغيرات في المهن التي تتطلبها الاوضاع الاقتصادية ومع استمرار في التانيان

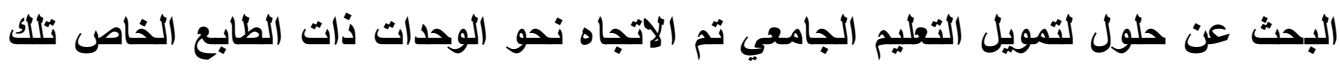

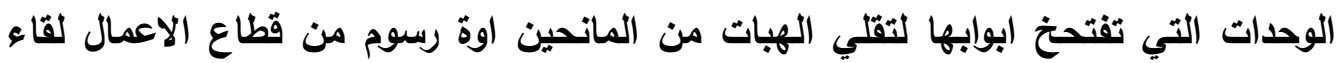
خذمات تقليمها لهذه المؤاسسات وهذا تطلب دور هذه الوحدات في تقايم خدماتها المجتمع . جوانب الضعف في الجامعاتو التى تقثل تحليـات تقوم الجامعات عن التوجه بـالسوق: تتعدد التحديات التى تواجه الجامعات و التى نقف حائلا نحو توجهها بالسوق و تبنيهاتيات الاستراتيجيات التسويقية تحسن من فعاليتها امام المجتمع و من اهم تلك التحديات ما يلى : 1- وجود ازمة ثقة بين الجامعة والمجتمع : رغم الجهود المبذولة من اجل زيادة موازنة الجامعات المصرية الا ان تكلفة الطالب إنبان

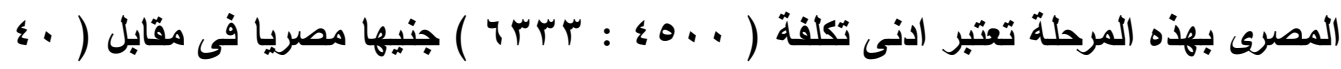

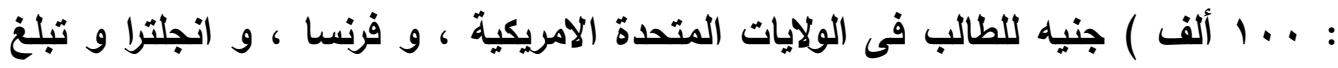

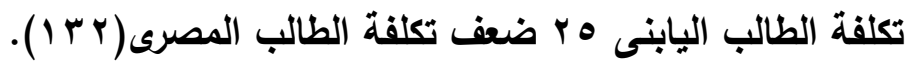




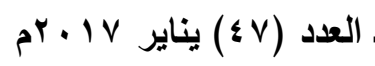

و تجدر الاشارة الى ان الزيادة فى موازنات الجامعات لا تمثل زيادة حقيقية بقدر

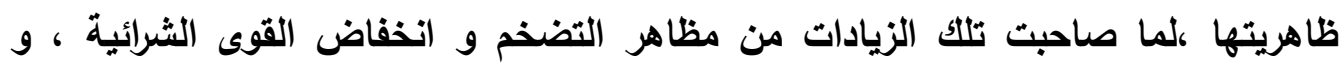

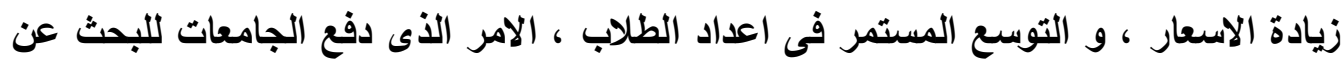
مصادر تمويل جديدة من خلال مشاركة مؤسسات المجتمع ، و هذا يتطلب قناعة تلك التك

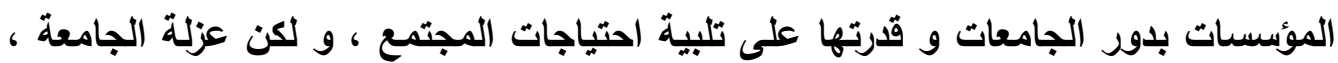
و عدم اكترثها بالقضايا المجتمعية ادى الى وجود ازمة ثقة بين الجامعة و المجتمع ، حيث

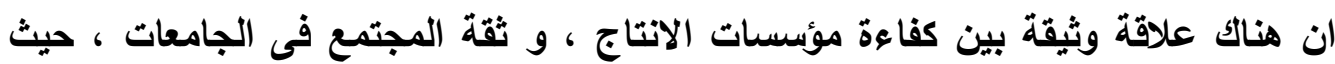
اوضح البعض انه كلما زادت كفاءة مؤسسات الانتاج ، زادت ثقة المجتمع فى الجامعات ، و و

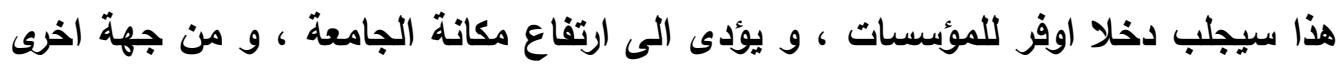

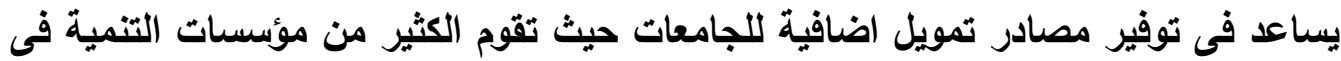
كثير من دول العالم بالمشاركة طواعية فى تمويل الجامعات طالما انها مقتنعة بأهمية

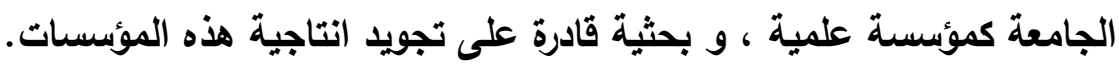
و تلا الاوضاع المجتمعية فى فترة التسعينيات على ضعف التمام الجامعات بقضايا المجتمع الحاكمة و ازماته المتلاحقة ، بل انه يسود وفى المناخ الجامعى - بصورة عامة -

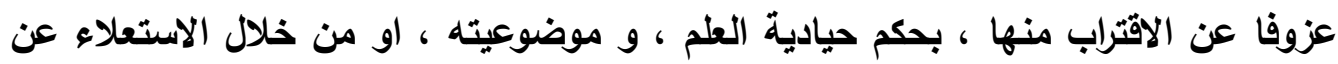
تللك القضايا و الخدمات ، ففى تلك الفترة لم يتضح اى تفاعل ايجابى بين الجامعات بقواها التدريسية و البحثية و بين اهداف التنمية الاقتصادية و الاجتماعية ، ظهر ذلك فى فشل

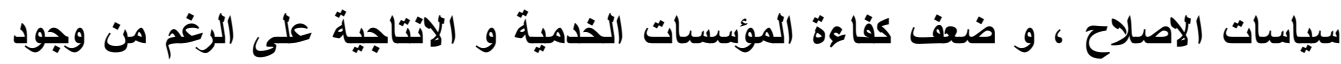
كيانات داخل الجامعات ( الوحدات ذات الطابع الخاص ) تمثل حلقة الوصل بين الجامعات ، و قطاعات المجتمع المختلفة ، و من ثم فان تباعد الموجود خلق نوعا من عدم الثقة او عدم

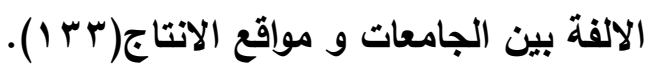
و مما يشير الى الفجوة بين الجامعات و مؤسسات الانتاج الاقتراح الأى قدمته الوثيقة

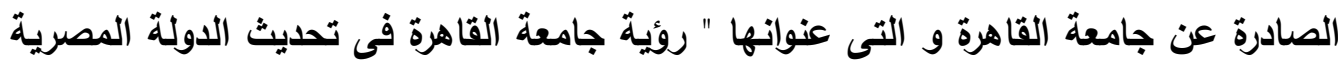
" و الأنة ينص على انثاء مراكز للبحوث و التطوير فى مختلف قطاعات الصناعة مع ريطها بالمراكز الاوروبية فى اطار اتفاقية المشاركة الاوروبية مع مصر لتكون مصدرا اساسيا

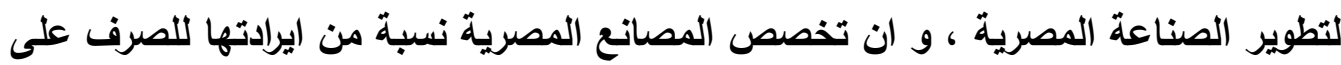




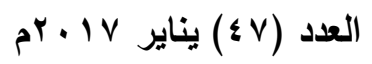

هذه المراكز و اللافت للنظر هو تجاهل الخبرات البحثية الوطنة ، فكان من المفترض ان تتص

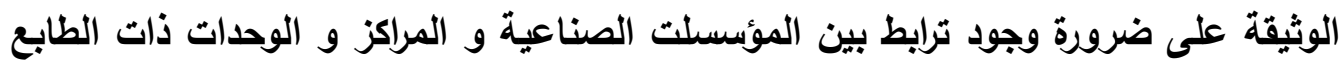
الخاص بالجامعة و الاكثر من ذلك ان هذا الاقتراح مقدم من الجامعة ذاتها فبدلا من ان لنول تسعى الجامعة لخدمة المجتمع ، و تلبية احتياجاته فانها تتخلى عن هذا الدور للمراكز

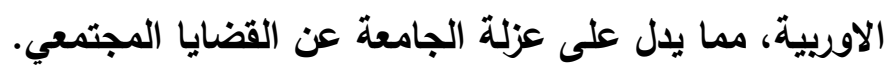

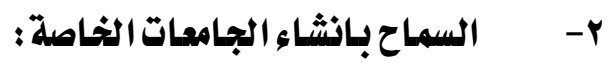
و يعد انعدام الثقة بين الجامعة ، و مؤسسات المجتمع احد المبررات التى ساهمت فى وجود الجامعات الخاصة حيث تهدف هذه الجامعات الى الاسهام فى رفع مستوى التعليم و البحث العلمى و توفير التخصصات العلمية الحديثة لاعداد المتخصصين و القنيين و الخبراء فى مختلف المجالات بما يحقى الربط بين اهداف الجامعة و احتياجات المجتمع و لا يعد هذا المبرر هو المبرر الاوحد لانشاء جامعات خاصة حيث استتد مؤيدو هذه الفكرة على ان الجامعات الخاصة تسهم فى التظلب على مشكلة عجز مصادر التمويل التقليدية التلازمة لمواجهة متطلبات التعليم الجامعى ، و من ناحية اخرى فان هذه الجامعة تستوعب ابناء القادرين ماديا ومن ثم تخفف الضغط الطلابي علي الجامعات الحكومية وعلي هذا اصبح السماح باتشاء الجامعات الخاصة هو احد الحلول المطروحة لحل مشكلات التعليم الجامعي الحكومي في السماح بانشاء جامعات خاصة . ارتبط التحول الي سياسية الانفتاح الاقتصادي بظهور طبقات راسمالية طفيلية شكلت بالتدريج جماعات ضغط في المجتمع وكان تاثير ذلك علي المجتمع خطيرا للغاية اذا ارتفع

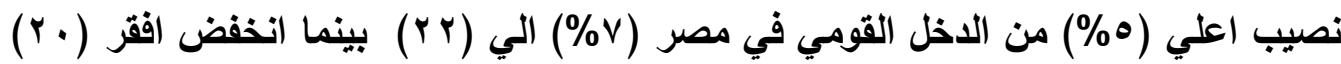
من (0) الي فقط وفي ظل ذلك المناخ الانفتاحي كان التعليم دوره الانفتاحي ايضا حيث بدات هذه الطبقة الجديدة في البحث عن التميز في هذا الجانب ايضا فاتجهت الي توفير تعليم خاص لابنائها يضمن لهم هذا التميز المنشود فكانت المدارس الخاصة ومدارس اللغات هي البديل للمدارس الدكومية ولم تكتفي هذه بذلك بل بدات تبحث عن قنوات جديدة في قطاع التعليم الجامعي لتشبع طموحاتها وتحقق مصالحها واستمرت المحاولات في هذه القضية من

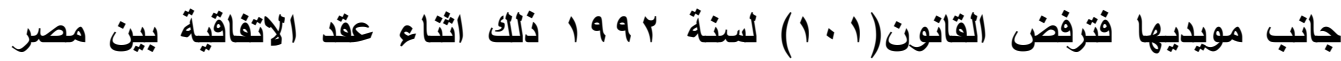
والصندوق النقد الدولي بثان برنامج الخصخصة في مصر (؟ ب الومن ثم فان صدور القانون 


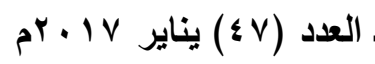

في هعذا التوقيت جاء متتاغما مع التوجه الاقتصادي الجديد الذي يهدف الي تقليص الدور الاجتماعي للاولة وتسعير الخدمات الاولية كما يعد ذلك نجاحا لتلك الطبقات الراسمالية فانجبته الثراء في خلق انماط تعليمية جديدة تضمن استمرار ابنائها في الحصول علي الماكن متميزة من خلال تخصصات وكليات معينة يتطلبها سوق العمل(ه ب I ) والجدير بالأكر ان من اهم اسباب انتصار مؤيدي فكرة الجامعات المصرية الخاصة بعد بدانه محاولات علي مدارس يقرب من r r عام (من 1909 - 1999) هو تبني الرئيس مبارك شخصيا لهذه الفكرة فبعد ان تغير المشروع كثيرا تولي الرئيس مبارك مهمة دفع عجلة هذا هنا المشروع حينما عقد اجتماعية المعروف يوم IV فبراير I99 19 مع رئيس مجلس الثعب والثوري ووزارء التعليم والتنمية الادارية والاسكان ليصنع المشروع علي العتبة الاولي في سلم التنفيذ بلاضافة الي غياب الوعي السياسي لاي احزاب المفاوضة التي تم تهميش دورها في ظل الاغلبية المطلة للحزب الوطني داخل مجلس الشغب وداخل المؤسسة الرئاسية

$$
\text { والسياسية في مصر }
$$

وهكذا يتضح من خلال العرض السابق ان نشاة الجامعات الخاصة كان استجابة لجملة من التحولات المجتمعية التي مر بها المجتمع المصري في تلك الفترة واستكمالا لسياسية الخصخصة وفي سبيل حل ازمة تمويل التعليم الجامعي تم ادخال شكل جديد من اشكال الخصخصة وهو خصخصة جزء من داخل الجامعات الحكومية ذاتها لتكون الدارسة فيه بمصروفات تغطي تكاليف دراسة الطالب وذلك لتوفير تمويل التعليم الجامعي الحكومي .

\section{الجزي الدرابع : استشراف مستقبل تسويق الخدمات التعلبمية في الجامعات المصرية}

بعد تحليل واقع الجامعات المصرية وتحديد مابها من نواحى قوة تسمح لها ببمارسة التسويق ونواحى ضعف تمثل تحديات فى الجامعات يجب مواجهنها من اجل ممارستها للتسويق ، وفى ضوء المعايير النظرية الحاكمة لتسويق الخدمات التعليمية فى الجامعات المصرية وفى ضوء منهجية البحث المتبعة يمكن اقتراح بعض السيناريوهات لتسويق

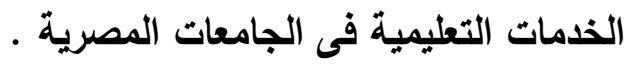
وعلى ذلك فان بناء السيناريوهات جاء وفقا للخطوات التالية: وصف الوضع الراهن وتحديد الاتجاهات العامة السائدة فى تسويق الخدمات

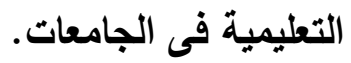




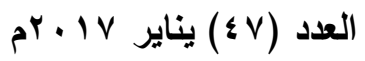

• هم ديناميكية النسق الخاص بتسويق الخدمات الجامعية.

• عرض السيناريوهات المقترحة لتسويث الخدمات التعليمية بالجامعات المصرية. الخطوة الاولى : وصف الوضع الراهن وتحلد الاتحاهات العامة السيائدة فى تسوريق الخدمات

التعلبمية في الجامعات.

تضمنت هذه الخطوة تحديد نواحى القوة فى الجامعات المصرية/لتى سمحت ببمارسة التسويق ، ونواحى الضعف التى عاقت الجامعاث عن ممارسة التسويق ، وكذلك تحديا الاتجاهات العامة السائدة أو بدايات التغييز والتى تتبئ بتحولات مهمة فى المستقبل ، وعلى ذلاك يمكن تحديد جواتب القوة التى تدعم تسويث الخدمات الجامعية وجواتب الضعف التى تعوق تسويقها (بناء على الدراسة النظرية للبحث ) على النحو التالى : أ- حوانب القوة :

الاهتمام بالبحوث التعاقدية لاعضاء هيئة التدريس لتقليل الفجوة بين الجامعة و - 1المجتمع

تقدم الجامعات الخدمات الاستشارية المختلفة لمؤسسات المجتمع المحلى. تلبية احتياجات اصحاب المصلحة الذين يحكمون على الخدمة الجامعية . دعوة رجال الاعمال للمشاركة فى مجالس الوحدات الانتاجية و الخدمية بالجامعات . تعميق لا مركزية الادارة و التمويل . التوسع فى بناء الجامعات لتلبية الطلب المتزايد على الالتحاق بالتعليم الجامعى • خلق انماط تعليمية جديدة تتيح تخصصات و كليات معينة يتطلبها سوق العمل. التوجه نحو الخصخصة الجزئية للتعليم الجامعى الحكومى بما يسمى بسياسة استرداد التكاليف و التى تعنى وجود تعليم يمول من خلال الرسوم الدراسية داخل الجامعات الحكومية المجانية و من ثم تقوم الجامعات باستعادة تكاليف العملية التعليمية. • البحث عن مصادر تمويل جديدة للجامعاث من خلال مشاركة مؤسسات المجتمع. توافر عدد مناسب من الوحدات ذات الطابع الخاص التي تقوم بتقديم عدد من الخدمات التعليمية والتدريبية والاستشارية والبحثية والانتاجة الامر الأي بساعد علي تلبية احتياجات قطاعات المجتمع المختلفة بالاضافة الي توفير موارد مالية للجامعة . 


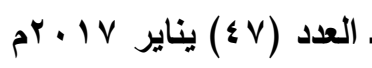

• توافر عدد مناسب من اعضاء هيئة التدريس من ذوي الكفاءة العالية في العديد من التخصصات المعرفية .

وجود قواعد بيانات للمستفدين يمكن عن طريقها تصنيفهم الي قطاعات مختلفة والتعرف

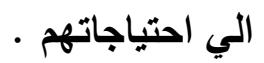

للوحدات ذات الطابع الخاص روئة واضحة تصاغ بمشاركة العاملين بالوحدة . يحرص المسؤولون عن الوحداث علي اشراك العاملين في جميع ممارستها . وجود موقع الكتروني لبعض الوحدات ذات الطابع الخاص يمكن عن طريقه الاعلان عن الخدمات التي تقدمها الوحدة .

للوحدات هيكل يوضح ادوار القائمين ومهامهم علي العمل بها والعلاقة بينهم . ب- حوانب الضعف : • ضعف وضوح فلسفة انشاء الوحدات ذات الطابع الخاص كمنافذ لتسويق الخدمات

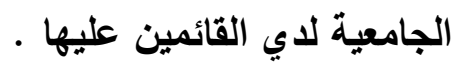
قلة اشراك المستفيدين من خدمات هذه الوحدات في تحديد انشطتها . افتقار هذه الوحدات الي الادوات التي تستخدمها للتعرف الي الاحتياجات الفعلية • للمستفيدين ضعف قدرة الوحدة علي تحديث الخدمات المقدمة بسبب قلة التعرف على الاحتياجات الفعلية او بسبب نقص الموارد المالية اللازمة لتحديث تلك الخدمات . • لا تزال الوحدات ذات الطابع الخاص موجهة بالانتاج ويستدل علي ذلك عن طريق : ندرة اهتمام الوحدات باراسة الجهات المنافسة وما تقدمه من خدمات لمحاولة ايجاد مزايا تنافسبة . نقص الكفاءات الادارية التسويقية فالوحدات لا تعتمد علي كوادر مدربة علي مهارات التسويث. قتلة توافر التجهيزات اللازمة في بعض الوحدات. قصور وسائل الترويج عن خدمات الوحدات ويتضح ذلاك عن طريق قالة عقد التدوات والمؤتمرات وورش العمل والتي يمكن عن طريقها التسويق لخدمات الوحدات بالاضافة الي ضعف الاستغلال الجيد للمواقع الاكترونية فمعظمها لا تحدث دوريا . 


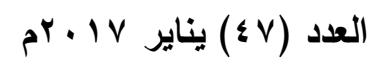

محدودية دور الوحدات في تسعير بعض الخدمات.

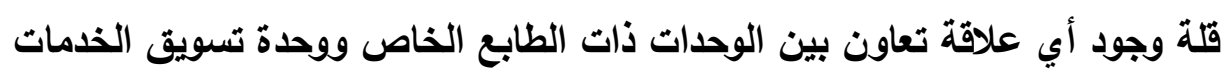

الجامعة .

• ضعف التنسيق والتكامل بين الوحدات ذات الطابع الخاص ويعضها داخل الجامعة . .

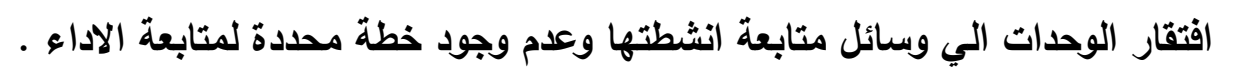

ندرة وجود تمثيل من الجهات المستفيدة في مجالس ادارات الوحدات.

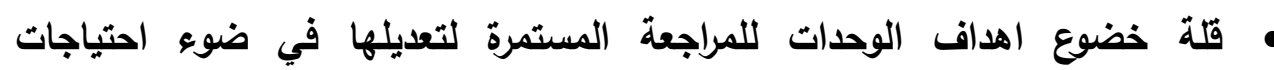
• المستفيدين

ندرة وجود معايير علمية لاختيار العاملين بالوحدات وتدخل الاعتبارات الشخصية في

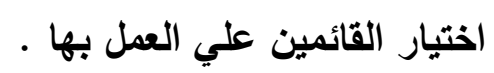

• ضعف اهتمام مقدمي الخدمات بالتعرف الي مدي رضا المستفيدين بصورة دورية .

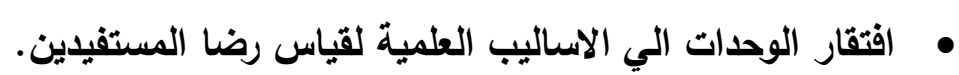
• قلة الافادة من نتائج الاستبانات التي توزع علي المستفيدين للتعرف علي مدي رضاهم. • وجود ازمة ثقة بين الجامعة و المجتمع حيث انه هناك علاقة وثيقة بين كفاعة مؤسسات الانتاج و ثقة المجتمع فى الجامعات. لا يتم الاعلان عن الوحدات ذات الطابع الخاص واليات تسويق الخدمات الجامعية الاخرى بشكل كافى.

ج- تحديد الاتجاهات العامة السائدة فى تسويق الخدمات التعليمية فى الجامعات.

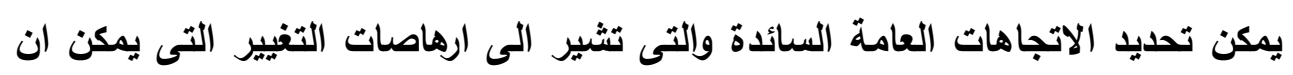
يكون لها تأثير على تسويق الخدمات التعليمية بالجامعات المصرية وذلك كما يلى : • الاتجاه الى الاستقلال المالى للجامعات من خلال اعطاء الحرية الكافية لمجالس الكليات

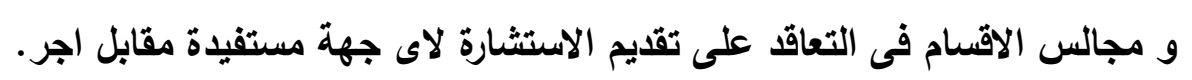

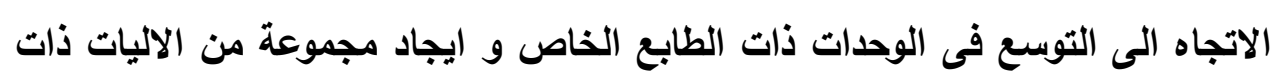
الفاعلية و الكفاءة التى تساعدها على القيام بدورها على اكمل وجه فى تقلم خدماتها

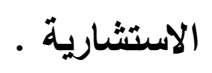




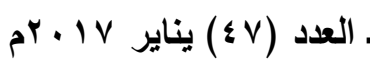

• • الاتجاه الى التوسع فى انثاء قنوات اتصال بين الجامعة و قطاعات المجتمع المختلفة.

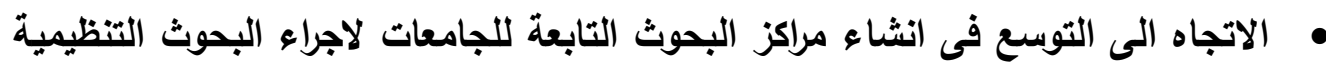
و نثرها و تمولها بالاضافة الى تقديم الاستثارات العلمية التخصصية و عقد المؤتمرات

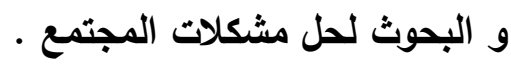

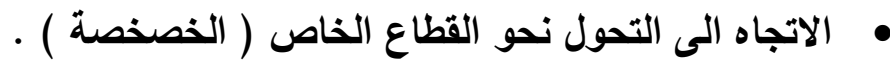

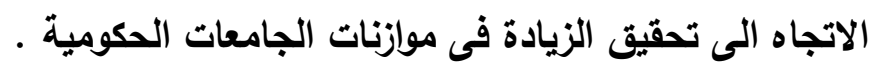

ـالاتجاه العالمى ندو الجامعة والصناعة.

الخطوة الثانية :فهم ديناميكية السياق الخاص بتسويق الخدمات الجامعية والقوى المحركة له :

هناك مجموعة من القوى المحركة والدافعة لتسويق الذدمات التعليمية بالجامعات ،

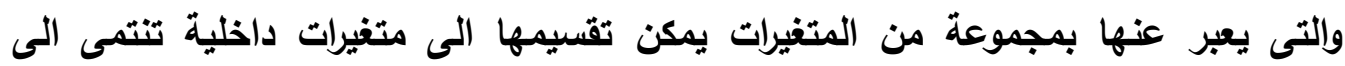
النسق محل الدارة ومتغيرات خارجية تعبر عن البيئة التى يعمل فيها السياق.

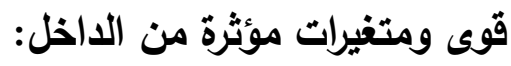

تحسين جودة الفرص التعليمية وذلك عن طريق جذب موارد اكثر للمؤسسة التعليمية .

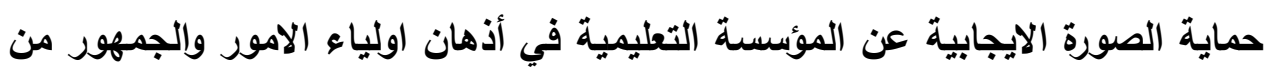

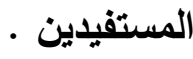

خلق سمعه اكثر تايدا للمؤسسة التعليمية وذلك بجذب نوعية افضل من اعضاء هئة التدريس علي درجة عالية من جودة الأداء وتثثيع الطلاب في التعرف علي المؤسسة

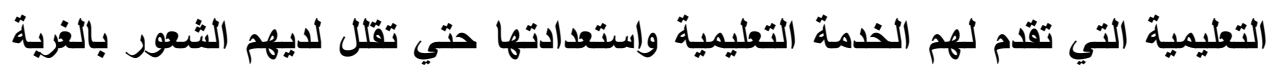
تجاه هذه المؤسسة التعليمية. • جذب نوعية افضل من الطلاب والتي تتوافر فيهم المهارات التي يمكن تنميتها وتعزيزها وفقا لاحتياجات سوق العمل . • توسيع امتداد الفرص التطليمية وذلك عن طريق مراجعة دورة حياة المنتج التطليمي

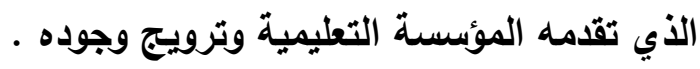

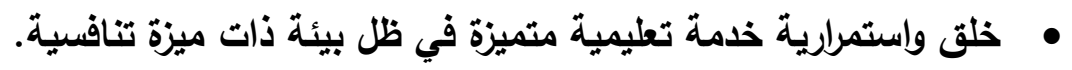

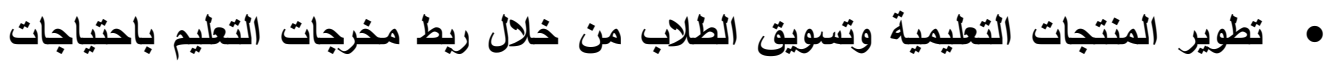

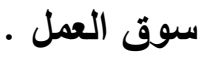




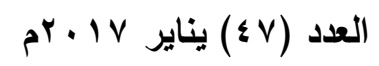

النمو والتتوسع في تقديم الخدمات التعليمية .

ريط التكلفة بالمكسب لكل خذمة التعليمية.

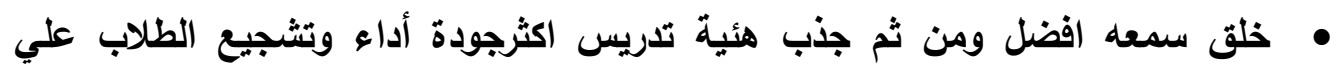
تحديد المؤسسة التعليمية باقدام اكبر وشعور اقل بالنفور منها ـأبها

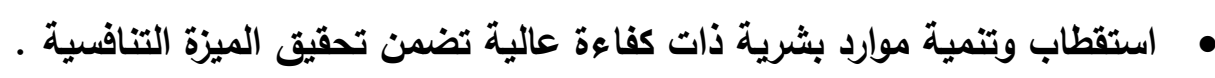

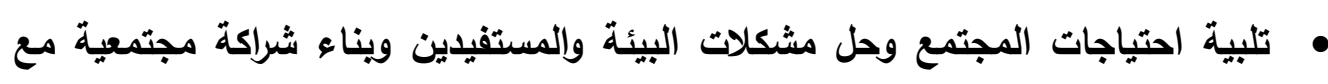

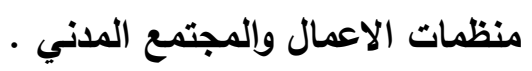
قوى ومتغيرات المؤثرة من الخارج: • تحديد المنافسون المباشرون وغير المباشرون للتعليم الجامعى سواء جامعات اجنبية او

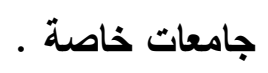
• تحليل سوق مخرجات التعليم الجامعى.

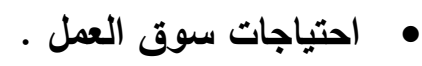
• • • عناصر المزيج التسويقى للجامعات المنافسة. القيود الاجتماعية .

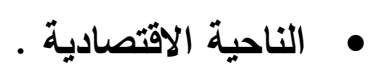

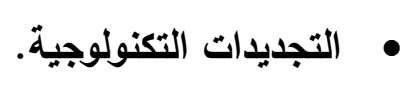
• السياسات المالية . .

الخطوة الثالثة : تحليد البدائل أو السيناريوهات المستقبلية لتسويق الخدمات التعليمية

\section{بالجامعات المصرية.}

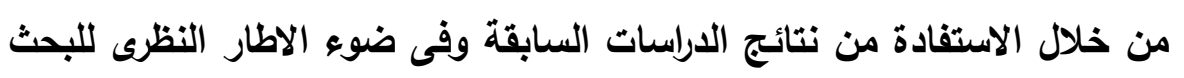

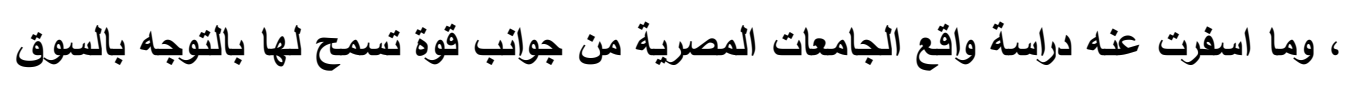

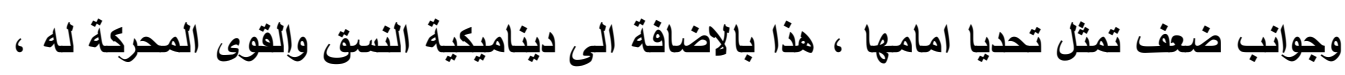

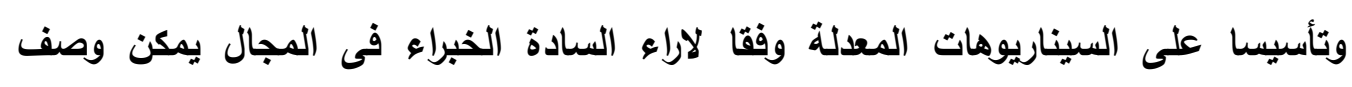

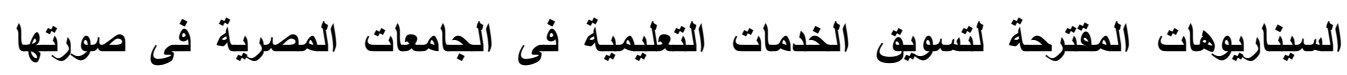

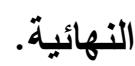
وفيما يلى عرض السيناريوهات المقترحة: 


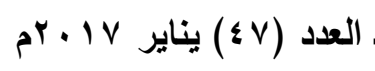

أولا : السيناريو المرجعى: وهو الذى يعكس الوضع الراهن او يحافظ على الاوضاع الراهنة ، ويتضمن عرض السيناريو المرجعى ما يلى:

$$
\text { ـ الافتراضات التى يقوم عليها السيناريو: }
$$

• ضعف الترويج لصورة الجامعة نتيجة قلة تعريف قطاعات المجتمع باتجازاتها وطبيعة

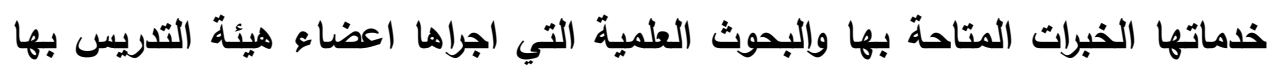
ذلك لقلة اقامة الندوات والمؤتمرات ووسائل الاعلام وعدم الافادة من دور الاعلام في

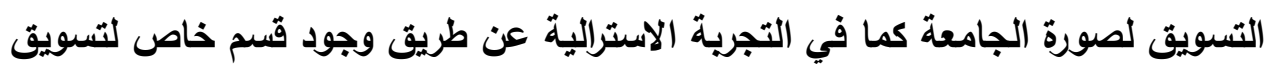

صورة الجامعة للمجتمع.

قلة الاهتمام بجودة الذدمات المقدمة من الوحدات ذات الطابع الخاص بالكليات وندرة استقطاب الكفاءات للعمل بالوحدة وعدم الاهتمام بتوفير التجهيزات اللازمة لقيام الوحدة بمهامها مثل تحديث الخدمات الجامعية بصورة مستمرة في ضوء الاحتياجات الفعلية لافراد المجتمع الامر الأي يؤدي الي فقد الثقة في مستوي جودة الخدمات الجامعية و قلة جذب اكبر عدد من المستفيدين. ندرة انشاء وحدات ذات طابع خاص متداخلة التخصصات بدلا من التركيز علي انشاء وحدات ذات طابع خاص متخصصة والتي غالبا ما يناظر احد الاقسام العلمية وهذا يسهم في قدرتها علي الاسهام في حل المشكلات المعقدة التي يتطلب حلها التعامل مع تخصصات عديدة . ضعف التحديد الدقيق للمستفيدين من الخدمات التى تقدمها الوحدة و قلة تصنفهم الى قطاعات بالنسبة لكل خدمة فى حالة الوحدات التى تقوم بأكثر من نشاط و دراسة التهات خصائصهم و اتجاهاتهم نحو الخدمات الجامعية. قلة الاحتفاظ بقواعد بيانات للقطاعات المستفيدة . ندرة استخدام الاليات التى يمكن عن طريقها التعرف الى احتياجات المجتمع مثل تنظيم

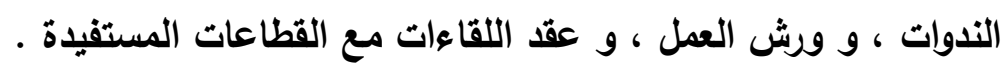

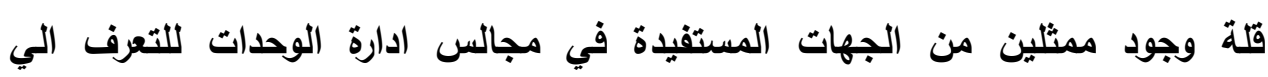
احتياجتهم الفعلية وكذلك قيام اساتذة الجامعة في المشاركة في مجالس ادارة المؤسسات (كما في التجربة الامريكية. 


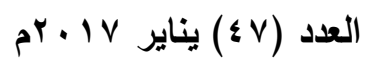

قلة تقديم الخدمات التي تتوافق مع الاحتياجات الفعلية للمستفدين ويتم ذلك عن طريق التحسين لجودة وتعديل الخدمات في ضوء تغير احتياجات الفئات المستفيدة . ضعف الاهتمام بالجاتب الترويجي للخدمات التي تقدمها الوحدة نتيجة عدم وجود فريق فئي متخصص مسئوول عن ترويج خدمات الوحدة. قلة وعي العاملين باهمية حسن التعامل مع المستفيدين وتزويدهم بالمعلومات اللأزمة للرد علي استسفارات المستقيدين. ندرة تلريب العاملين بالوحدة علي مهارات التسويق • قلة التنسيق بين الوحدات ؤذات الطابع الخاص بكل كلية والوحدات ذات الطابع الخاص باص لوات الاخري بحيث لا يحدث تداخل او تكرار بين انشطة الوحدات . التداعيات المحتملة او المتوقعة عن حدوث السيناريو المرجعى والتى تثمل ما يلى : • احجام مؤسسات المجتمع عن الافادة من خدمات الوحدات ذات الطابع الخاص • انفصال الخدمات الجامعية عن الاحتياجات الفعلية للمجتمع. • ضعف جهود الوحدة في تعريف المجتمع بخدماتها. قلة الاهتمام بتقديم معلومات عن مزيا الخدمات المقدمة مقارنة بالجهات الاخري. قصور في بعض الجوانب المتعلقة بادارة الوحدات ذات الطابع الخاص. ضعف قرة الوحدات علي قياس رضا المستفدين. تعقد الاجراءات الادارية. ندرة اختيار العاملين في الوحدة في ضوء معايير عملية بل الاختيار يكون لاعتبارات شخصية . لأن قـة تدريب القيادات المرشحة للعمل بالوحدات ذات الطابع الخاص علي الامور الادارية والمالية والتسويقية . ندرة عقد دوارات تدربية للعاملين بالوحدة لرفع كفاعتهم وتعريفهم بطبيعة الادوار المنوطة بهم لتيسير العمل المستفدين الامر الذي يساعد علي استقطاب عدد اكبر من المستفدين واستمرار تعاملهم مع الوحدة . 


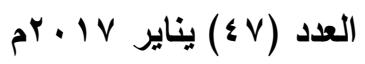

مبردات تنقيذ السيناريو المرجعى:

هناك مجموعة من العوامل / المبررات التى تدعو الى استمرارية تنفيذ هذا السيناريو من

أهمها

جمود التشريعات المالية والادارية .

• الجمود الاداري وعدم الاتصال بالمجتمع - •

• ضعف تقبل اعضاء هئية التدريس والمسئوولين بقلة ملائمة التوجه التسويقي للمؤسسات الجامعية علي اساس ان الجامعات مؤسسات غير ربحية ويمكن التظلب علي ذلك من خلال التركيز زيادة الوعي باهمية تسويث الخدمات الجامعية ويتم ذلك عن طريق عقد التدوات واللقاعات والدورات التدريبة لاعضاء هئية التدريس للتوعية باهمية التوجه التسويقي بالوحدات ذات الطابع الخاص التابعة للجامعه وتغيز اتجاهاتهم السلبية نحو

تسويث الخدمات الجامعية .

تفضيل الجهات المستفيدة التعامل مع المؤسسات الخاصة ويرجع ذلك الى ضعف ثقافة المشاركة المجتمعية ، غياب ثقافة التثمية الاجتماعية ، الخصام بين الجامعة والمجتمع المدنى نتيجة الاعتقاد بالبرج العاجى للجامعة وضعف الايمان بلور البحث العلمى فى التطوير وتحسين الانتاج والخدمات.

ثانيا :السيناريو الاصلاحى:

يحمل هذا السيناريو توقعات بالاصلاح ، وينطلق من افتراض يتجه الحى اصلاح الاوضاع الراهنة ، وليس تغييرها بشكل جذى ، وذلك بهدف تعميق الايجابيات الموجودة بالفعل فى الواقع ، ويظلب على هذا الاتجاه الاصلاح الجزئى ، ومعالجة المشكلات بعد تراكمها ، ويتضمن هذا السيناريو تحسين الاوضاع الراهنة دون ان يؤدى ذلك الى اعادة الهيكلة ، مما يؤكد على وجود صراع بين اتجاه التطوير واتجاه بقاء الاوضاع على ما هى عليه من اجل الاستقرار - الم

وسيتم تناول السيناريو الاصلاحى من خلال ما يلى :

الافتراضات الاساسبة للسنياريو الاصنلاحى):

• الاعتماد علي اكثر من وسيلة ترويجية لتعريف المجتمع بالخدمات المقدمة من قبل الوحدات الجامعي ويمكن ارسال مجموعة من المطبوعات التي توضح الخدمات التي 


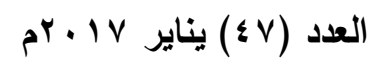

تقدمها الوحدة والتجهيزات المتاحة لكل الجهات المستفيد مع الاخذ في الاعتبار مدي

مناسبة الوسيلة لخصائص المستفيدين واختيار الوقت المناسب لتقديم الرسالة . • التعريف الي الجهات المنافسة وما تقدمه لجذب عدد اكبر من المستقيدين سواء كان ذلك

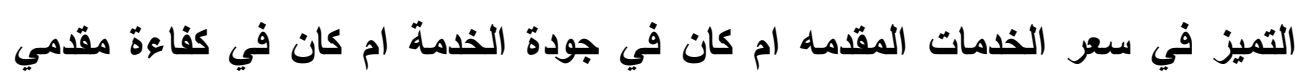
الخدمة.

• التسويق لصورة الجامعة من خلال تعريف قطاعات المجتمع بانجازاتها وطبيعة خدماتها

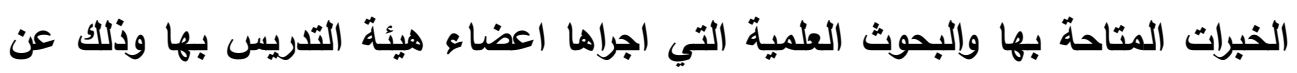
طريق اقامة الندوات والمؤتمرات ووسائل الاعلام وعدم الافادة من دور الاعلام في لهي

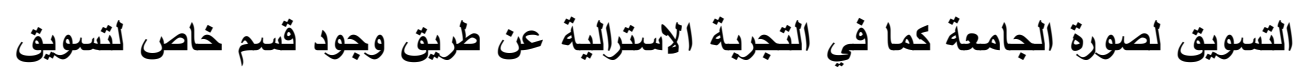
صورة الجامعة للمجتمع. • الاهتمام بجودة الخدمات المقدمة من الوحدات ذات الطابع الخاص بالكليات و استقطاب الكفاءات للعمل بالوحدة و الاهتمام بتوفير التجهيزات اللازمة لقيام الوحدة بمهامها مثل بهات

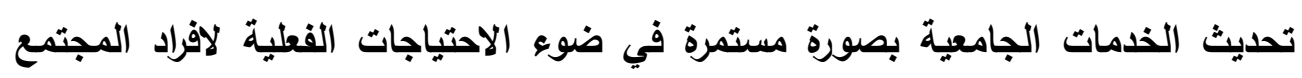

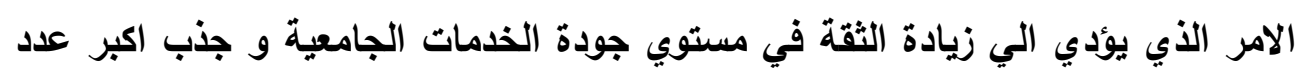
من المستفيدين. • انشاء وحدات ذات طابع خاص متذاخلة التخصصات بلالا من التركيز علي انشاء وحدات ذات طابع خاص متخصصة والتي غالبا ما يناظر احد الاقسام العلمية وهذا يسهم في قدرتها علي الاسهام في حل المشكلات المعقدة التي يتطلب حلها التعامل مع تخصصات عديدة . ع • التحديد الاقيق للمستفيدين من الخدمات التى تقدمها الوحدة و تصنيفهم الى قطاعات بالنسبة لكل خدمة فى حالة الوحدات التى تقوم بأكثر من نشاط و دراسة خصائصهم و اتجاهاتهم نحو الخدمات الجامعية.

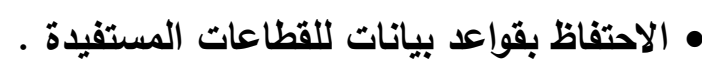
• استخدام الاليات التى يمكن عن طريقها التعرف الى احتياجات المجتمع مثل تنظيم الندوات التهات

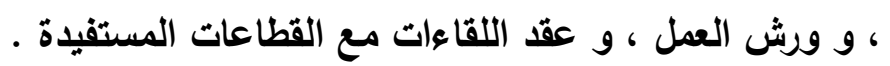




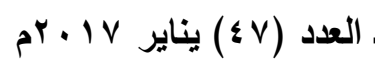

• وجود ممثلين من الجهات المستفيدة في مجالس ادارة الوحدات للتعرف الي احتياجتهم

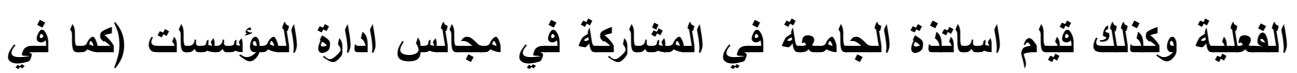

$$
\text { التجربة الامريكية. }
$$

• تقديم الخدمات التي تتوافق مع الاحتياجات الفعلية للمستفدين ويتم ذلك عن طريق التفايق التحسين لجودة وتعديل الخدمات في ضوء تغير احتياجات الفئات المستفيدة .

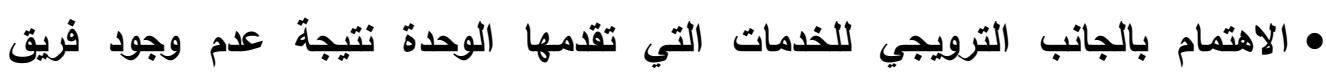
متخصص مسئوول عن ترويج خدمات الوحدة . • الاهتمام بتمية وعي العاملين باهمية حسن التعامل مع المستفيدين وتزويد هم بالمطومات المدات اللأزمة للرد علي استسفارات المستفيدين.

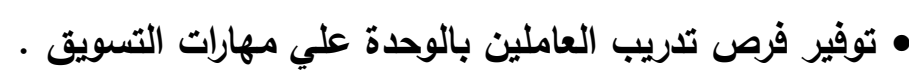

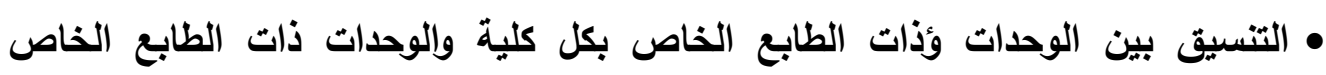
الاخري بحيث لا يحدث تداخل او تكرار بين انثطة الوحدات.

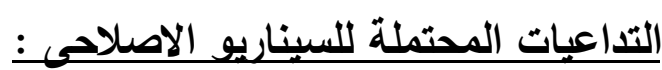
• تسويق البرامج التعليمية و البحثية و المشروعات و التدريب على السن التس اقتصادية تنافسية .

• الحصول على عدد كبير من المنح و الدراسات و المشروعات الحكومية .

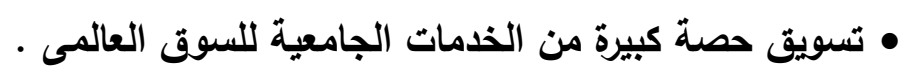

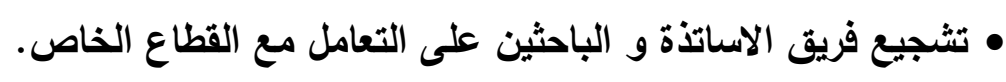

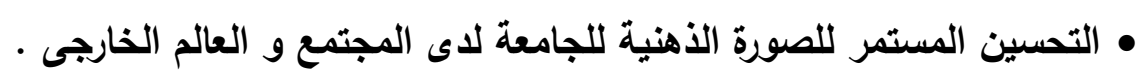

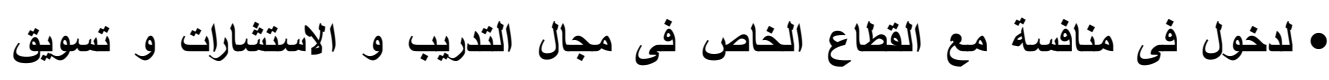

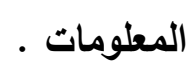

• بيع عدد كبير من الاختراعات و البحوث التطبيقة لقطاع الاعمال الخاص.

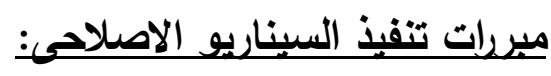

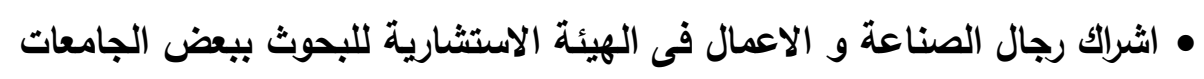

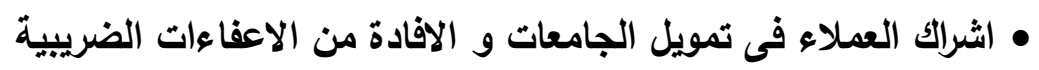
• فرض رسوم اضافية على الطلاب الاجانب 


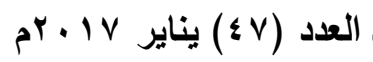

• تقديم برامج تدريبية تدر دخلا احقاقيا و برامج لتعليم الكبار • اجراء تعاقدات المؤسسات الحكومية و غيرها و فرض رسوم استشارية و خدمات مدفوعة

الاجر

• جمع فريد من المنح و التبرعات لتحسين الخدمة التعليمية ثالثا : السبناريو الابتكارىى

يرتكز هذا السيناريو على التحول الكيفى فى ممارسات واجراءات تسويق الخدمات التعليمية بالجامعات ، وهو لا يركز فقط على فهم ايجابيات المناخ الجامعى ، وانما يمتد الى حفز الطاقات الابداعية الموجودة فى الجامعات ومنافد تسويقها على نحو يؤدى الى اسثثمارها - الاستثمار الافضضل

$$
\begin{aligned}
& \text { وتتمثيل مظاهر السيناريو الابتكارى فيما يلى : } \\
& \text { الافتراضات الاساسية للسيناريو الابتكارى : }
\end{aligned}
$$

• توفير حاضنات تكنولوجية لتحويل نتائج البحوث الى مشروعات ناجحة و هى مشروع تعاونى بين الجامعة و الحكومة بمشاركة القطاع الخاص .

• انشاء وكالات البحث و هى مؤسسات تعمل كوسيط بين الجامعة و قطاعات الاعمال وظيفتها تحديد المشاركة لتوجه المؤسسات الصناعية و احتياجاتها من البحوث اللازمة (لملها ) • عمل متززهات العلوم و هى مناطق مجهزة ملحقة بالجامعات تقوم الجامعات بتقسمها لبيعها او تأجيرها لاصحاب المشروعات التجارية و الصناعية التى تعتمد على نشاط البحوث بالجامعة لانتاج الادواث و الاجهزة المختلفة . • توافر ما يسمى بالرعاية او تتبنى مؤسسة او اكثر الاثراف المادى على الجامعاث او الكليات فى مقابل بعض الفوائد مثل الاعتراف برعاية المؤسسة فى لوحة كبيرة توضع فى الجامعات تمكين المؤسسة من عرض بعض المنشورات عن منتجاتها الارشادية بالمؤسسة الراعية كل عام فى مجلة الكلية هذا بالاضافة الى الفائدة المتبادلة التى تعود على الجامعة من مشوره الخبرات بخصوص المنتجات الصناعية و تسويث الجامعة

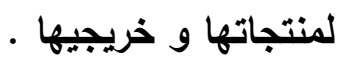




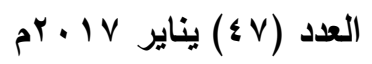

• توافر المشروعات التى تتبناها الجامعة او الكلية حيث توفر فرص لتدريب الطلبة

$$
\text { والعاملين و يشارك اعضاء هيئة التدريس ( لقاءات - ندوات - بحوث - استشارات ) }
$$

• توفير البحوث التعاقية التى تلجأ بها المؤسسات الى الجامعة لمساعدتها فى تلى تلثيل العقبات التى تواجهها عن طريق الابحاث التى تقدمها الجامعة و نمول المؤسسة الباحث. • تقدم الجامعات على انشاء مركز بحوث بوجه لقطاع صناعى معين يتولى علاج المشاكل

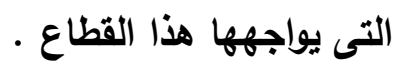
• انشاء مركز لمنح تراخيص لاعضاء هيئة التدريس و الباحثين فى الجامعة للحصول على هلى هلى ترخيص تسجيل اختراعات و البحث عن منافسة تجارية لنتائج الابحاث .

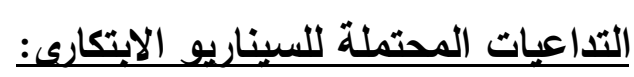
• إنشاء نظام لجمع البيانات لتحديد الاحتياجات التعليمية أو الخدمات للقطاعات المختلفة بالمجتمع ثم تصنيفها، وتوزيعها على المراكز الخاصة بشئون خدمة المجتمع للمساهمة الماتهات في الوفاء بها. • تقديم خدمات استشارية في المجالات الآتية: التخطيط الاستراتيجي للمشروعات، وتصميم، وتتفيذ المشروعات، وإداراتها. • تحسين إجراءات العمل في الجامعة، وهذا يعني معاونة الجامعة على مواجهة التحديات التي تواجهها مثل إرتفاع تكاليف العملية التعليمية، ونقص الموارد، وارتفاع مستوى الخدمة المتوقعة، وغيرها. • تقديم برامج أكاديمية عديدة مع التأكيا على تقديم تعليم عالي الجودة في المرحلة الجامعية الأولى والدراسات العليا، وكذلك برامج التنمية المهنية.

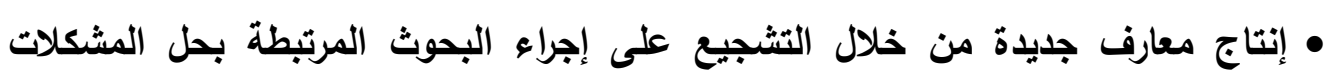
المجتمعية التي تستجيب لاحتياجات المجتمع على المدى الطويل.

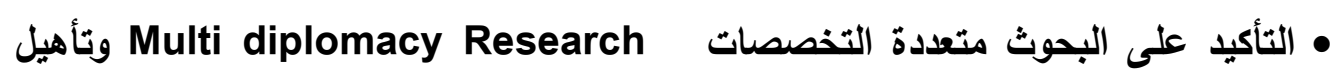
الدارسين ليصبحوا متخصصين في مجالاتهم، وذلك من خلال تظوير قراتهم على استخدام المعارف، لمنفعة المجتمع. 
العدد (\&) يناير IV

• المساعدة في عقد لقاءات بين العاملين بالثركات، والمؤسسات وبين القيادات الجامعية واعضاء التدريس، والموظفين للمساهمة في نقل خبرات الجامعة للمجتمع المحلي من بن جهة، والتعرف على احتياجات، ومشكلات تلك المؤسسات من جهة أخرى.

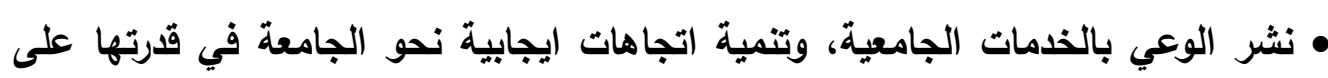
تحقيق التطوير في المجتمع. • تقديم معلومات مفصلة عن البحوث التي تقدمها الجامعة، وتحفيز الشركات، والمؤسسات

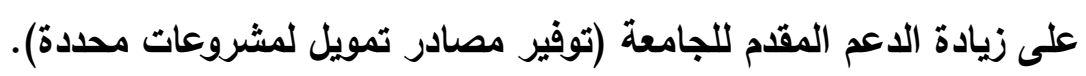

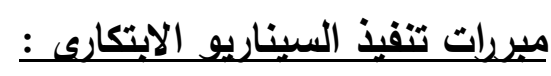
• مراجعة الهيكل التنظيمي للوحدات التابعة للجامعة، ومهام كل وحدة، والأدوار، والمسؤوليات؛ لتحديد فرص التوسع في السوق، ويتم ذلك بمساعدة فريق عمل متخصص، وياستخدام عدد من الأدوات منها (SWOT) الأي يساعد في تقييم الوضع الحالي لتلك الوحدات؛ لتحديد التوجه المستقبلي لها. • مشاركة رجال الصناعة فى مجالس ادارات الكليات و مراكز البحوث و المشاركة فى وضع

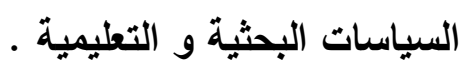

• توافر مقياس جودة الخدمات لقياس مدى رضا المستفدين من الخدمة . .

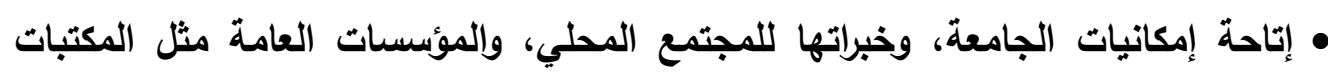

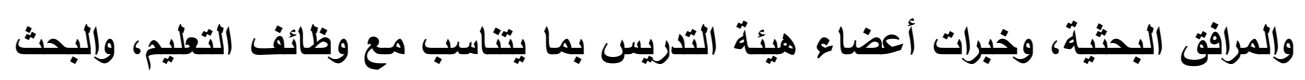
العلمي التي تقوم بها الجامعة. • المساهمة في التنمية الثقافية، والاجتماعية، والاقتصادية وذلك من خلال تقديم بلامدامج متميزة في مختلف المجالات استجابة لاحتياجات الولايات المتحدة، والعالم ككل بصفة ولاعة ولهاديه عامة. مئمة • التعاون مع الهيئات الحكومية، وغير الحكومية، ومع المؤسسات التعليمية الأخرى، ومع المؤسسات الصناعية، والاقتصادية. • اقامة شراكة بين المؤسسات التجارية و الصناعية و الجامعة . . 


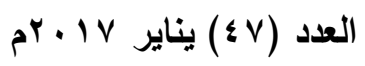

• ظهور مفهوم صداقة المستهلك حيث نوفر كل احتياجات المستهلك و رغباته للانضمام و الرضا عن الخدمة التعليمية بها نقاط القوة التي تمتاز بها الوحدات ذات الطابع الخاص

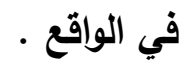

• ريط وظيفة خدمة المجتمع باحتياجات المجتمع و الفئات المستفيدة من تلك الخدمات

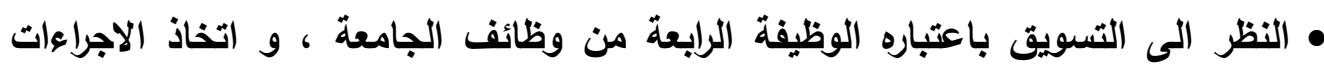
القانونية و التشريعية و التنفيذية التلازمة لتفعيل ذلك. باعنه • نشر ثقافة التسويق بين افراد المجتمع الجامعى باعتبار عملية التسويق مسئولية كل

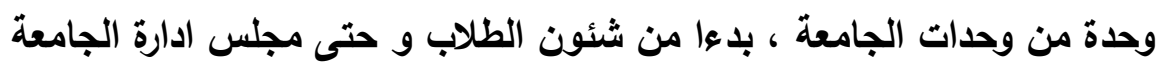
• الاستفادة من تكنولوجيا المعلومات و الاتصالات فى التسويق الالكترونى للخدمات

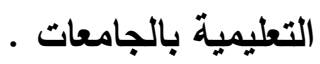
• وضع خطط خمسية و سنوية لتسويق الخدمات التعليمية بالجامعات بهاف التسويق المحلية و الاقليمى و الدولى للخدمات التعليمية ، و ربط هذه الخطط بالخطط الاستراتيجية للجامعات

• القيام ببحوث تسويق تهف الى التعرف على احتياجات العملاء من الطلاب و اولياء الامور و كذا مؤسسات اللمجتمع المدنى الخدمية و الانتاجية.

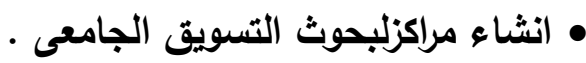
• تجزئة اسواق الخدمات التعليمية الى قطاعات لقياس الحاجات و الطلب المستقبلى على الخدمات التعليمية بالجامعات . الجماته • استفادة الجامعات المصرية من الفرص التسويقية المتاحة محليا و اقليميا ، من خلال الاهتمام بدراسة احتياحات السوق المحلى و الاقليمى و العالمى من الخدمات التعليمية

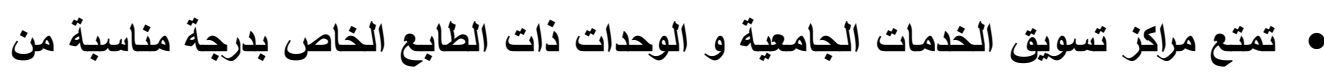
الاستقلال المالى و الادارى.

• تنمية الموارد البشرية للجامعات المصرية بما يمكنها من تقديم خدمة تعليمية متميزة.

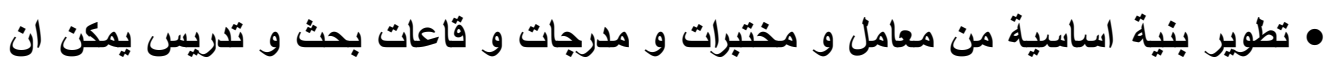
تسهم فى تقديم خدمة تعليمية متميزة . 


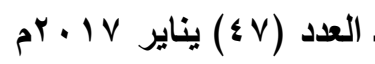

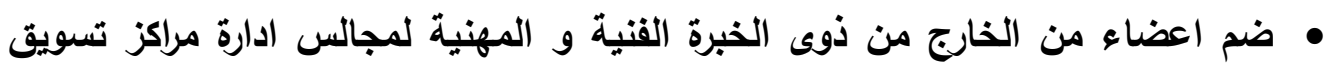
الخدمات بالجامعات المصرية. • توافر علاقات تنظيمية بين مراكز تسويق الخدمات الجامعية و الوحدات ذات الطابع الخاص المختلفة بالجامعة المصرية . التتسيق و التعاون و التكامل و تبادل الخبرات بين مراكز تسويق الخدمات المختلفة بالجامعات المصرية . • ت توافير الكوادر التسويقية المتخصصة فى تسويق الخدمات التعليمية بالجامعات. • تنويع و زيادة حجم الخدمات التعليمية التى تقدمها الجامعات الحكومية المصرية. • تطوير مزيج تسويقى للذدمات التعليمية بالجامعات قادر على المنافسة محليا و اقليميا و دوليا.

• تقديم خدمات تعليمية تركز على السلوكيات و المهارات الى جانب تركيزها على المعارف

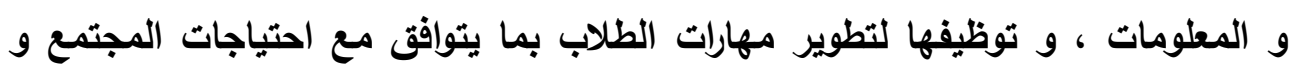

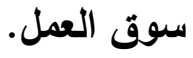
• التركيز على الخدمات التعليمية المستحدثة و التى تركز على استخام تكنولوجيا المعلومات و الاتصالات كالتعليم عن بعد و التعليم الافتراضى .

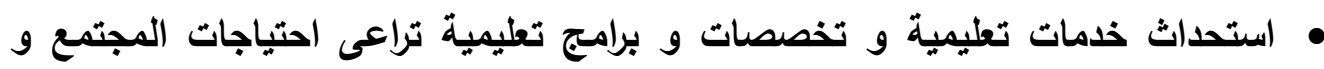

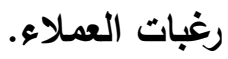
• قيام شراكات بين مؤسسات المجتمع المدنى و الجامعات بهدف تبادل الخبرات التسويقية للخذمات التعليمية بين الجانبين. • استخام الاساليب التكنولوجيا المعاصرة فى برامج الخدمات التعليمية بالجامعات.

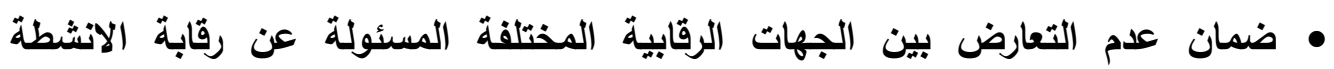
التسويقية بالجامعات.

• تطوير نظم لتقويم برامج الخدمات التعليمية من وجهة نظر المستفيدين منها. • التركيز على ضمان جودة الخدمات التعليمية و التحسين النمستمر بهاف ارضاء التهاء العملاء من الطلاب و اولياء الامور و مؤسسات المجتمع الخدمية و الانتاجية. 


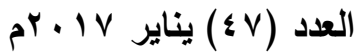

\section{المراجع}

1. Jianguo liu, "Factors influencing Students' choice of selected private universities in china, "un publish PhD. Dissertation, Department of Educational leadership and Foundations, Brigham Young university, Brigham 2005, PP 45-46.

r. أحمد إسـماعيل حجى؛ حسـام حمدى عبد الحميد، الجامعـة وإلتنمبـة البشـرية أصـول نظريـة

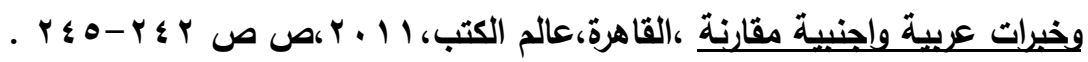

r. عمر نصير مهران رضوان ،إدارة تسويق الخدمات التعليمية:العليات ومتطلبات التطبيق ،ميلية

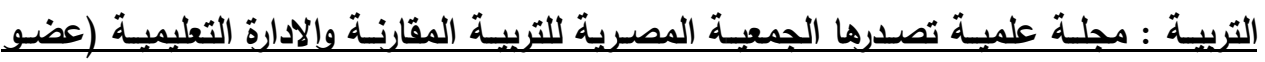
المجلس العالمى لجمعيات التربية المقارنـة)، السنة الرايعة عشر ،العدد الواحد والثثلاثون،بنبراير

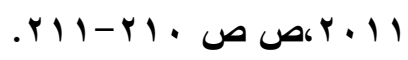

؛. عمر نصير مهان وأخرون،الإدارة والقيادة التريوية ، مراجعة عادل عبد الفتاح سلامة، القاهرة ،

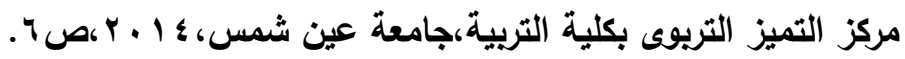

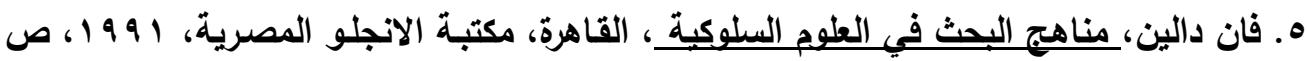
$.1 \leq 1$

7. ضياء الدين زاهر، الدراسـات المستقبلية ، منـاهج وأسـالبيب وتطبقات، القاهرة، المركز العربي

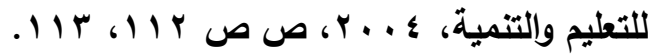
V. أمين عبد العزيز حسن، استراتيحيات التسويق في القرن الحادي والعشرين، القاهرة، دار قباء

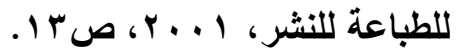

8. American Marketing Association: Definition of Marketing, Available Online at:http://www.marketingpower.com/ARC/pages/Community/Additiona 1/Definition/default.aspx(Accessed May 2011)p6.

9. David G. Tolks and Marc Farr. Market Segments for Higher Education Marketing Intelligence and planning. Vol 13. Issue 4, New York, 1995.p245

10. Jirawan Kaolmarsratana, "An Application of Marketing In higher Education In Thailand: A Case Study of Private Diversities "unpublished PhD Dissertation The graduate Faculty, Oklahoma state university, Oklahoma 2002, P.18

11. jirawan Kaolmasratana, op.cit. P.19. 


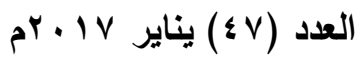

12. L. Michelle Morris, Integrated Marketing: the Process and Challenge Implementing this Evolving Concept at three Private universities, unpublished PhD Dissertation, The Graduate Faculty. Texas Tech: university. Texas 2003. P27.

13. Robert Stefko, The Marketing of university, analyzing the organizational Markets, and the student Recruitment Process 2003, Available

http://www.wshifm.edu.P1/uploadedfiles/FCIC/File/O20\% VCZelni/ope re/archiwum/no2. (Accessed: (11/4/2008).

ـ ا ـمحد صبري حافظ وآخرون، المشكلات التظيمية لتسويق الخدمات الجامعية في بعض كليات

جامعة الأزهر، دراسة الخدمات الجامعية في بعض كليات جامعة الأزهر، دراسـة ميدانية مجلة

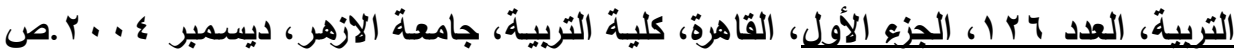

$$
\text { 19^-107 ص }
$$

15. Natavud Pimpa, Marketing Australian universities to their students, journal of studies in international Education, Vol 9. No. 2 . 2005. p36

16. Ann Pegoraro, using university websites for student Recruitment : A Study of Canadian diversity home Pages Examining Relationship Marketing Tactics and website usability, unpublished PHD Dissertation The Faculty Of The Graduate Collage The university Of Nebraska, Lincoln, 2006.p20

V اشيرين حامد ، نموذج مقترح لقياس جودة الخدمات التعليميـة بالتطبيت على مؤسسات التعليم العالى فى مصر ،المجلة المصربية للارسات التجارية ،كلية التجارة- جامعة المنصورة ، السنة

$$
\text { r r }
$$

1 ا ـنهلة عبد القادر هاشم ، مستقبل تسويق المؤسسـة التعليمية الثانويـة العامـة فى مصر ، مجلـة التربية :محلة علمية محكمة تصدرها الجمعية المصرية للتربية المقارنة والادارة التعليمية ، السنة

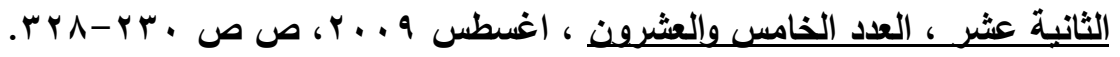

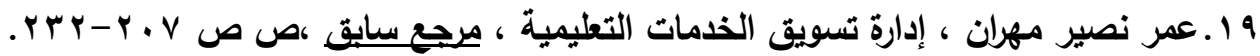
• • . جيهان محمد شفيق ، تصميم مقياس جودة الخدمات التعليمية للتعليم العالى " روئة واقعية" ، المؤتمر الدولمى العاشر للجمعية العربية لتكنولوحيا التربية بعنولن : أفاق فيى تكنولوحيا التربية في

$$
\text { القترة من }
$$

ا ـ أمين عبد العزيز حسن ، إستراتيحيات التسويق فى القرن الحادى والعشريذ ، القاهرة ، دار قباء

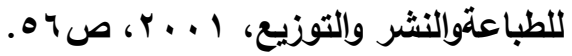


العدد (\&) يناير IV

r r.دعـاء محمد عبد القتاح جوهر ، التسـويق الإستراتيجى للمدرسـة الثانويـة العامـة فى مصر :

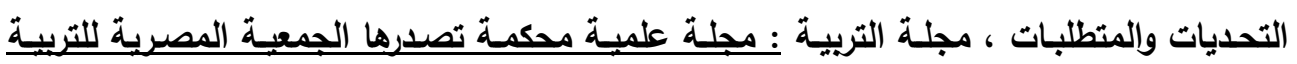

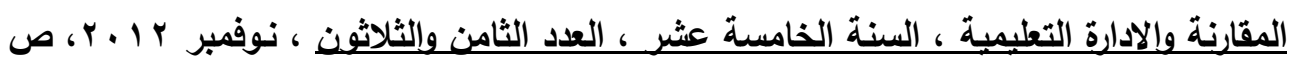

. $r \leqslant 0$

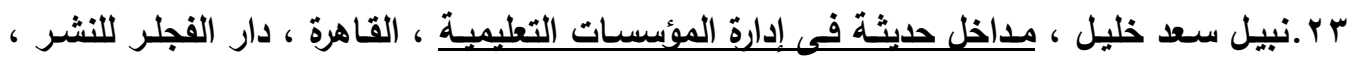
r r $r$ r. 10

؟ ؟.حسام حمدى عبد الحميد ، نظام مقترح لتسويق تخصصات الاراسـة باللغة الاجنبية بالجامعات

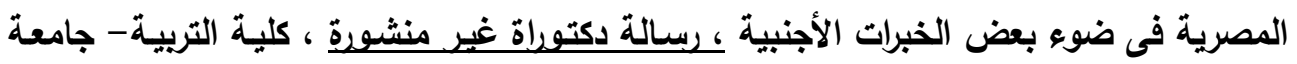

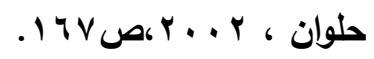

25. A. Ivanovic And P.H. Collin. Dictionary of Marketing Third Edition London Blooms bury Publishing PLC. 2003. P 167.

26. Cary L. Cooper and Chr.s Argryris. The Concise Black well Encyclopedia of Management (oxford Black well Business Publishers, 1998. P.204.

27. A. Ivanovi And P.H. Collin, Op . cit, PP245, P246.

^ץ.سيد محمد جاد الرب ـ إدارة الجامعات ومؤسسـات التعليم العالي استراتيجيات التطوير ومناهج

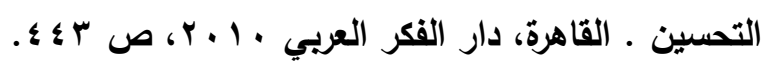

29. 1 -A accessed June 20,2014 Http://webhost.bridgew.edu/adirks/old/papers/mktheor.htm.

• . . أحمد إسماعيل حجي وحسام حمدي عبد الحميد ،الجامعة والتتمية اصوال نظريـة وخبرات عربيـة

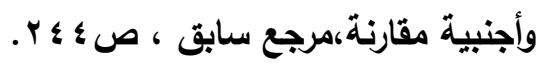

31. Ramneek Kapoor et al ,Services Marketing :Concept \&Practices ,New Delhi :Tata McGraw-Hill Education,2012,p12.

32. Kenneth B .Kahn ,Product Planning Essentials ,United States:M.E.Sharpe,Inc,2011,p12.

rr.مجدي المسيري ،المدخل الاستراتيجي لتسويق الخدمات الجامعيـة، (بحث مقدم إلـي المؤتمر

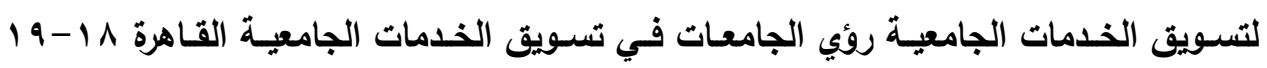

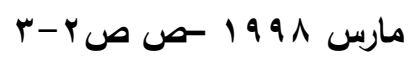

ـ ז.إبراهيم صديق علي ،تسويق الخدمات الجامعية بين عرض المتاح والاستجابة لها هو مطلوب

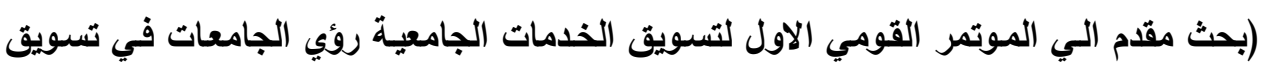

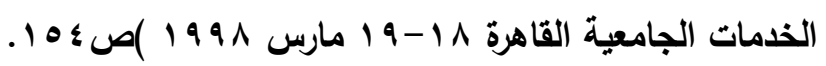


العدد (\&) يناير IV

35. Molete Moseki, "Segmentation The Consumer market ,"in Introduction To Marketing,3ed,south Africa :juta and company Ltd,2005.p64-65.

36. Mukee Neil, Social Mobilitization and Social Marketing in Developing Communication: Lessons For communicators ,Malaysia :Southbound publishers, 1993,p9.

37. Bruce j. Walker et al, Fundamentals of Marketing, New York:Mcgraw-Hill.inc,1994.p169.

^r. هناء عبد الحليم سعيد ، ادارة التسويق : مدخل استراتيجى ، القاهرة ، دار النهضـة العربية ،

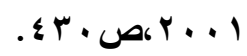

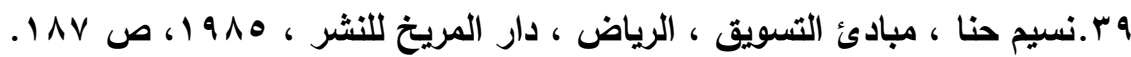

40. Michael J.Baker, Marketing Strategy and management ,2 ed ,London: Macmillan press.Itd,1992,p405.

41. Linda Pinson, Anatomy of aBusiness plan:astep by step- Guide to building Abusiness Securing your company's Future,5 ed ,United States : Dearborn Trade publishing,2001,p 38

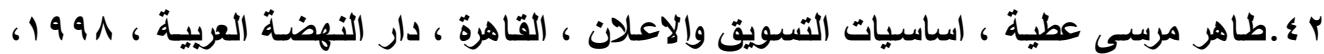

$$
\begin{aligned}
& \text { ص }
\end{aligned}
$$

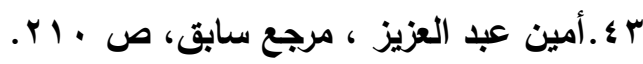

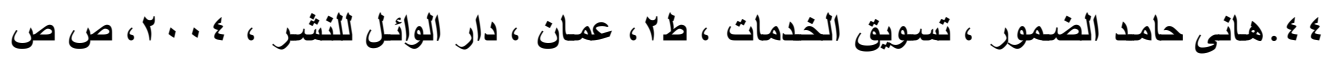

$$
\text { .r|N-r|Y }
$$

45. Raymond p.Fisk et al,Interactive services Marketing ,Boston : Houghton Mifflin Company,2008,p 119-122.

46. Philip Kolter ,Marketing Management ,Millen Edition ,New Jersey: practice-Hall, INC,2000,p279

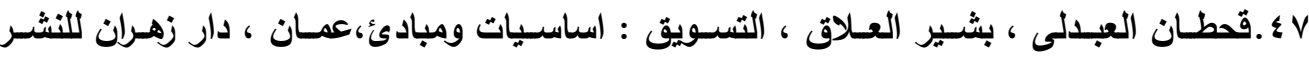

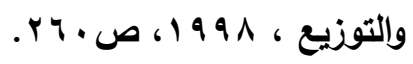

48. .Paul Peter and Jammes H.Donnelly,Marketing Management Knowledge and Skills,9 ed Pennsylvania: McGraw-Hill Higher education,2008,p111.

9 ـ ـ الثد القصبى ، استثمار وتسويق البحث العلمى فى الجامعة ، مجلة مستقبل التربية العربية ،

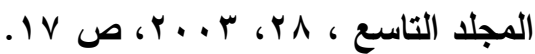

50. julian Dent, Distribution Channels: Understanding and Managing channels to market,2ed,London: kogan page publisher,2011,p11 
العدد (\&) يناير IV

51. Philip Kotler and Gary Armstrong Marketing - Twelfth Edition Education international, 2008.p12

52. Michael J. Etzel and others, Marketing. Fourteen Edition, London, M.C Grqw Hill, 2007. P.563.

53. Tapan K. Panda ,Marketing Management :Text And Cases .India :Excel Books,2009.p6

54. Lester Massingham and Geoffrey Lancaster, Essentials of Marketing Management ,London ,Routledge,2010,p19.

55. Rajan Saxena, Marketing Management, 3rd ed (New Delhi: Tata McGraw - Hill Publishing Company Limited, 2005),p 508.

56. Kenneth E. Clow and Donald Back, Integrated Advertising, Promotion \& Marketing Communications, 2nd ed. (New Jersey: Pearson Prentice Hall, 2004), 68-69.

57. Norton Paley, The Marketing Strategy Desktop Guide (London: Thorogood Publishing, 2007), 102-105.

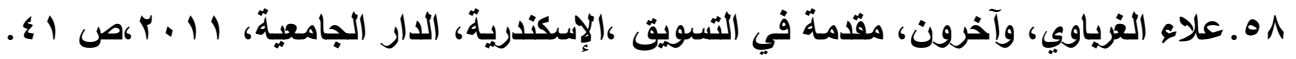

59. K, Rama Mohana Rao, Services Marketing, 2nd ed (New Delhi: Pearson Education, 2011), pp192-194

60. . Strydom Johan,ed,Introduction To Marketing ,United Kingdom:Juta Academic Ltd,2004.p22.

61. Philip Kolter and other, Princoples of Marketing Eighth Edition New York Prentice Hall Inc 1999. P.116.

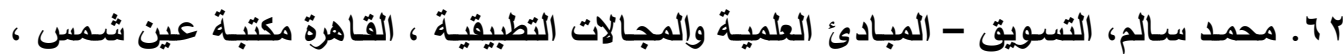

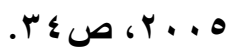

63. - Rajan saxena , marketing management ,3rd ed ( new Delhi : Tata McGraw - hill publishing company Limited,2005),p508 )Kenneth E. Clow and Donald Back,

64.

65. integrated advertising, promotion \& marketing communications, 2nd ed. ( new jersey : Pearson prentice hall , 2004 ),pp 68-69

66. Philip Kotler and Gary Armstrong. Op. cit. P53.

67. k.rama moahana rao ,services marketing,2nd ed ( new Delhi : Pearson education ,2011),pp192-194.

68. Michael D. Hartline and O.C Ferrell, marketing management sterategies,5th ed ( south-western : cengaga learning, 2011),p323 1

69. Philip kotler and Karen.F.A. fox, strategic marketing for educational institutions ( new york : prentice - hall inc. Cliffs ,1995),p23.

70. meenakshi gupta, principles of management (new Delhi : Phi learning private limited,2009),p211. 
العدد (\&V) يناير IV

71. M. Govindarajan and S. Natarajan, Principles of Management (new Delhi : Prentice- Hall, 2005),p 1

72. Paul Szwarc, Researching Customer Satisfaction Loyalty (London: Kogan Publishers, 2005),p 6.

73. George William R., "International Marketing and Organizational Behavior Partnership in Developing Customer - Conscious Employees At Every Level, “ Journal Of Business Research, 1 (1990),pp 63-70.

74. Mulkherjee. P. N., Total Quality Management (New York: Prentice Hall. 2006), p40.

75. Poornima M. Charantimath, Total Quality Management (Singapore: Pearson Education, 2003), p236.

76. "Academics" Accessed july 19, 2014 http://www.wisc.edu/academics

77. "UW-Madison research expenditures top the \$1 billion mark " Accessed july 19, 2014 http:/www.news.wisc.edu/18499

78. mission statement " Accessed july 20, 2014,

79. http://www.wisc.edu/about//leadership/mission.php

80. "small Business Development Center" accessed july 22,2014 http://www.bus.wisc.edu/cped/sbdc/programtopics

81. technology support center" accessed july 22,2014 http://www.bus.wisc.edu/about-us/admin/technology-support- servies

82. "wisconsin alumni association" accessed july 23,2014

83. http://www.uwalumni.com/home/waa/waa552.aspx

84.

85. university of Wisconsin- Madison on Wisconsin magazine " accessed july 25,2014http://www.uwalumni.com/news-stories/on-wisconsin

86. "office of quality improvement" accessed july 25,2014,

87. http://www.quality.wisc.edu/services.html

88. university communications and marketing " accessed july 27,20014

89. http://www.uc.wisc.edu

90. "corporation \& foundations" accessed july 27,2014

91. , http://www.support.uw.org/corporations-fundations

92. "foundations partnerships" accessed july 27,2014,

93. http://www.support.uw.org/corporations-foundation/foundation-partnerships

94. office of university relations "accessed july 29,2014,

95. http://universityrelations.wisc.edu/about-the-office/

96. "office of university relations" accessed july 29,2014,

97. http://universityrelations.wisc.edu/policies-and-guidelines

98. "mission statement accessed july29,2014"

99.

http://www.campagin.ox.ac.uk/priorities/students/mission_statement.h tml 


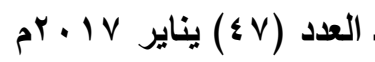

100. research strategy : accessed July 30.2014

101. strategic plan 2013 -18 accessed July 29.2014

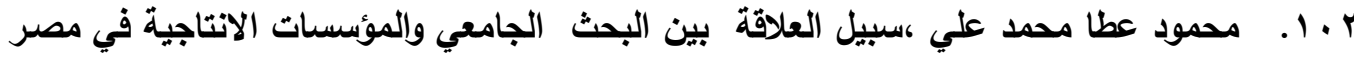

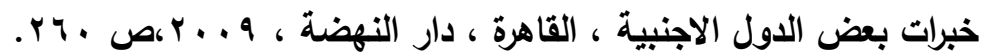

103.meet our consults accessed july 30.2014,http://www.isis innovation.com/ consulting/ MeetOurconsultants.htm1

104.scientific advisory board "accessed July 29.2014,http://www.isisinnovation.com/ consulting/casestudy-sabs.htm.

105.about isis enterprise "accessed july 29.2014,http:// www.isis/innovation.com/enterprise.

106."The Oxford Science Park "accessed july 29,2014,http://www.oxfordsp.com/about-history.asp.

107.deciding what right for you accessed july 31.20104 occpations /deciding-right -for -you

108.Pupil affairs offices",accessed july 31.20104,http://www.ox.ac.uk/puplic_affairs/ about_us/puplic_affirs_office/index.htm

109."Design \&Publications office" accessed july31,2014,http:// www.ox.ac.uk/public_affairs/about_us/design_publication_office/ind ex.htm.

110."News\& Information Office",accessed july 31,2014

111. http://www.ox.ac.uk/public_affairs/about_us/New

Information office/index.htm

112."Melbourne Engagement and Partnerships office",accessed August 2014,http:// memo.unimelb.edu.au/about_us.

113."Melbourn Research Services ",accessed August 2014 http:// mro.unimelb. edu.au/content"Melbourn Research Services

114.University Communications"accessed August 3,2014. http://msl.unimelb. edu.au/unicomms.

115. University Marketing , accessed August 5,2014,http://marketing unimelb.edu.au/about_us.htm1.

116."Career\&Employment "accessed August 9,2014 ,http://careers.unimelb. edu.au/ student.

117."General information"accessed August 11,2014.http://www.tsinghua. edu.au/ publish/newthuen.cnt/about_th/about_1 htm

118.http:/www.timeshighereducation.co.uk/word_university_ranking/21 3-2014/subject_ranking/subject/engineering-and IT.

119. "Local Coorperation"accessed August 11,2014,http://tsinghua.edu.au/ publish/newthuen_ont/research/reserch3-1 htm. 


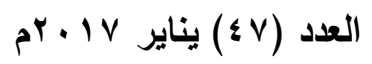

120. "Enterprisa Cooperation"accessed August 12,2014,http:// www://tsinghua. edu.au/publish/newthuen_ont/research/reserch3-2 htm..

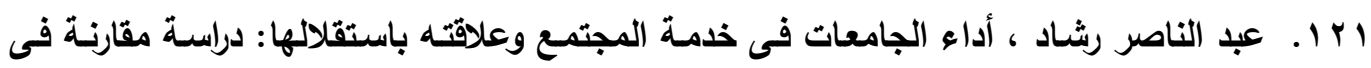

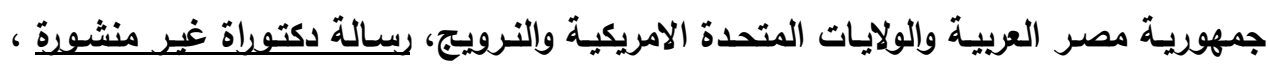

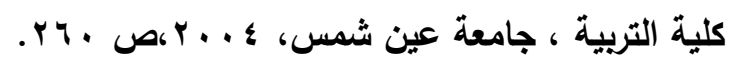

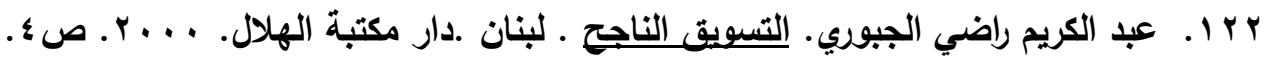

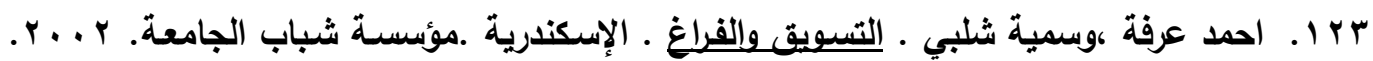
ص מזr

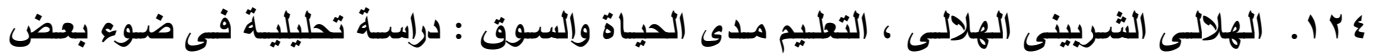

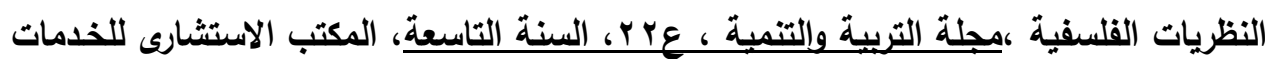

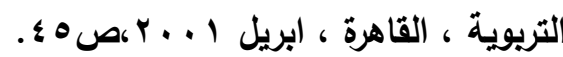

$$
\begin{aligned}
& \text { ه 1 ا. . هناء عبد الحليم سعيد، مرجع سابق، ص • 9. }
\end{aligned}
$$

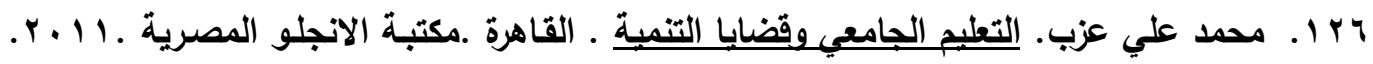

$$
\text { ص ص ז }
$$

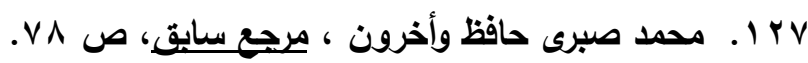

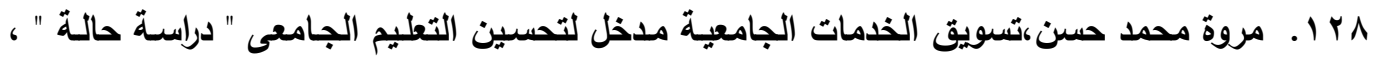

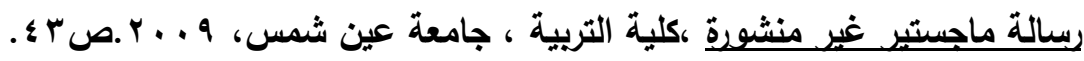

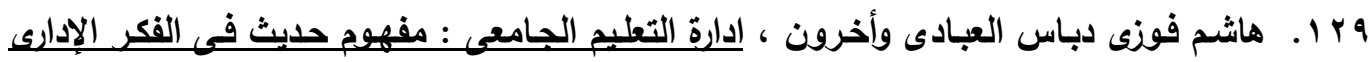

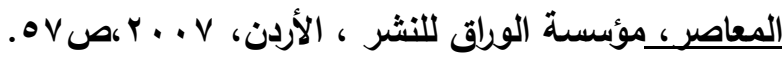
• r 1. محمد منير مرسي، الاتجاهات العديثة في التطليم الجامعي المعاصر وأساليب تدريسية ، القاهرة

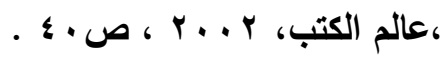

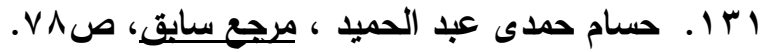

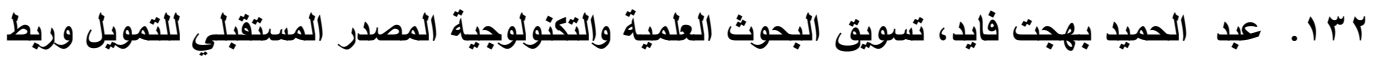
الجامعات بقضايا المجتمع (مؤتمر جامعه الزقازيق بغنوان الجامعة بين المتطلبات والامكانبات

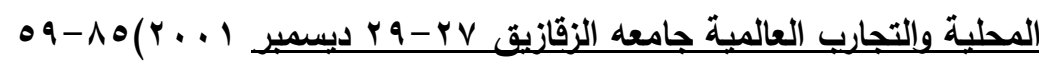

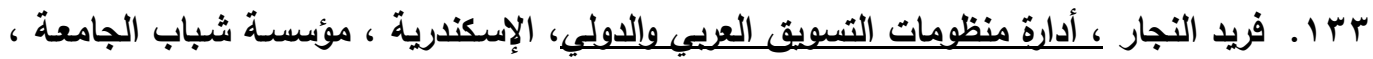

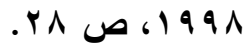




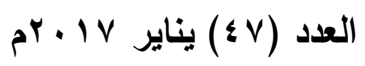

ع ب ا . راشـد القصبى ، أمسال العرباوى ، خصخصة التعليم الجامعى فى ضوء بعض التجارب العالمية

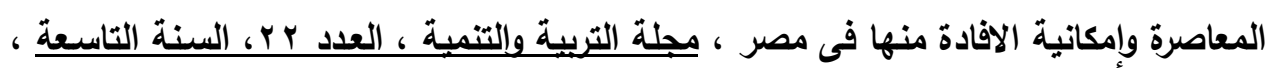

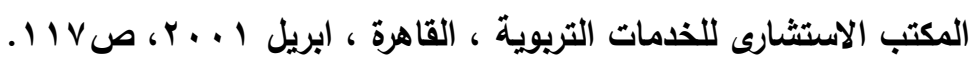
ه ب ا . فريــ راغـب النجـار، إدارة الجامعـات بـالجودة الثــاملة ، ايتـراك للنشـر والتوزيـع، القـاهرة ، . $r \Lambda_{\omega_{6}} r . .$.

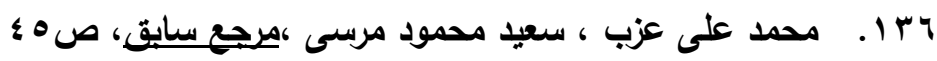

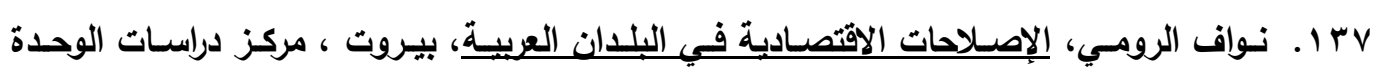

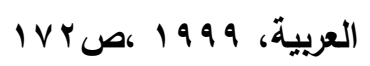
^ ז ا . عبد الرحمن أبو المجد رضوان، التعليّ الجامعي الخاص : الواقع وتحديات المستقبل النموذج

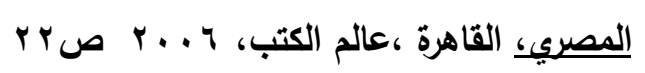

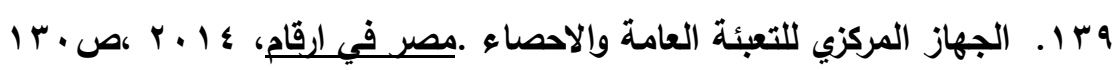
• ـ ا . حسين بثير محمـود " حول التعليم الجـامعي : افـاق جديدة في التعليم الجـامعي "ـ (المـوتمر

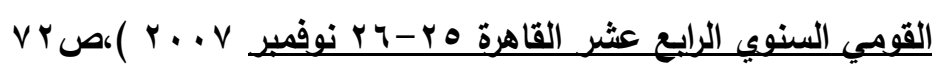

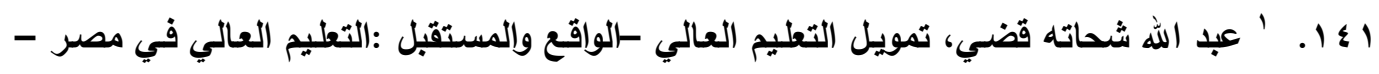
خريطة الواقع واستشراف المستقبل (المـوتمر السنوي الثامن عشر للبحوث السباسبة القاهرة

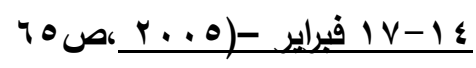
ץ ـ ا ـ أسامة مجاهد ورضوي صلاح واقع التعليم العالي والجامعي في مصر ــارسـة وصفية التعليم العالي في مصر التعليم العالي في مصر واستشراف المستقبل (الموتمر السنوي الثامن عشر للبحوث السباسبة القاهرة ع ع بـ ا ـ محيا زيتون، التعليم في الوطن العربـي في ظل العولمـة وثقافة السوق بيروت، مركز دارسـات

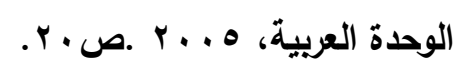
؛ ؛ ا . نادر فرجاني، التعليم العالي والعولمـة منظور مصري :التعليم العالي في مصر -خريطة الواقع

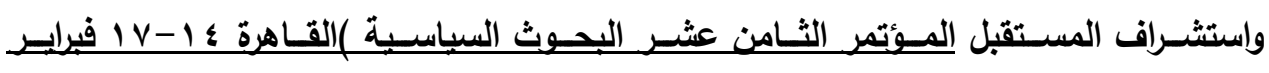

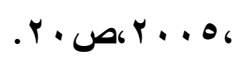

ه ؛ 1 . محمد على عزب ، سعيد محمود مرسى ، مرجع سابق ، ص 7V.

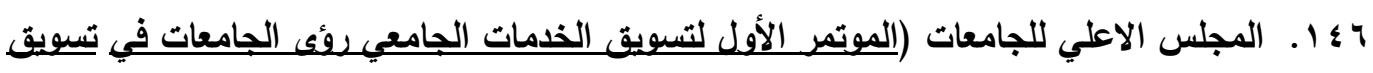
الخدمات الجامعية جامعه القاهرة 1 1-9 امارس 


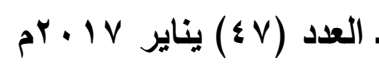

\section{ملحق رقم (1) مبردي}

أسماء السادة المحكمين مرتبة ابجيليا

\begin{tabular}{|c|c|c|c|}
\hline كلية التربية -جامعة & أتصناذ التربية الدقارنة والإدارة & أ.د/إبراهيم عباس الزهيرى & 1 \\
\hline كلية التربية -جامعة بنها & أتعتئاذ التربية المقارنة والإدارة & أ.ذد/ أحمد إبراهيم & $r$ \\
\hline كلية التربية -جامعة & أتعليتية التربية المقارنة والإدارة & أ.دد/أحمد إسماعيل حجى & $r$ \\
\hline كلية التربية - جامعة عين & أتعليتية التربية المقارنة والإدارة & أ.د/سعاد بسيونى & $\varepsilon$ \\
\hline كلية التربية - جامعة عين & أتعليتية التربية المقارنة والإدارة & أ.دد/ عادل عبد الفتاح سلامة & 0 \\
\hline كلية التربية - جامعة كفر & أستاذ التربية المقارنة والإدارة & أ.دد/ عبد الجواد بكر & 7 \\
\hline كلية التربية - جامعلة & أتعليتية التربية المقارنة والإدارة & أ.د/ فاروق شوقى البوهى & $\mathrm{v}$ \\
\hline كلية التربية - جامعة & أتعليتيةذ التربية المقارنة والإدارة & أ.دـ / نبيل سعد خليل & $-\Lambda$ \\
\hline كلية التربية - جامعة عين & أتعليمية التربية المقارنة والإدارة & أ.د/ نهلة عبد القادر هاثم & 9 \\
\hline
\end{tabular}

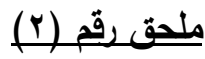

\section{السيناريوهات البيلة قيل التعديل}

أولا : السيناريو المرجعى: وهو الذى يعكس الوضع الراهن او يحافظ على الاوضاع الراهنة ، ويتضمن عرض السيناريو المرجعى ما يلى: الماني

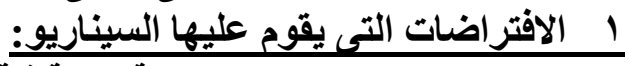

• ضعف التسويق لصورة الجامعة نتيجة قلتة تعريف قطاعات المجتمع بانجاز اتها وطبيعة خدماتها

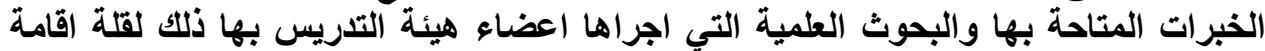

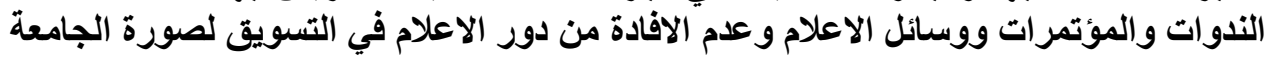

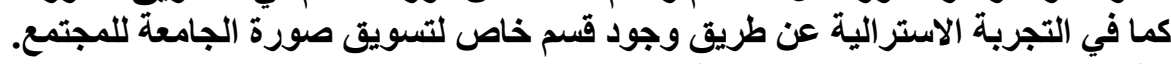

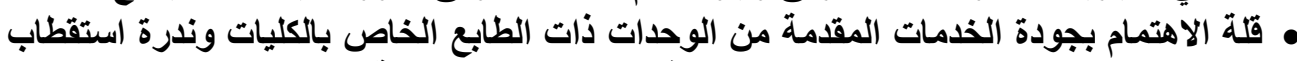

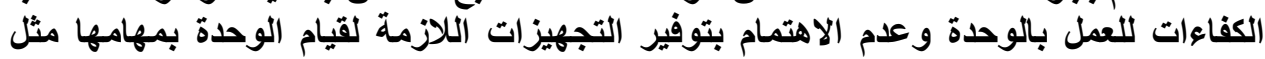

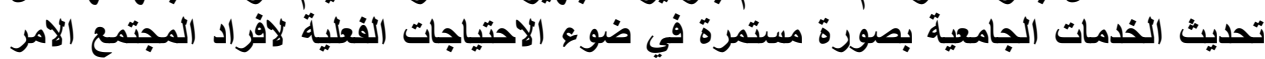

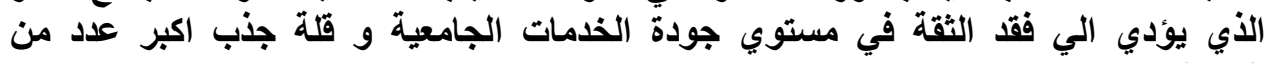

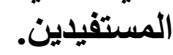
• ندرة انشاء وحدات ذات طابع خاص متاخلة التخصصات بلا من التركيز علي انثاء وحدات

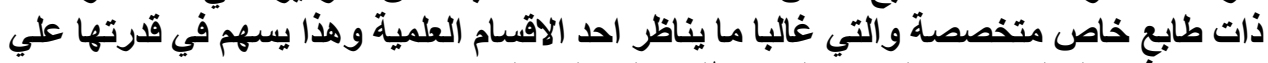

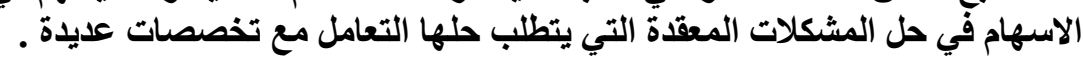




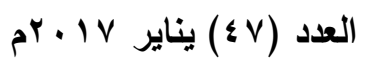

• عدم التحديد الاقيق للمستفيدين من الخدمات التى تقدمها الوحدة و قلة تصنفهم الى قطاعات

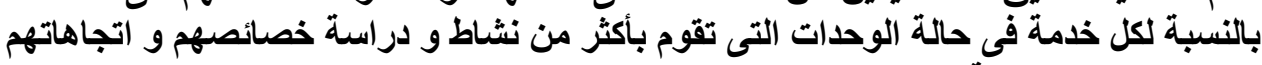
نحو الخدمات الجامعية. ه عدم الاحتفاظ بقواعد بيانات للقطاعات الجات المستثيدة .

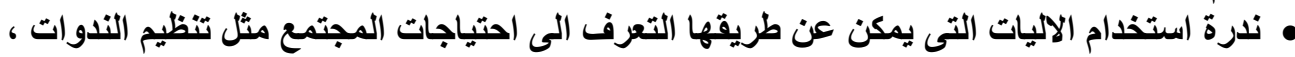

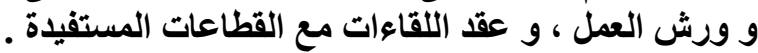

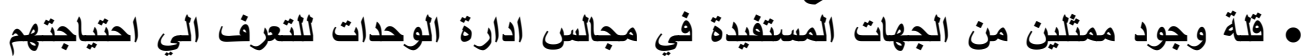

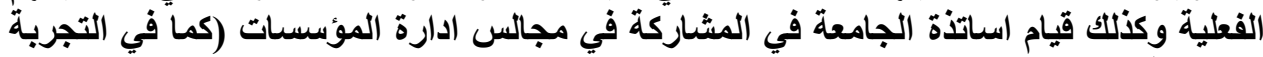
الامريكية. ق التة تقديم الخدمات التي تتوافق مع الاحتياجات الفعلية للمستفدين ويتم ذلك عن طريق التحسين

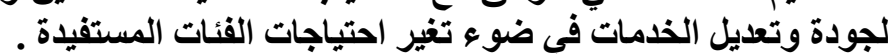

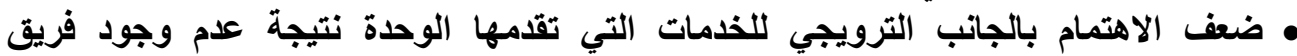

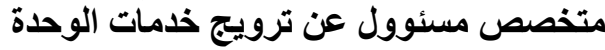
هـلة وعي العاملين باهمية حسن التعامل مع المستفيدين وتزويدهم بالمعلومات التهات اللأزمة للرد علي استسفارات المستفيدين.

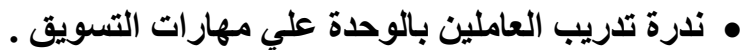

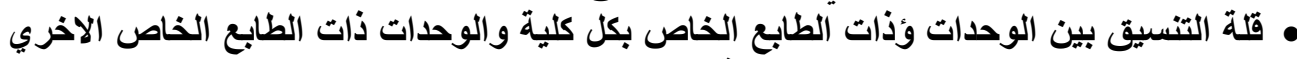

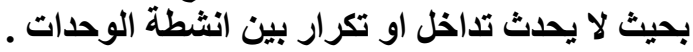

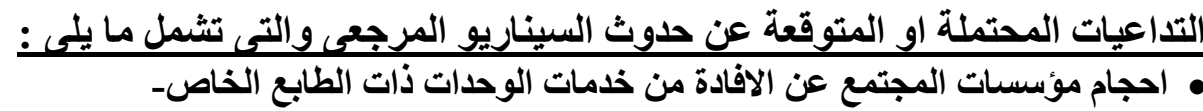

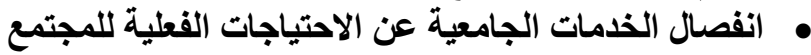

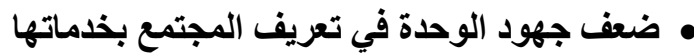

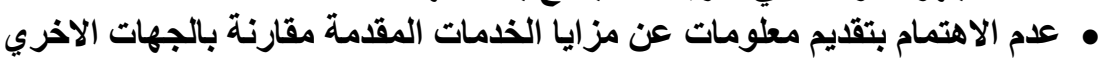

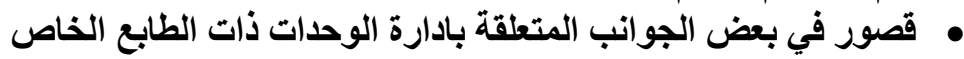

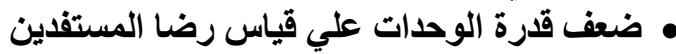

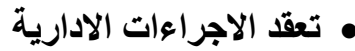

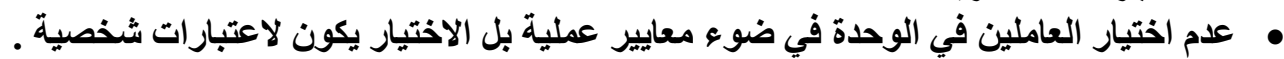

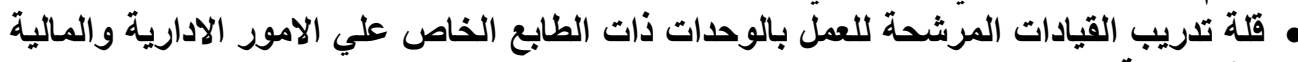

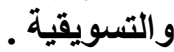

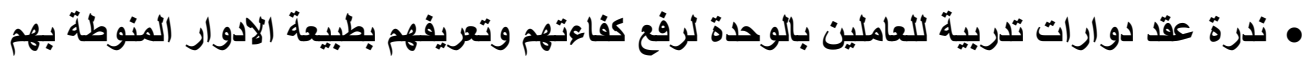
لتيسير العمل المستفدين الامر الأي يساعد علي استقطاب عدد اكبر من التورة المستفدين واستمرار

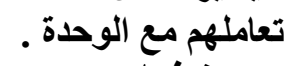

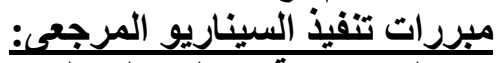

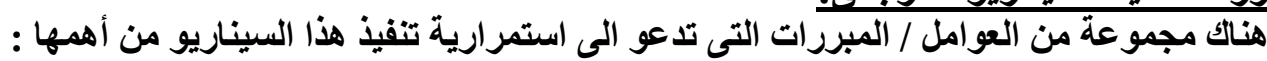

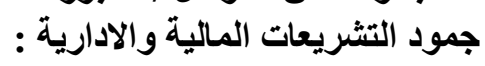

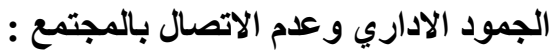

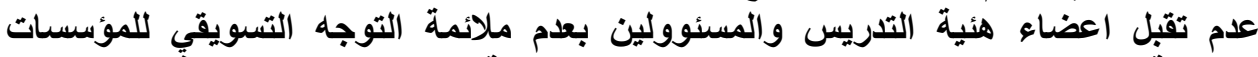

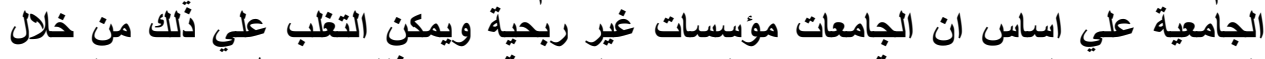

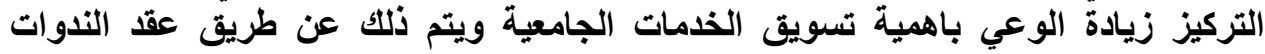




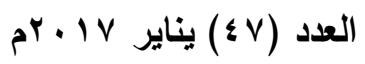

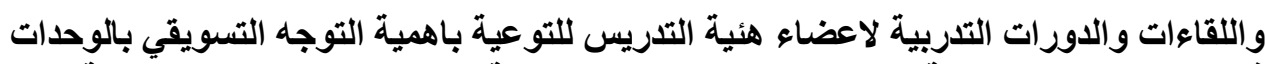

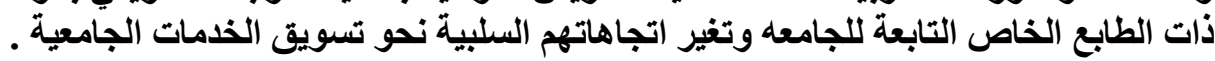

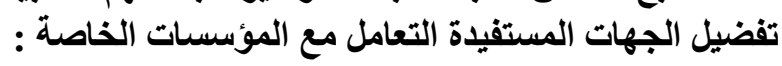

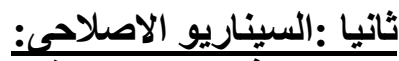

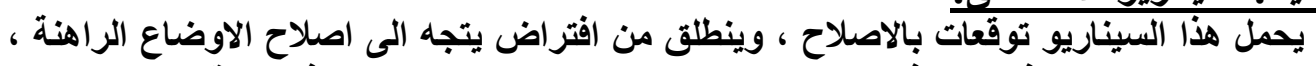

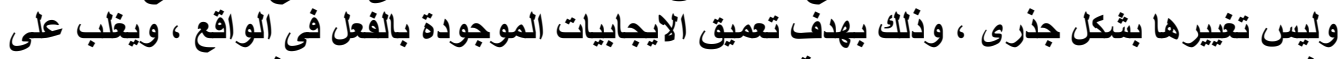

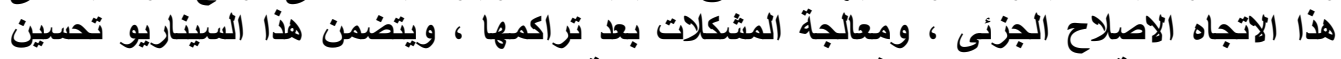

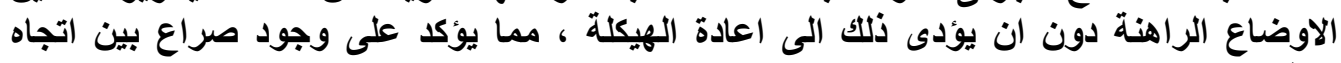

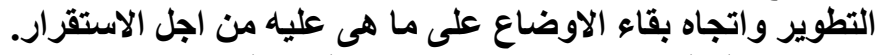

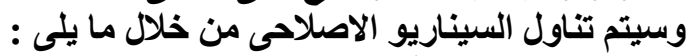

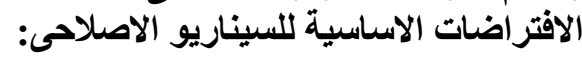

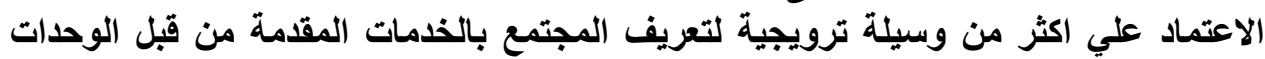

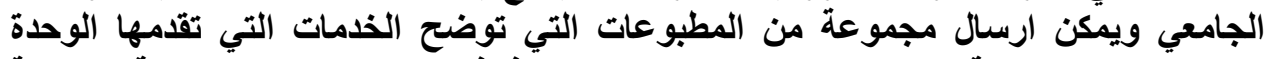

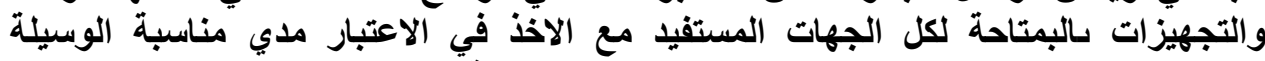

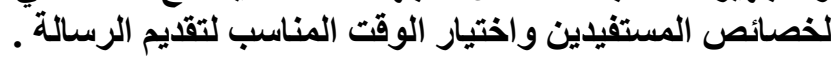

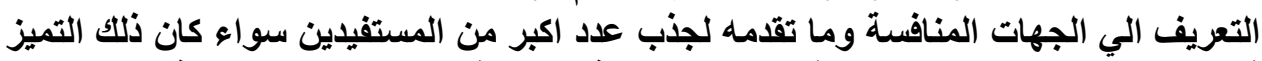

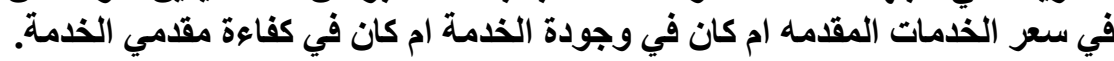

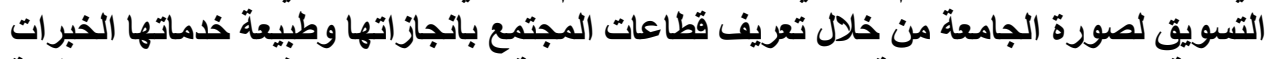

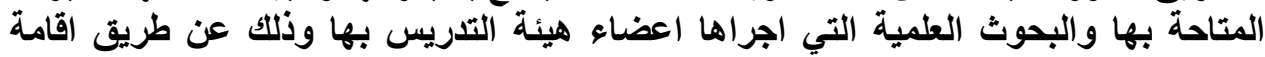

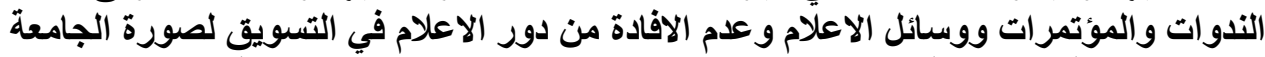

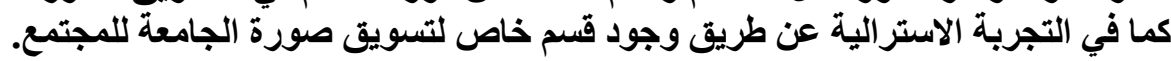

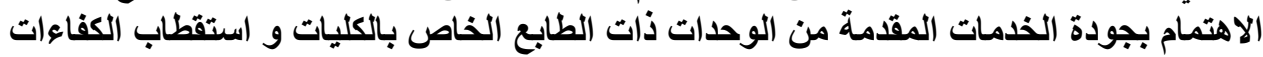

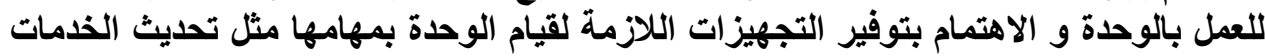

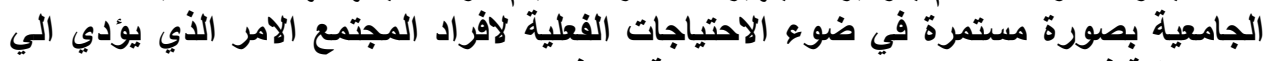

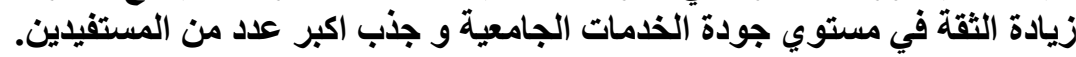

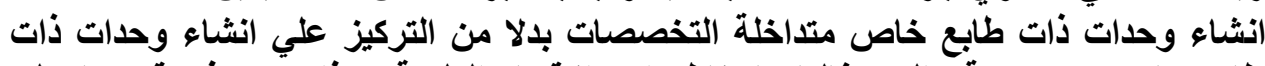

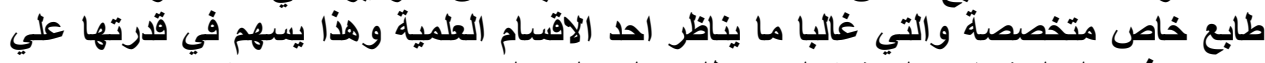

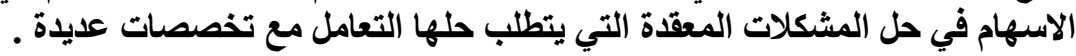

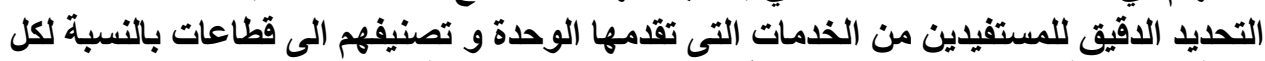

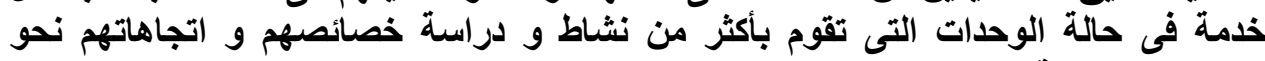
الخدمات الجامعية. الاحتفاظ بقواعد بيانات للقطاعات المستفيدة . استخدام الاليات التى يمكن عن طريقهات التات التعرف التى احتياجات المجتمع مثل تنظيم الندوات ، و و

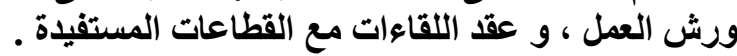

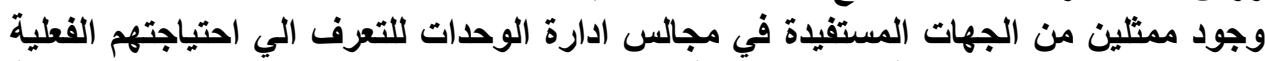

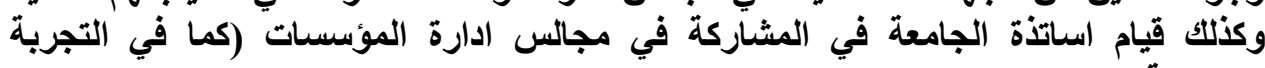

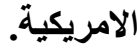
تقديم الخدمات التي تتوافق مع الاحتياجات الفعلية للمستفدين ويتم ذلك عن طريق التحسين

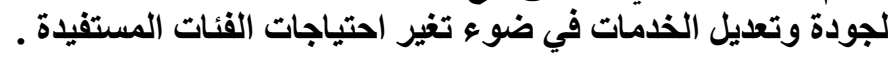




\section{العدد (\&V) يناير}

الاهتمام بالجاتب الترويجي للخدمات التي تقدمها الوحدة نتيجة عدم وجود فريق متخصص

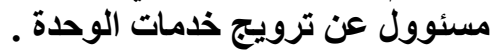
الاهتمام بتنمية وعي العاملين باهمية حسن الترودين التعامل مع المستفيدين وتزويدهم بالمعلومات

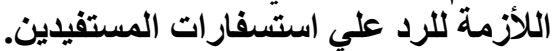

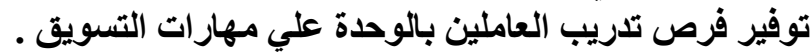

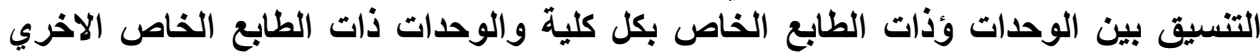
بحيث لا يحدث تداخل او تكرار بين انشطة الوات الوحدات.

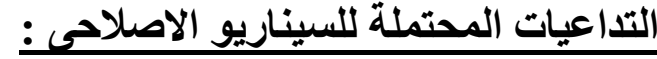

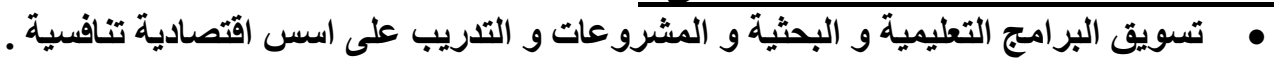

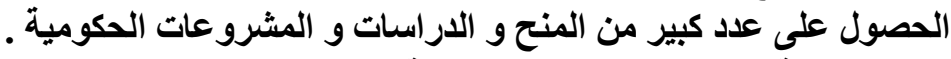

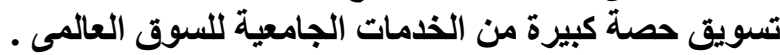

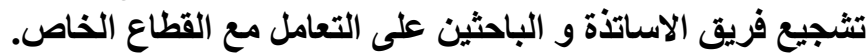

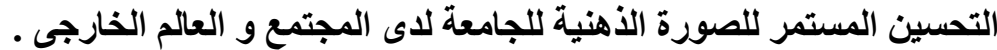

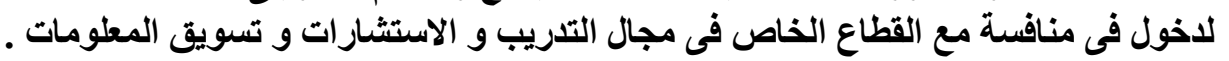

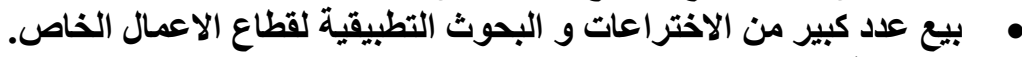

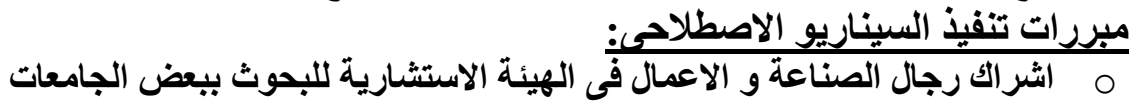

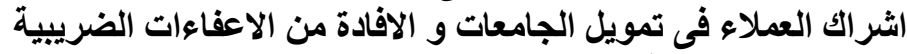

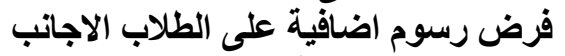

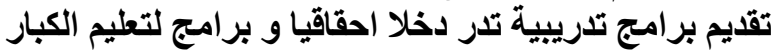

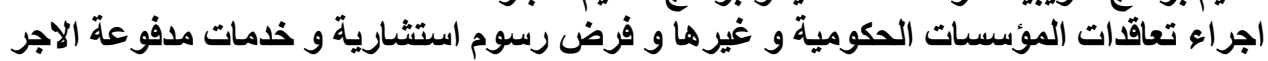

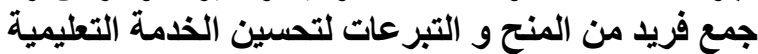

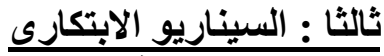

يرتكز هذا السيناريو على التحول الكيفى فى ممارسات واجراعات تسويق الخدمات التعليمية

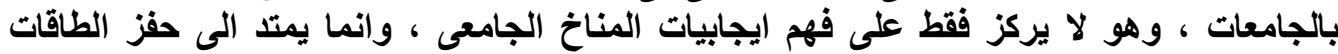

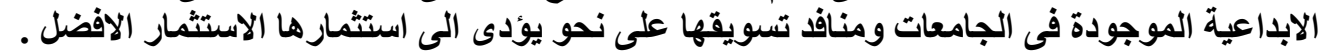

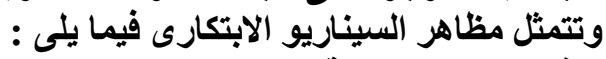

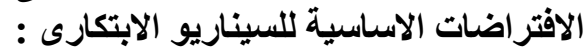

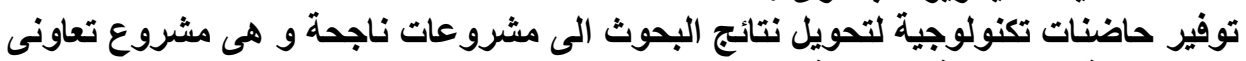

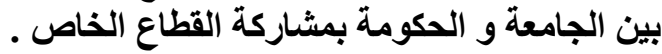

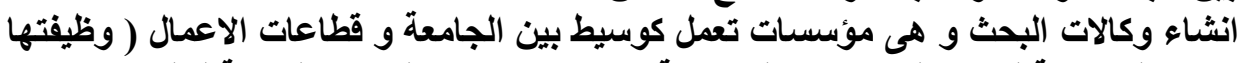

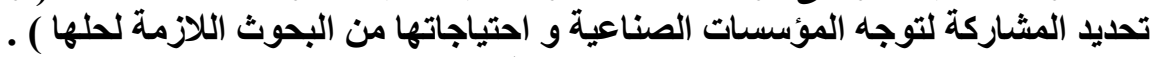

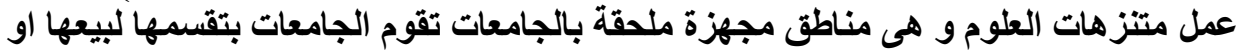

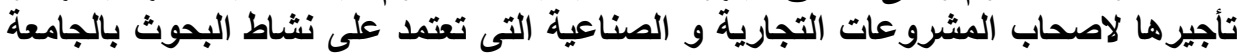

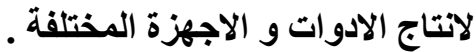

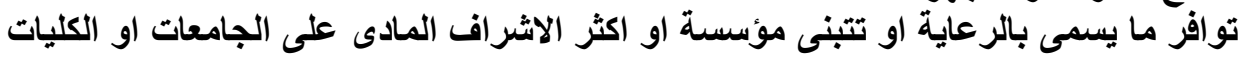

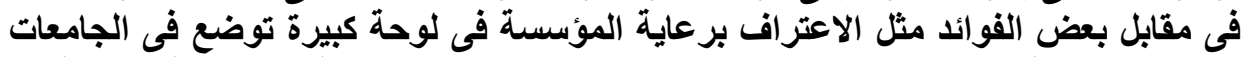

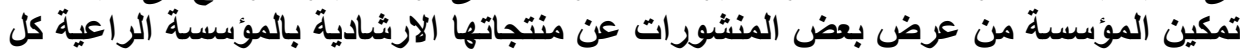

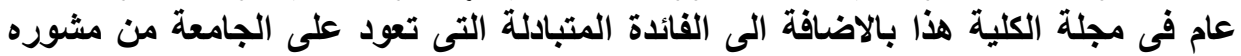

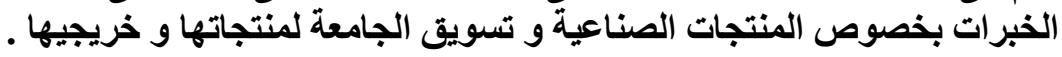




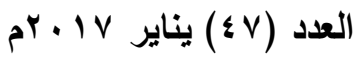

توافر المشروعات التى تتبناها الجامعة او الكلية حيث توفر فرص لتدريب الطلبة و العاملين و

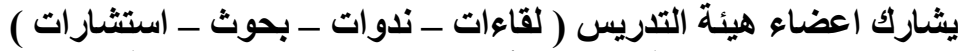

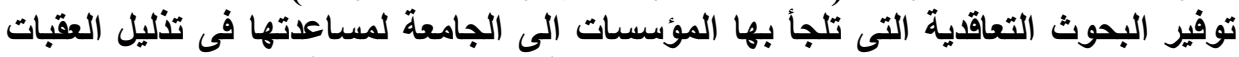

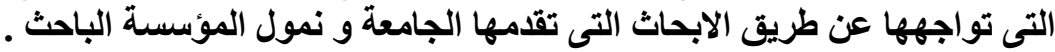
تقدم الجامعات على انشاء مركز بحوث بوجه لقطاع التهاء صناعى معين يتولى علاج المشاكل التى

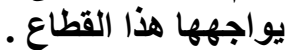
انشاء مركز لمنح تراخيص لاعضاء هيئة الترايس و الباحثين فى الجامعة للحصول على الإنى

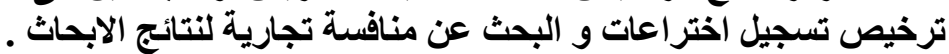

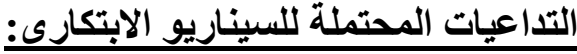

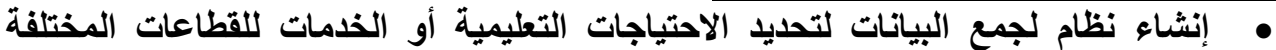

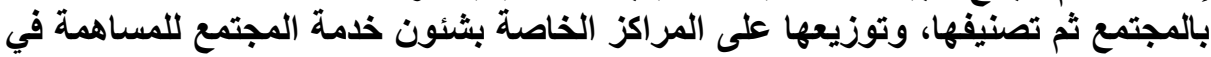
الوفاء بها. تقديم خدمات استشارية في المجالات الآتية: التخطيط الاستراتيجي للمشروعات، وتصميم،

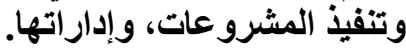
تحسين إجراعات العمل في الجامعة، وهذا يعني معاونة الجامعة على مواجهة التهات التحديات التي التي التهاتي

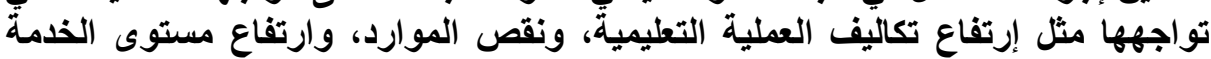

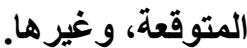
تقديم برامج أكاديمية عديدة مع التأكيد على تقديم تعليم عالي الجودة في المرحلة الجامعية

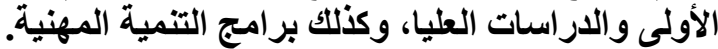

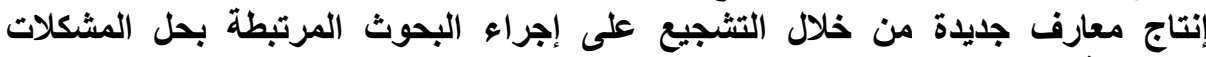

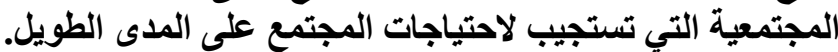

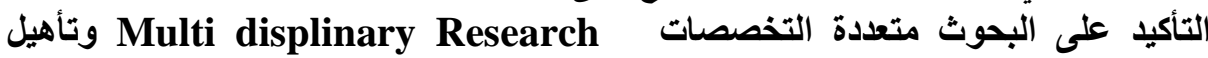
الدارسين ليصبحوا متخصصين في مجالاتهم، وذلك من خلال تطوير قدراتهم على استخدام

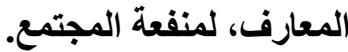
المساعدة في عقد لقاءات بين العاملين بالثركات، والمؤسسات وبين القيادات الجامعية المينة

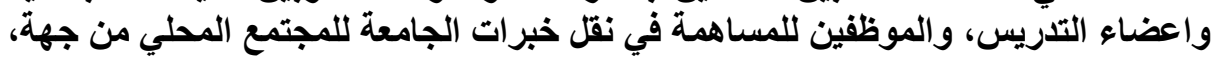

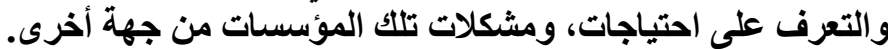

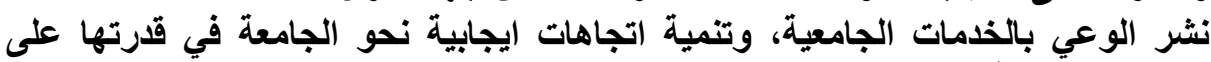
تحقيق التطوير في المجتمع. تقديم معلومات مفصلة عن البحوث التي تقدي التدمها الجامعة، وتحفيز الشركات، والمؤسسات

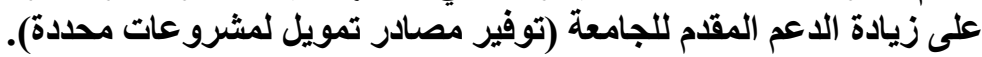

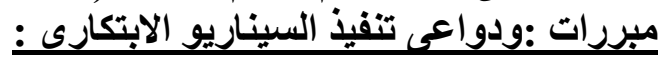

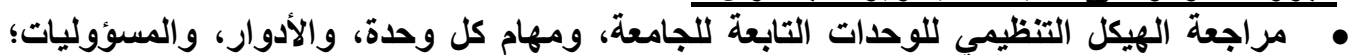

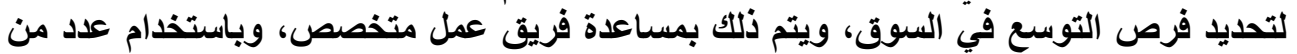

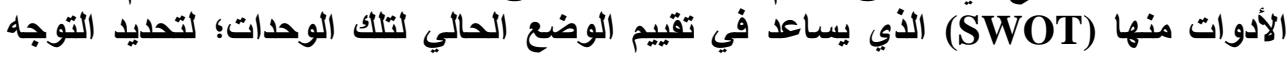
المستقبلي لها. مشاركة رجال الصناعة في مجالس ادارات الماتيات المبات و مراكز البحوث و المشاركة فى وضع

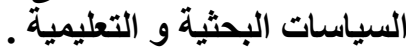
• توافر مقياس جودة الخدمات لقياس مدى رضا المستفدين من الخدمة . 


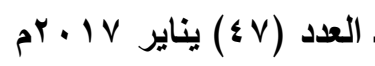

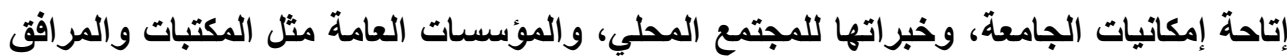

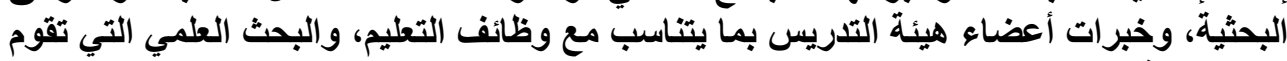

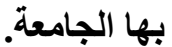

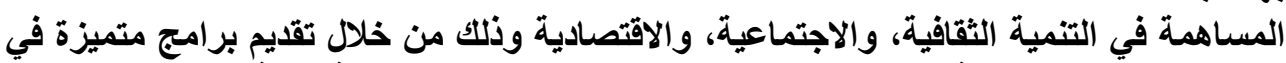

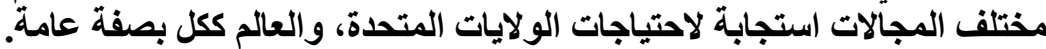

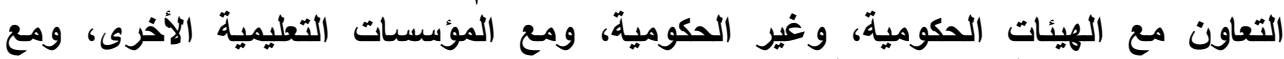
المؤسسات الصناعية، والاقتصادية.

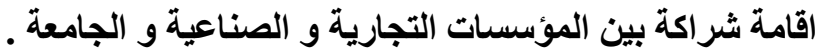

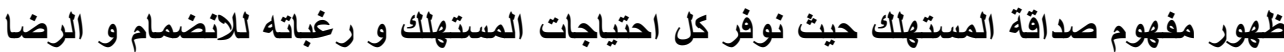

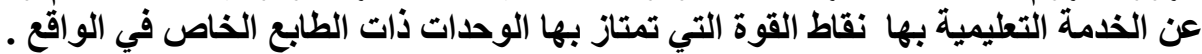

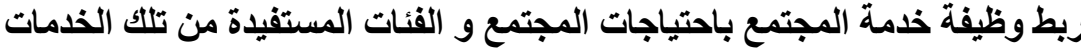

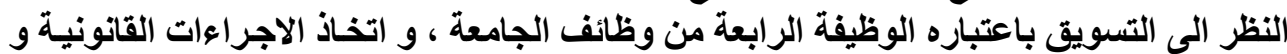
التثريعية و التنفيذية اللازمة لتفعيل ذلك.

نشر ثقافة التسويق بين افراد المجتمع الجامعى باعتبار عملية التسويق مسئولية كل وحدة من أبن

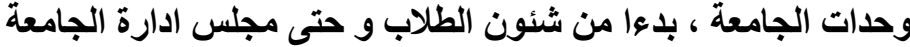

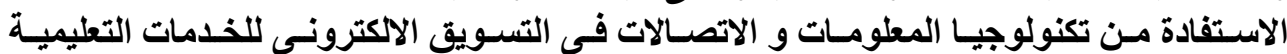
بالجامعات وضع خطط خمسية و سنوية لتسويق الخدمات التعليمية بالجامعات بهـف التهات التسويق المحلية و

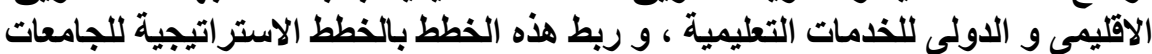

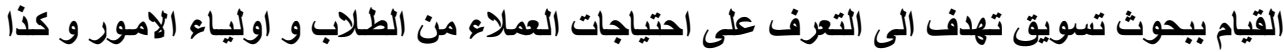
مؤسسات اللمجتمع المدنى الخدمية و الانتاجية التئية

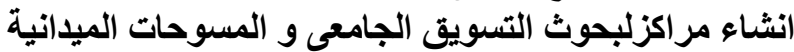
تجزئة اسواق الخدمات التعليمية الى قطاعات لقياس التيات الحاجـات و الطلب المستقبلى على الخدمات

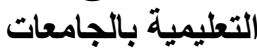
استفادة الجامعات المصرية من الفرصات التوص التسويقية المتاحة محليا و اقليميا ، من خلال الاهتمـام

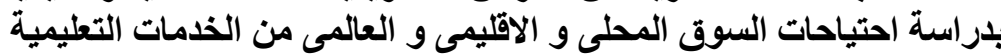

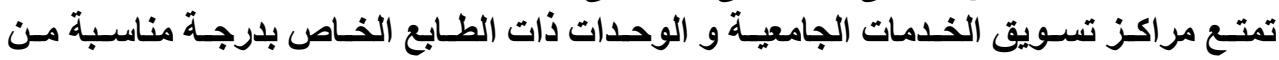

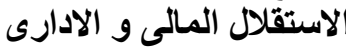

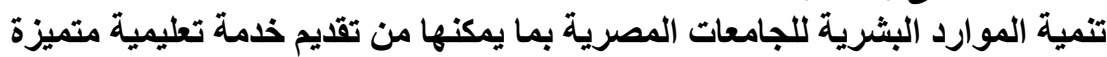

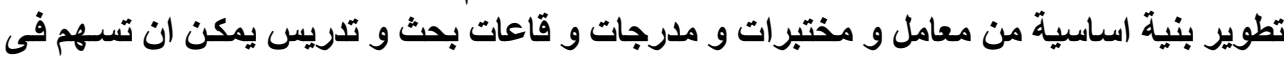

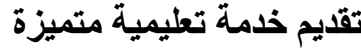
ضم اعضاء من الخارج من ذوى الخبرة الفنيـة و المهنية لمجـالس ادارة مراكز تسويق الخدمات بالجامعات المصرية

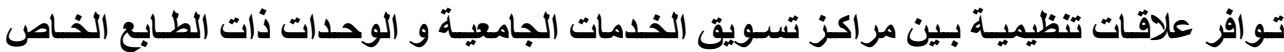

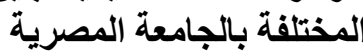
التتسيق و التعاون و التكامل و تبادل الخبرات بين مراكز تسويق الخدمات المختلفة بالجامعات توافير الكوادر التسويقية المتخصصة فى تسويق الخدمات التعليمية بالجامعات 


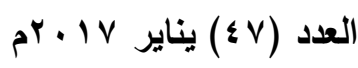

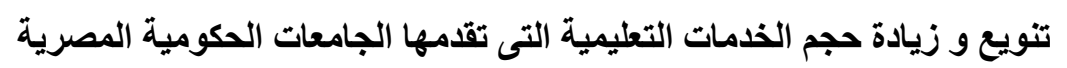

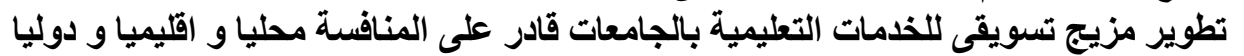

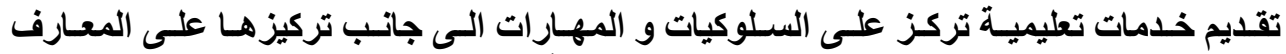

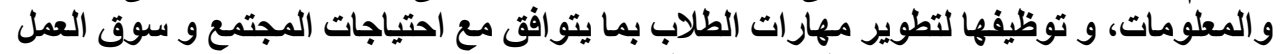

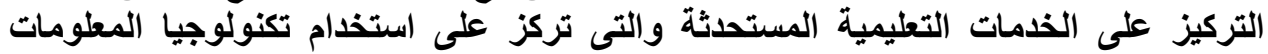

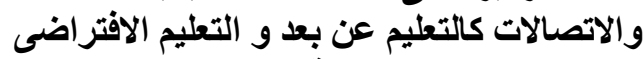

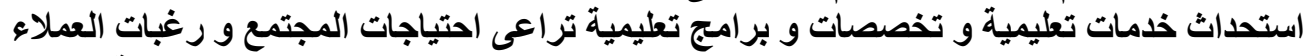

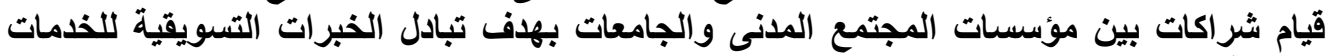

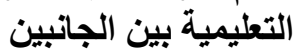

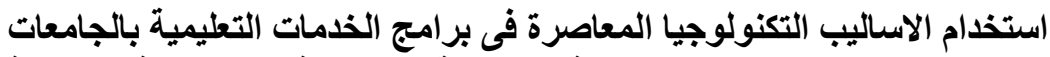

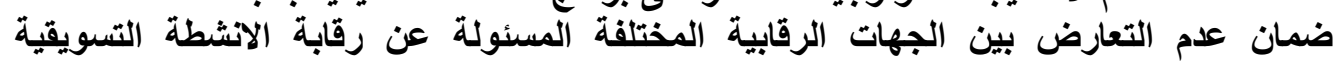
تطوير نظم لتقويم برامج الخدمات التعليمية من وجهة نظر المستفيدين منها

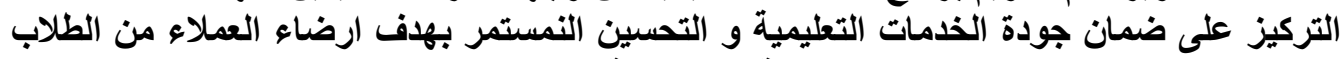
واولياء الامور و مؤسسات المجتمع الخدمية و الانتاجية الخية الخية 